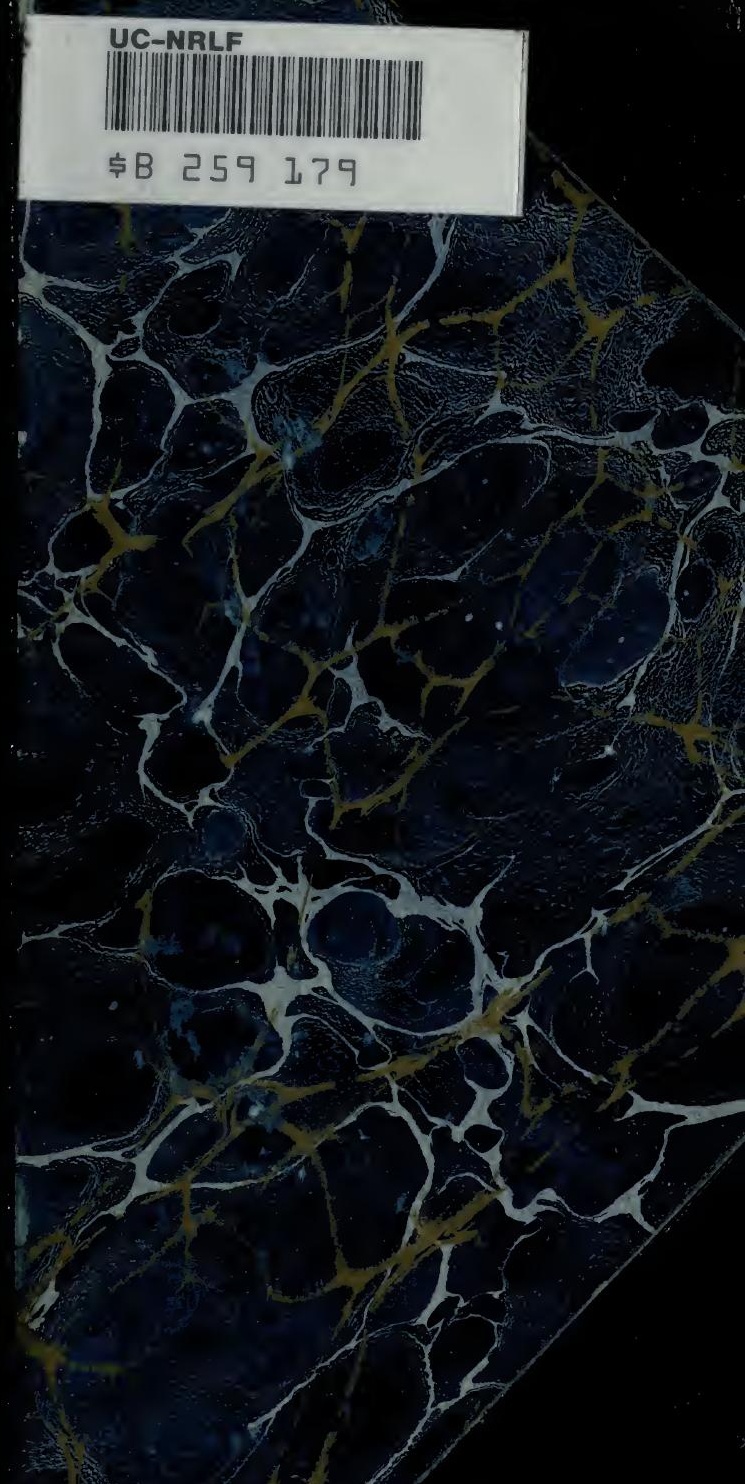



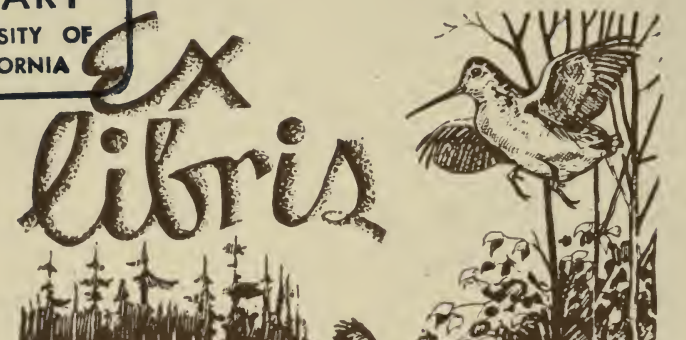

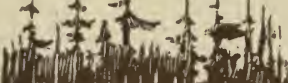
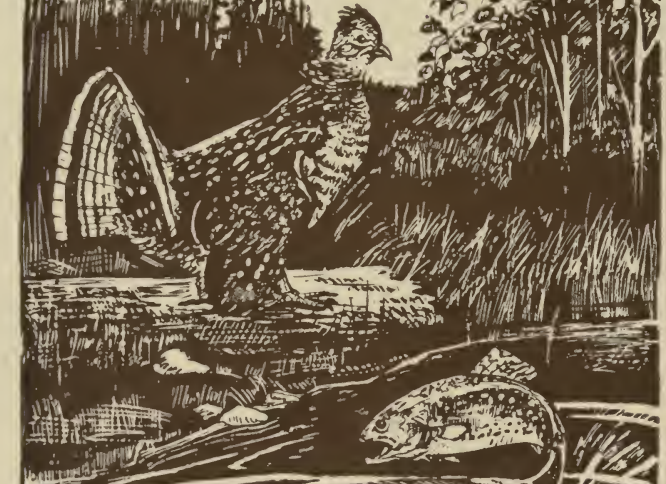

The Sporting Gallery AND BOOKSHOP, INC.

No. 38, East 52nd St.. New York 

vH 

Digitized by the Internet Archive in 2007 with funding from Microsoft Corporation 


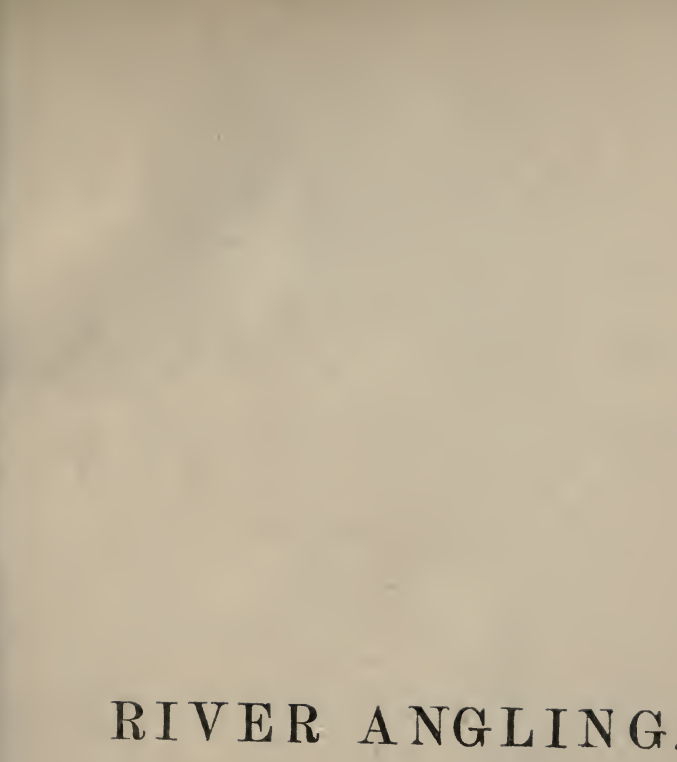

\section{RIVER ANGLING.}




\section{.}

is 


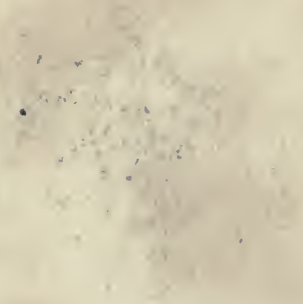



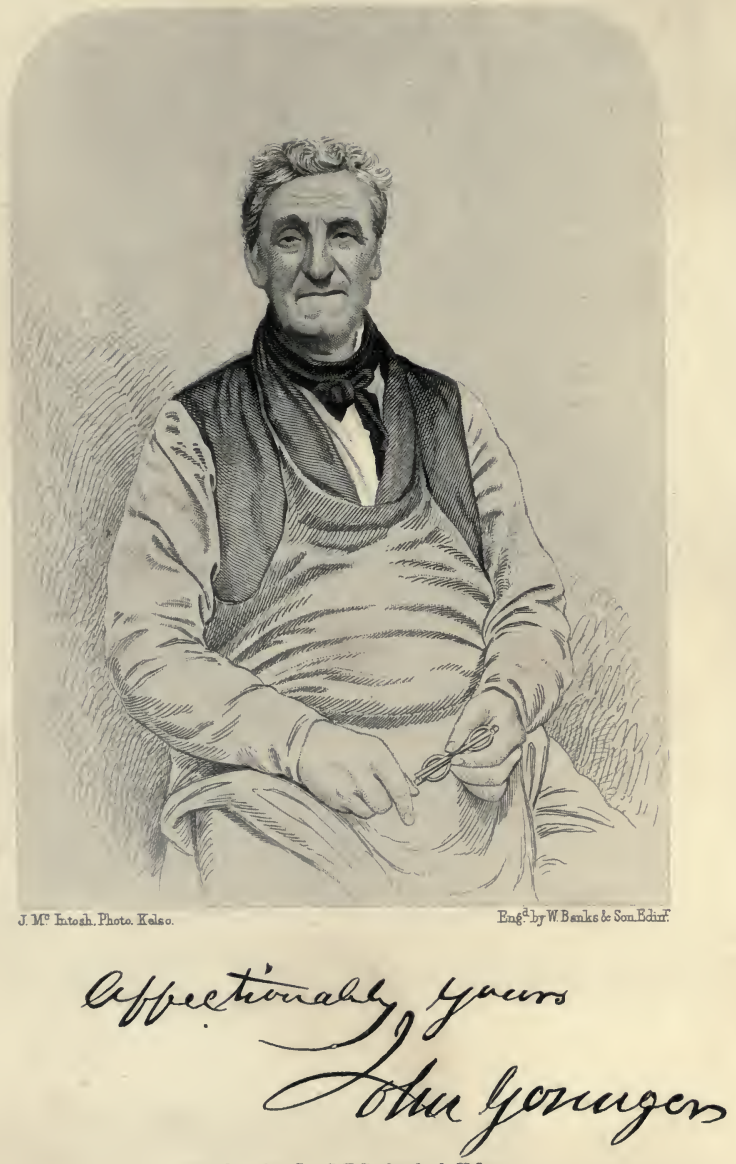

Published by J.\& J. H. Rutherford, Kelso. 
A manly heart lost this our Border land, When thine, O Younger, to the grave was borne;

And friends, even some who never clasped thy hand, In every valley thy departure mourn;

For generous hearts are few upon the earth

And genial natures, such as guided thee :

Grave thoughts and sad swept o'er thee, but thy mirth Out-rode them all-a life-boat on the sea :

And 'mong thy friends how many felt the charm Of thy keen intellect and racy tongue!

Thy tide of thoughts, thy feelings ever warm,

Portrayed a nature deep, and fresh, and young

Even in thine age ; and long thy name will stand Respected, honoured, loved, on thine own Border land. 



\section{RIVER ANGLING}

FOR

\section{SALMON AND TROUT.}

BY

\section{JOHN YOUNGER. \\ 1)}

WITH A.

MEMOIR, AND LIST OF THE TWEED SALMON CASTS.

There are who think these pastimes scarce humane. Yet in my mind (and not relentless $\mathrm{I}$ )

His life is pure that wears no fouler stains.

Armestrong.

KELSO : J. \& J. H. RUTHERFURD. EDINBURGH : WILLIAM BLACKWOOD \& SONS. 
PRIXTFD BY, . AND J. H. RUTHERFURD, KELSO. 


\section{SH 685 \\ Y 6 1864}

\section{ADVERTISEMENT'.}

When the last Edition of River Angling was partly printed (1860), the death of the Author caused it to appear in a less complete state as to arrangement of matter than it would otherwise have done. In the present Edition this has been carefully attended to by the Editor, an experienced Angler; and from this, and the supplementary chapters by him on Creeper Fishing, etc., the Publishers confidently issue the present Volume as a complete work on River Angling for Salmon and Trout.

KeLso, February 1864.

\section{$\bar{M} 844814$}





\section{CONTENTS.}

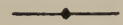

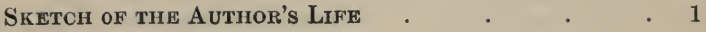

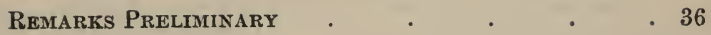

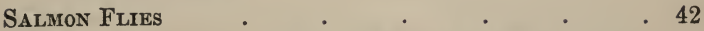

Unknown natural causes prevent Salmon taking, 43-Nature not imitated in Flies, 43-Note, 43-Flies reduced to six distinct kinds, 44-First Fly, 45-Second Fly, 47-Third Fly, 48-Fourth Fly, 48-Fifth Fly, 49-Sixth, or Maule Fly, 51-Mr. Maule, 53.

Miscellaneous Observations on Salmon Flies .

To vary the three first flies, 54-Tinsel, 55-Pig's Wool for Tufts, 55-Colours, 55-Flies by which Salmon are "raised" 56-Colours to be proportioned, 57-Fowls for dressing feathers, 58-Preserving feathers, 59-Size of flies of more importance than colour, 59-Angling, point most essential, 61-Size of flies to vary according to depth of water, 61-Experienced angler knows where to fish, 61-Irish and Tweed Flies suit according to state of river, 62- "The Erne, its Legends and Fly Fishing," 63-[NotE-In the three places in the text where "Earn" occurs, read Erne] -Shrimp considered natural prototype of Salmon Fly, 64-Fly taken most readily when well sunk, 64-Note bearing out same, 65-Twice exceptions to this noted, 66Author's impression that all Flies are taken for Shrimps, 67 -Note as to colour of Shrimps, 67.

Trout Flies, Natural and Artificial .

Natural Flies, how bred, 71 -Note on ditto, 71 -Another 
note on ditto, 72-Trout Angling different from Salmon Angling, 74-Flies should be shapen after living model, 75-To make Flies, 76-1st March Brown, 2nd Pale Yellow Dun, 77-Material of which to make the latter, 78-Note on Buntings, 78-Fly for May, 80.

Curious Phenomena relative to the "taking" of Salmon and Trout

Miscellaneous Observations on Trouting, Trout Flies, Tackite, and Rods

Fishing up Stream, 87-The "old system" discarded, 89Voracity of the Trout, 89-Trout not capricious, 90-When Trout not "taking," mutilate wings of Fly, and sink Fly well in the water, 91-In July and August continue the earlier Flies, 92-Size of Fly larger than the natuial Fly for certain states of water, 93-Note on ditto, 93-Mistake of Authors, 94-Fine Gut to be used, 95-Rods, 96 (see also p. 105 for Rods).

On the Dressing of Flies .

Salmon Flies, 99-Trout Flies, 100-Note, 101-Dressing on loops, 103.

Casting or Wheer Lines .

Note on ditto, 104.

\section{Fishing Rods}

Notes on Fishing Rods, 105 and 107.

\section{Salmon Angling}

Throwing the Line, 108-Striking, 112-Working the Line, 113-Not to become flustered in a run, 115.

\section{General Observations on Salmon Angling}

Perfection of Fly Fishing, 118-Dislike of Dyed Gut, 118-

Note on Gut, 118-Sunk Fly successful, 119-Sea-trout Hook in Northern Rivers, 120-Difference of Flies used in Northern Rivers, 121-John Haliburton and Tweed Hooks, 122-Note, 122-" "General leading principal" for size and colour of Flies, 124.

Where and how to cast, 126-The angler not to stvike, 126Editor's note in favour of striking, 126-Whipping the 
water, 128-“Job's patience," 129-Atmospherical influence, 129-“Greener years!" 130-Poetry and trout-slaying, 131 .

\section{ANgling with Worm for SalmoN}

Feat of John Haliburton, 133-Worm used, 133--Note against the use of brick dust for worms, 134-Size of hooks used, 134-How to bait, 135-How to angle, 136-Another feat of John Haliburton, 138.

ANGLiNg WITH WORM FOR TROUT

The worm preferred and how to keep fresh, 139-Note on preserving worms, 139-The time for worm fishing, 139How to bait, 140-Where to angle, 141-An old gamekeeper's feats, 142-Rivers in which the brandling worm is successfully used, 143-Note on the brandling, and a very large take made by it, 143.

\section{Angling with Minnow}

The state of water most suitable, 144-How to angle (trout and salmon), 145-Sprats a good bait for salmon, 146[Minnow for bait, see text and note at page 149].

Angling with Par-Tail.

Angling with Roe . . .

\section{Creeper Fishing, by the Editor}

When it begins and ends, 153-Up in the morning early, 154 - State of water for, 154-How and where to angle, 155Fine gut to be used, 157-Hooks, and how to bait, 159Striking and sinkers, 160-Creepers, where to find and how to keep alive, 161-Rivers best adapted for creeper fishing, 162-Size of trouts taken by this bait, 163. [Note-Page 153, line 5, for "either," read Cotton.]

Stone-Fiy Fishing, BY the EDItok

When it comes in, and where to find flies, 164-State of water preferable, 165-The preferable fly, 165-How to angle, 166-Waltonian hymn, 167.

Worms and Worm ANgling, By the Editor .

The best season for worm-angling, 168-The "time of day" to angle, 169-Up-stream fishing necessary, rod, a long line to be used, and striking, 171-The places to fish, 172 
-Hooks, 172-Worms : black-headed worm, marsh worm, 173-Brandling, 174-How do trout so greedily devour worms, land animals? 174-Worms live in the rivers, 175 -Mistakes as to this of anglers and authors, 176-Reason why trout are fondest of worms in midsummer, 177.

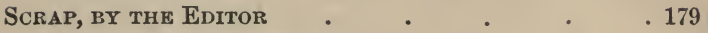

Notes on Water Insects . $\quad . \quad \ldots \quad . \quad . \quad 179$

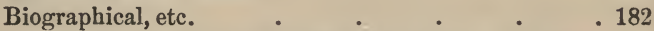

Jock Smail, 192-James Baillie, 184-Homeward Route, 186.

Descriptive List of the Salmon Rod Casts in the Tweed, including the names of Proprietors . . . 188

Descriptive List of the Tributaries of the Tweeả for Trout Anglers, by the Editor . . . . 214 


\section{SKETCH OF THE AUTHOR'S LIFE.}

If he should not have been successful in any of his intentions, yet there remains this consolation benind-that these, his pursuits, by keeping the body and mind employed, have under Providence, contributed to much health and cheerfulness of spirits-even to old age.-Gilbert White.

WhILE the work now presented to river anglers was passing through the press, a painful incident, and one deeply connected with its matured completion, occurred in the death of the author. A pang of sorrow, such as only the loss of many endearing qualities could occasion, shot through many a heart within miles of his residence, as it was spread from lip to lip that John Younger was dead. On a long summer day, the 19th of "June, when the pleasant sights and objects of his "dear native valleys" wore their freshest aspect, John Younger died. For some time previous, his hardy compact frame, that had stood the buffets of a life longer than the common span, shewed signs of decay. There is little doubt that porerty, with its saddening distractions, weighed upon the elasticity of his nature. Physical ailments, 
of the class that would have been greatly modified by easier circumstances, had begun to drag him back from various literary enterprises, which his attempts at public lectures had marked out. The lithe motion of body and of limb became touched with the proofs of declining strength; yet, his many personal friends never doubted on counting on his familiar presence for years to come. Death, however, came quickly and sternly, and after a brief struggle with a paralytic seizure, John Younger succumbed. In his views of life, and its allotments of trial, he had ever cherished a wish that his end might come under circumstances in which he wouldleave the world without being a tax or trouble to any. The wish was gratified; and the week that saw him looking from the river head-lands of his beautiful Lessudden, saw him also lying in St Boswells' churchyard.

It is trite enough to remark, that John Younger was no common man. His equal has seldom been seen in the class to which he belonged. When it is borne in mind that his education was exceedingly meagre, costing from first to last not more than is now expended on a middle class child in one quarterthat he plodded along in the same groove of occupation and habit all his life. long-and had few 
opportunities of being abroad, and obtaining for his natural acuteness of observation the extended range of objects that is essential to enlarged mental culture, the conviction is forced upon the observer who offers an estimate of him, that, falling in at his proper place he was one of these men of mother wit, original ideas, and marked capacity, who, in Scotland, are represented by Robert Burns, and Hugh Miller, John Leyden, and The Ettrick Shepherd.

As a follower of the somewhat lightly esteemed, but essential avocation of shoemaker, he belongs to the illustrious craft from among whose awls and lasts have come, according to Coleridge (in defiance of the stale Latinism), some patriots of large soul, theologians with pale faces, and hair crisp with study, missionaries of world-embracing christian zeal, critics, and their victims - the builders of the lofty rhyme.

As we find from the autobiography, which during a course of many years he had prepared, "he was the child of honest parents, the youngest of a family of six, was born at Langnewton, in the parish of Ancrum, on the 5th of July, 1785." Langnewton standing on the high banks of the Ale, at that time had pretentions to rank as a Scottish village, from which, by the rural changes, it has passed into a seldom seen, unvisited hamlet. It had the usual 
village characteristics, and Younger commenced the school of observation on what he saw and heard in it. There was the now obsolete weaver of "customer wark," the never to be obsolete blacksmith, with his nightly band of quidnuncs, such as Burns saw when a boy - the ploughman, the day labourer, the poacher, the hand-spinning matron, the dominie, and the way-faring "Daft Jock." Towards it, as the place of his nativity, and of the earliest and most varied recollections of his life, his heart always yearned. In the Ale he caught his first trout, and under an ash tree, in a corner of the churchyard of the village, was his mother's grave.

Sixty years ago Scotland was a poor country. She had been fighting during all her history out of a cold soil, a wet climate, and a certain sourness or grim earnestness of character, acquired by long contact with hard times-social, civil, religious and agrarian-when the black famine years, that saw out the old century and ushered the new one in, made clean teeth throughout the land. It may well be imagined what were the sharp household straits that children with empty stomachs had to struggle through. The quarter loaf rose to close on two shillings. Wheat stood at one hundred and twenty-five shillings a quarter. Parliament, by statute, enforced 
economy in the use of bread, prohibiting its consumption until it had been baked for twenty-four hours. The slip of an urchin did not even enjoy the licence of cow-herding. To make ends meet in his father's struggles, he was early encased in a sheep-skin apron, and made to jerk outhis elbows in drawing rosined thread. A conscript seized upon the village green, he possessed native instincts that soon sharpened into faculties, and he sought companionship with members of animated nature. The boy became an adept in the knowledge of birds and beasts; and hawks, blear-eyed owls, and flippant jack daws, squatted around him. Bird cages blocked up the light of day, and the shoemaker's shop, the lounge of village gossipers, was vocal with the contending songs of whole coveys of linnets and canaries. John often wondered how his honest father tolerated such an uproar. Out of doors he early picked up a knowledge of the habits and kinds of birds. The slightest twit in a hedge or wood, would tell its name; and he did not require the old poacher, who sat smoking on the settle of the yellow-ochred cottage door, to tell him the destination, on the minnowy stream, of the great flaunting heron which sailed high over the village chimney tops. The best angler to this day is he who knows most about the habitat of the finny 
tribe; and the shoemaker lad, with his quick perceptions, learnt how to catch trout almost at his will. He would cut his hazel* wand from the young wood, and though the trouts might be shy to the nicest turn out of rod and tackle, he would come home with the, bunching strap of silvery spoils, till all the village lads looked amazed. This was the fashion in which the author of the present work furnished the proof of his early attainments in the gentle art.

There needed to be no readier sign of the natural cleverness of the prentice shoemaker than his waterside craft. In his own words, "he flew to the Ale water and fished for trout as much for his dinner as for amusement." In the dear years a dinner purveyed with so little labour was not to be despised, for these were dreadful times. They have served all the men who fasted in the pinches of the hungry epoch with a tale of such distress as has not died out till this day. How often have readers of this notice heard old men narrate the dismal story of meal at seven shillings the stone! Flodden itself has hardly sent down to after times so sad a sough as

Hazel seems to be a kind of wood that anglers instinctively draw to ; anglers at least who cannot pay for shop-made rods. In Walton's time it was the favourite wood, and. James Baillie, accounted by several authors and many anglers the best fly-fisher of the present day, angles daily with a two-piece hazel rod cut from the wood-bank, and anglod with as cut. $-[\mathrm{EDR}$. 
have those dear years! We find few written records of them too. They were too early for our best working-class autobiographers, Hugh Miller and Somerville. When John Younger's autobingraphy is given to the world we will have the right idea how the poorer families fared. His share in it was not small, for he had nearly perished from the long want of sufficient sustenance. He has described himself as the member of the family, who, with his natural shiftiness, was selected to seek credit at the corn mills in the neighbourhood where meal was sold. When he had procured a supply he set off at full speed (for he knew the household was at the starving point), running over the dreary fields with the pock under his arm. Temptation would assail him, and he would untwist the neck of the bag, and gulp down with hungry hurry the dry meal, and then, lest he should be tempted again, he would twirl up the neck beyond ready reach, and run with additional speed. What a picture of the times is here presented! The Scottish people may well cherish the memory of the period with pride, for they endured the trial nobly. The sensitiveness as to accepting parochial relief even survived the crisis. John Younger's account may enable even statesmen to compare the different ways in which the Scotch and the 
Irish have borne up against the calamities of $\mathrm{fa}$ mine.

John Younger was a manly-hearted boy,and strove to utter no murmur in his hard pressed father's hearing. He bore up against despondency, and like Bunyan, he even owned to a bit of monologue; for one day, while staring into a pool of water, he fancied his shadow accosted him by saying, "keep up yer heart Jock Younger, keep up yer heart ma man Jock." Jock took the hint, and heaven sent brighter days.

John's first contact with literature deserves to be noted. He had read Jack the Giant Killer, and scarcly dreamed of anything higher than the great nursery epic. A blacksmith in advance of his time repeated a portion of "Doctor Hornbook," mentioning the name of Burns, who was then only a few years dead. The slenderly versed shoemaker asked "whae was Burns?"- "Burns, man (was the rejoinder), have ye never heard of Burns the poet, who beats Allan Ramsay, and the whole lot of Scotch poets to sticks !" John heard the bookish Burnewin with melancholy curiosity, and sighed at the idea of exclusion from such poetic wealth. But St Boswells' fair came, and he sallied up the thronged alleys between the krames with sixpence in his pocket, and grasped the 
prize of his heart, a sewed copy of the said "Burns' Poems." Home he went, for the fair had no further charms for him. Into the heart of a blackberry bush, that flourished with a kind of arbour shape in his father's garden, he tumbled, and, with a bright disdain, left the showman-spoutings, the busy hum, the gaudy, touting, holiday enticements, to those who cared for them.

The village of Bowden was not far off. A line from Clapperton, an old Scotch poet, "at Bowden, on black Monanday," shews that the village had received poetic mention. In addition to being the birth place of Thomas Aird, the imperfect fulfiller of great poetic promise, it takes credit for fostering the nativity of Andrew Scott, the author of the quaint but classic piece of dialogue rhythm "Symon and Janet," beginning,

Surroundit wi' bent, an' wi' heather, Where muircocks an' plivers are rife, For mony lang towmond thegether,

There lived an auld man an' his wife.

To Andrew, John made up and was received with kindliness. In return, John rendered homage as to genius, and a friendship was formed, lasting till the old barnman flung down the flail never to uplift it. 
The era of the false alarm, originating in the juncture of Buonaparte's threatened invasion, was a period of vivid sensations to the subject of our notice, as it was to most at that time. He was strutting on the top of his teens, and shouldered a firelock as a member of the Militia Corps. This he did with a perfect consciousness expressed all through life, that fighting was the most abject of all human occupations. The trade of soldiering was abhorrent to his moral sense and the habits of his mind; and no member of the peace society could have more scrupulously examined the motives under which he appeared as a defender of his country. In one of his opinions on the subject, afterwards recorded, he says, "it is very distressing for the human mind to contemplate the dire movement of congregated masses of flesh and blood, dragged out in the train of hellish ambition for the most horrible purposes, following individuals who shew themselves so utterly unworthy of even personal existence." On the night on which the beacons were lighted, the 31st January, 1804 , when the heart of the nation heaved in one fiery swell of patriotic feeling, John marched to the place of rendezvous, ten miles distant, and tore his trousers in scaling the palisades of Kelso bridge tollhouse. The grotesque features of his night's adven- 
tures, full many a time and oft he was wont to bring up at the annual convivial meeting, held at St Boswells to this day, to commemorate the historic event, and the story never grew tiresome in the telling.

At twenty-five, John had settled in life, had a wife, Agnes Riddle by name, and a house of his own, shoemaking his trade, and St Boswells or Lessudden his residence for life. In a notice of a man who, spent his days in following one of the most plebeian of occupations, it is difficult to find individual incidents to make out the track of his existence. His original thinking powers soon marked him off as one who could not be invisible in the dead inertness of rural life. On the north side of the village was a picture of silvan and river scenery, in the winding of the peerless Tweed, such as might have haunted any man possessing less idealism than John, with the pleasure which nature in her diviner glimpses yields. There was Dryburgh, rearing its timestricken gables among the trees; but strange to say such an object excited no pleasure in John. These haunts of monks and their worn out superstitions he despised, as having formed part of the imposture which had retarded freedom of ideas and common sense among men. $\mathrm{He}$ had more true delight in watching the motions of the water ousel 
skipping and coquetting on the river shallows, or in listening to the snatch of the red-breast's pleasant or plaintive carol on the apple tree, than in the survey of all the abbeys of Domesday book. " The monks (with him) were dead and buried, and let them lie, without bringing them on the stage of life, where they had done so little to deserve mankind's respect." Curious to say he did not care at all for the writings of Sir Walter Scott. With some who knew him little, this may be set down to an absence of true imaginative culture, but the fact was, it arose out of a quaint peculiarity of mind. He looked on the Waverley literature as "old piper stories," "dwarf and witch tales," and monstrous caricatures, of Scottish manners. He never threw himself in Scott's way, though living in the same locality. When he sauntered to the top of the village cliff to look riverward, and sniff the western breeze, the object in the landscape which the resting place of the minstrel formed, would catch his eye and yet excite no passing sigh.

The following work will have suggested that fishing was one of his greatest sources of recreation. In the course of years it passed from recreation almost to regular occupation. The Tweed, the stately stream, in its scenic associations and bright remem- 
brances of sport, and friends, and merry hours, became the silver bond that knitted all his sympathies to the locality of St Boswells. The kind of Austrian rigour with which angling privilege on the river is now protected had then no existence. There is not a shadow of a doubt that the Tweed was then far more the poor man's river than it is now. Things stood on an easier footing between laird and commoner. John Haliburton, on his perch of Craigo'er, rented the Merton water at fifteen pounds a-year, with a cow's grass, and often as he passed his friend, the shoemaker's door, he called out a kindly invitation for him to come down and get a cast. Younger's great natural powers of observation, conjoined with a wary watchfulness of fish, and steady practice at the rod, united in making him a proficient in the art. His reputation increased as his friendships extended, and from far and near, his fishing knowledge and company were courted. Apart altogether from his literary turn and tendency to blacken paper, he was marked off as a man of note, and hailed as a "Tweedside Gnostic." The shoemaker's shop was a house of call for all the Waltonian brotherhood: dukes, lords, Galashiels weavers, escaped Parliament men, squires, cotton lords, and the whole medley whose boot heels ever 
crunched the pebbly shore of the glorious river or its tributaries, came at times to hear John Younger discourse on the theme, which, ahead of rivals, he had so well mastered. And what a crack was his ! And how meagre and few the souls for whom it possessed no relish. He could tell the waggle of the wand that could most deftly throw the line, and the bits of wood that, pieced together, made up the best style of rod. Rods he could manufacture on the shrewdest principle of effect. Fishing tackle and hooks he knew by intuition; for how a salmon viewed things as he lay in his watery haunt was part of the fishing art. The occupation of shoemaker made fishing boots ready to his hand, and he came to be noted for his skill in the fabrication of these gentlemanly appurtenances of the pursuit: but it is unnecessary to dwell with any minuteness on this branch of his many acquirements, as the following essay discloses all the proofs of a most extensive knowledge of the subject.

Out of all the wide variety of friendly contacts, it may be assumed that John Younger had many opportunitios of increasing his knowledge of the ideas current in the world beyond the sphere in which he had to make his bread. The late Sir Robert Peel, in one of his speeches, said he had 
studied the wants of the nation by contact with the highest personages of the realm, and had conversed with the Highland shepherd on the hills, and heard him tell his artless views of human life ; and many a member of the governing class, or of the "upper ten thousand," would discuss public affairs in perfect equality with the obscure shoemaker, and perhaps gather convicticn on some point which he had failed to elicit amid the contentions of party and the perplexities of unconscious prejudice. On one occasion when the Hon. J. E. Elliot was visiting his constituency, being Member for Roxburghshire, he happened to call in a friendly way upon his friend the shoemaker, who, talking of political affairs, remarked, that he never had enjoyed an opportunity of seeing Lord John Russell ; and that with his recollections of public men it would be a pleasure to him just to shake hands with a politician whose personal integrity men of all shades of opinion respect. No sooner said than done. The worthy member got John Younger crushed into the carriage beside him, and whirled him off to Minto House, where Lord John Russell happened to be on a visit; and there and then he left the two to a conversation, such as produced a lively impression of pleasure upon both parties. 
We are aware that John Younger came to be viewed with some jealousy, as a man who held extreme political opinions. With his outspoken disposition, and forcible powers of expression, he could hardly escape such an imputation. In this respect we think he was misjudged. He was a poor man, and naturally took the side that poor men take when questions affecting popular privileges are under discussion; but he was remarkably free from all political crotchets. When the chartist movement was at its formidable stage he was invited to take part in it, but declined, seeing no good results to follow, and imputing to it not a few bad ones at the period. He has recorded the following remark on political discussion: "The man who will tell me that because I am a poor man, I have no business with the government of my country, I must despise as something worse than a simple idiot." He has the following just remarks on public affairs, and the principle by which they should be conducted. "A continual stirring, in what are called state contentions, is kept up by parties for public offices, in idea of honour or profit, or both ; but these are comparatively like winds and storms to the balance of the general atmosphere, partial and trivial in their effects, compared with the spirit of the exclusive principle, 
which is ever generative of those heartburnings which excite to political volcanoes, eruptions, and earthquakes." The Reform Bill he hailed as a great and just measure, constituting " an inestimable general privilege," which "would exercise a wholesome influence over the tergiversations, and abuses of public trust by the governing few:"

On the corn laws, the repeal of which has done more to sweeten the breath, as Dr Chalmers phrased it, of British society than any measure in living memory, John Younger vented his hottest ire; their evils he summed in few words-they hood-winked the farmer, and raised to the poor man the price of bread. He heaped on these laws his bitterest scorn, and threw off various Corn Law Rhymes to fan the flame which their prolongation was exciting. Some of these found their way to Ebenezer Elliott, the Corn Law Rhymer of Sheffield, who, in a letter of acknowledgment, asked why their author wasted his strength in verse when he possessed so much natural energy as a prose writer. Elliott's letter was accompanied by a gift of a complete edition of his works, of which John was exceedingly proud.

Twelve years, however, before the corn laws closed their account of social and civil mischief, John Younger had registered himself an author. In 1834 2 
he gave to the world a small publication, entitled "Thoughts as they Rise," a poem in Byronic measure. It was an attempt at a poem, constructed "without an imaginary hero, romanting through its cantos." Whether owing to the plot wanting thus confessedly the part of Hamlet, or to the disrelish on the part of the public, for moralizations by a shoemaker on human affairs, the work fell still-born from the press, and further cantos, which were threatened, John kept to himself. .

The poem is, however, a remarkable production for a working man, if we consider the command over the English language, the easiness of versification, the occasional force and beauty of the sentiments which it betrays.

At random we make an extract:

"And so I envy none their lands and dower, Nor all that they can claim below the skies,

Yet can't resist the wish I had the power,

To wipe the tear from modest mourning eyes.

How blest to deck the lowly humble bower

With winter fire, and summer sunshine joys,

Change many a sigh of want into a song,

And cause the stream of life flow clear along. *

$\%$

Or this picture of rural zest:

" 0 , how I love the moorland scene of spring Beneath the smile of morning's ruddy glow, The whirr of heath-cock, and the curving swing Of snipe high booming $0^{\circ} \mathrm{er}$ the marshy flowThe fond solicitude of flapping wing, 
To lead the wanderer from the nest below; I love the swuff of every out-field featherBy wood or stream, or "mid the purple heather."

With the bulk of men engaged in manual occupations, writing is irksome and slow work; the fingers are stiff, and the connexion between brain and penholding is an awkward task. John Younger was an exception to all this. He would beat his lapstone and draw his thread all day, and betake himself for relief to letter writing. His invariable plan was to make his knees his writing desk, and in this uninviting attitude the great bulk of his MS. was produced; not scrawled and blotched, but presented in a small clear elegant penmanship, which in the case of a self-taught workman is rarely met with. With friends at a distance, men who had left St Boswells for the broader field of adventure and pursuit which it could not supply, or friends of a chance intimacy, he maintained an extensive correspondence, making his epistles so much the record of his careful thinking that he took copies of them. In this way an immense quantity of manuscript accumulated in the course of years, significant of the ceaseless mental activity which characterised him. At his death there were more than seven hundred copies of letters which he had addressed to friends. Many of these had been written to men of literary eminence or 
public distinction, giving his views of the opinions associated with their names. This collection he cherished as the treasure of his mental history. Sometimes when leaving home he used to warn his family that if the house took fire in his absence, next to saving themselves they should save these writings. Composition coming so readily to him, and friends often hinting the propriety of the step, he betook himself, after the period of middle life, to prepare an autobiography, a species of personsal narrative always interesting, no matter what may have been the limited sphere of existence of the writer. The work in his hands grew from less to great, so that some years before his death it amounted to the contents of two goodly volumes.

It contains much racy description of local occurrences and manifestations of village character, beginning with life at Langnewton, and following on in narration of the fate, fortunes, and families of his acquaintance. The publication of the work will, we trust, be not long deferred; and we venture to describe it such as will form a genuine accession to autobiographic literature.

Shoemaking was but a poor trade to a man struggling with a family, and pulled at by needy friends; and it was to be regretted that so much literary 
industry, as he displayed, brought such slight rewards. On several occasions he received an acknowledgment for articles connected with angling or natural history. In 1840 he appeared as the author of the Essay on angling, of which the present work is a re-written edition. He often lamented that he could not bring the knowledge he possessed on many subjects to more account. The year 1847 brought an opportunity by which he could measure his capacity and literary grasp with the men of his class. John Henderson, Esq. of Park, a gentleman distinguished for his zeal in every good cause, by way of directing public opinion to the better observance of the Sabbath, proposed three prizes for the best Essays on the "Temporal advantages of the Sabbath to the labouring classes." John Younger's eye fastened on the public announcement. "The hour and the man" had come together, and he resolved to try his hand in the competition. More than a year passed away, when the intimation was exultingly speeded over the south of Scotland that John Younger had obtained the second prize. A thrill of pleasure cheered Tweedside as the good news was repeated from mouth to mouth, and John became the theme of applauding tongues in every circle. To London he must go to receive the prize of $£ 15$ from the Earl 
of Shaftesbury in Exeter Hall. He was whirled out of Lessudden one afternoon, and the following day saw him in London lionized amid the plaudits of multitudes. It was the triumph which ambition could have envied, to have seen the north country shoemaker, with the guileless unpretending presence standing up to receive the well-won reward. This was the greatest event in John Younger's life, and he ever afterwards referred to it as something, in its public and exciting accompaniments, far beyond the possibilities that fate had allotted to his career.

To mark the gratification which was experienced in the district, by this recognition of his abilities, he was entertained at a public dinner, in St Boswells Inn, by a highly respectable gathering, and presented with a purse of sovereigns.

Upon the solid merits of the "Light of the Week," the title of the essay, we need not occupy much space in remarking. We question if the author ever held the pen with a freer or more vigorous style. The composition is admirable throughout, distinguished by sententious force, picturesque illustrations, and a vivid logical treatment of the subject, such as the pulpit or divinity of a heavier texture might envy.

Shortly after the event, a vacancy having occurred 
in the village post office, the appointment was, on the recommendation of the Hon. J. E. Elliot, at that time member for the county, conferred upon John, in the belief that his advancing years would find an easier living than in toiling at his old trade. The result, however, proved different from what was expected. The rigid exactitude of rule, the perplexing net work of forms and business routine, were more than one accustomed to the simple machinery of making shoes could overtake, and when the life was nearly vexed out of him, in January $1856 \mathrm{John}$ threw up the appointment in disgust. To the present writer and a friend, who ealled shortly after, he said he felt himself, when postmaster, like a caged squirrel running over its never-ending wheel, but that when he was free he felt himself just like the squirrel on the top of a tree, "ready to jump wherever he liked."

The celebration of the Burns' centenary, in 1859, stimulated John to bring out a lecture on the genius and character of the national bard. He had a fancy that he could treat the subject in a way of his own believing that many traits and perplexing points in Burns' history had been misunderstood, and that purely literary men had not been grounded as he had been in the experience of a social condition, 
similar to that from which Burns started, to take the natural and plain, common-sense view of the poet's case. At the very period that old William Burnes* was breaking his heart, and working the flesh off his bones with vexation on the "seven poor acres of nursery ground," near to Alloway Kirk, John Younger's father was making a hard fight to get ends to meet by cobbling shoes and renting a fourteen acre farm on the Langnewton barony. Old Younger had "to thole a factor's snash," like him of Doonside, and the son remembered that the crisis of the household arrived when the cow was distrained for rent.

Like Burns, John Younger, from infancy, had cherished a deep and earnest sympathy with nature. He had all his days loved the country, and never had been a denizen of city or town. The woods, the green fields, the dingles and dells, and shady coverts of the river side, the red-breast perking among the berry bushes of the cottager's garden on a grave autumn day, the blackbird or throstle piping in the budding beech, the great crow armies blackening the fields, or drifting up into mid air with many-throated clangour, and scattering themselves away in the endless fields of sky, the fresh, newly furrowed land,

* Robert Burns spelled his name differently from his father. -[EDR.] 
with the white pick-maw sailing about the sober ploughman's team-gang, the sights and sounds that had their being ere man betook himself to build cities and live in masses, were the educating influences that had made John Younger what he came to be, and which inspired him with an ambition to interpret in plain story the life of Robert Burns. And common consent, though candid enough to admit that some of his conclusions might be open to objection,'confessed that John Younger was in a large degree successful in what he had undertaken. His critical estimate of Burns had a rough matter-offact quality about it. He did not sail in the clouds in flights of eloquence, or discourse in grand allegorical tropes like Carlyle. With a pooh, pooh, and a humph of contempt, he ridiculed the so-called romance, "The glory and the joy," with which imaginative writers had surrounded the bard's existence. Very much romance indeed, he thought, there was about the greatest man in a nation lying in a stable loft, and spending his pain-racked midnights amid the perfumes of such an abode, listening to the nags below stirring, stamping, or riving at the fusionless bog hay! He considered that Burns was too much the companion of every day suffering to sustain any such picture as Wordsworth had 
drawn, and thought that he drove his plough to another tune, that of dour, determined, conquering toil, tugging at his awkward nags amid the birns and bumping boulders of a farm which never could yield meat or clothes, or household peace to the poor tenant. He thought if ever Burns played a servile part it was in dedicating his poems to the Caledonian Hunt. What did such a pack care about poems! They were a bye word in Scotland at the very time, for a story had gone abroad that they had hunted a bitch fox over several miles of country, and at the death found the poor animal had carried one of its pups all the way in its mouth. It was a treat to see the unaffected bonhomie of the "old man eloquent," elevated on the lecture bench, to talk of Burns. He had the key of a sympathetic fellow-feeling to all the phases of Burns' life. No one who listened, but admitted that a shrewder, more instinctive apprehension of that life, had seldom been produced. When he came to offer selections of the favourite poems, his warm loving admiration of the verses knew no bounds. "Here awa, there awa, wandering Willie," he designated the tenderest and most beautiful love song which ever came from the lips of man; and as his voice repeated several of the stanzas, the tributary tears of emotion coursed down his cheeks. The lec- 
ture was delivered in most of the towns and villages in the Border district, and the proceeds were sufficiently respectable to promise, by his extending his tour, what would be a nest egg for the wants of his advancing years. A number of his Border friends resident in Glasgow invited him to the western metropolis to deliver the lecture there. $\mathrm{He}$ was able to accomplish the visit, but with unfavourable results to himself. Exposure to extremely severe weather during his movements, brought on an attack of rheumatism, which prostrated and confined him to his lodgings for several weeks. The attendant expense of this misfortune melted away most of his gains, and he reached Lessudden as poor as ever.

During the long and severe winter of $1859-60$ he was seldom seen abroad, and did not regain much strength. Generally cheerful and unrepining, he began to confess himself as growing old, and less able for active work at his ordinary trade. In conversation on some of his favourite topics, he regretted he had accomplished so small a portion of what he felt was within his reach. He had a fancy he could prepare several papers on some of the social changes which had come under hisobservation - furnishing sketches of the rural improvements and altering condition of the population, and cognate subjects. Work of this 
description he was well able to perform, and he was urged by his friends to over-take it. Daily bread, however, was still with him to be reached by working with the leather apron about him, and he continued to make or cobble shoes, to the extent which his health permitted. For several months he had been less before the public eye, and when the stroke which separated him from all earthly friendships occurred, a painful surprise was created. As we have stated in the opening of this notice, his end came quickly. He had been apparently in nearly his usual health and spirits, and had been persuing his favourite story from the German, "The Journal of a Poor Vicar" a narrative which he almost knew by heart-when illness, disclosing a hopeless paralytic seizure ensued, and before another day was gone John Younger was dead.

That John Younger was a recognized celebrity was seen in the many genial tributes to his character and attainments which instantly appeared in the Edinburgh and local press-several of them eloquent and lengthy. In the Scotsman's article he was designated as "one of the most remarkable men of the population of the south of Scotland; whether as a genial writer of prose or verse, or a man of high conversational powers, and clear common sense, the 
shoemaker of St Boswells had few or no rivals in the south-in his death leaving behind him no enemies, and the memory of a guileless, unblameable, honest life."

The Caledonian Mercury had a similar kindly notice. Yrunger's friend for many years, eminent as a scholar and linguist, William Brockie of the Sunderland Times, gave a sketch of his character, summing the leading features of his career, thus- "Of poor, but honest and respectable parentage, he continued poor, but honest and respectable; his whole life a hard struggle against poverty, owing in a great measure to unfortunate family and business connections. Happy in wedded life, he was for many years a widower-his children grown up and settled. Nature made him a poet, a philosopher, and a nobleman; society made him a cobbler of shoes (a good one), a postmaster (indifferent), and a mortgaged feuar of Lessudden."

In the village in which he had spent the greater portion of his more than three score years and ten, the death of its most notable man was felt with the pang which friendship feels when its circle is suddenly narrowed. John Younger dead! he who gave a character to the little town, and who brought many a visitor to it; who always evoked the play of 
human nature's kindlier moods. John was not adjudged as without faults. In some of the pursuits of life he was not a successful man, and perhaps in a world in which the material measure is apt to be applied, a short-coming of success is not viewed as without blame. He was deficient in practical talent. Industrious and second to none as a maker of shoes, he never acquired the art which could carry him beyond the rank of a small country tradesman. At times in his eareer he had his foot beyond the threshold of difficulties, when some business or domestic contingency would drag him back, and he was the same poor man. It spoke much to the general tone of his character that even those who might have occasion, by business transactions, to sit in judgment on him, always stopped short of a harsh conclusion, and finished with an expression of sympathy or kind regard. The warm and respectful feeling shewn towards him by every one, avouched his possession of qualities of head and heart honourably combined. In the village all felt his departure. The boys and girls who would not disturb the bird's nest in his garden, nor furtively abstract the flushing fruit of his plum tree, will cherish his memory. The old inhabitant who had plodded on life's journey, and had often stepped in to compare notes on public and 
local matters, missed the social crack and sneeshin mull. The fascination that was wont to draw delighted listeners, and which stirred so many a bright conversation, and shook out so many a bright idea, which grappled with the dialectics of ever so varied subjects of human enquiry, had disappeared. The end of the pleasant village, with its garden intersections and quaint bye lanes, its crumbling bluff of river wall, and commanding outlook on the umbrageous pomp of wood and stream, had "lost its wierdest and its wariest eye."

One morn we missed him on the accustomed hill, Along the heath, and near his favourite tree,Another came, nor yet beside the rill,

Nor up the lawn, nor at the wood was he.

In personal appearance John Younger had always a hale hardy look. Possessing a frame compactly knit, of moderate height, of an erect open bearing, he wore into years without shewing many traces of age. When a young man he was distinguished by his agility and skill in athletic and manly sport, and he excelled as a pedestrian. The faithful etching prefixed to the volume gives the man in his facial expression as he is remembered by all his friends. There was a guileless, frank kindliness of manner about him, which carried in it the freemasonry of 
warm fellow-feeling, and placed him at his ease with all with whom he came in contact.

We have in the preceding pages attempted to introduce the reader to a familiar conception of the man as he appeared in his own walk of life, from an impression that the naked publication of the work on angling would have been meagre without some light being thrown upon the character and occupations of its author. We might have enumerated some of the subjects which he illustrated by his descriptive pen; many of them were fugitive sketches, but in good hands, they would bear a reappearance in a volume of selections. His poetical effusions, always marked by merit, were more a proof of his varied ability than of any strong natural bias to the cultivation of the muse. In summing a notice of his life, it may not be out of place to present a specimen of his success in this department of literary craft. The first piece was written in 1837, and abounds in the home feeling which marked his domestic history. The second breathes a spirit of the tenderest conjugal love, and as a memorial of their married life, is as creditable as it is delicately expressed. John was in the fullest sense a domestic man, a kind and indulgent father, and a faithful husband. For the partner of his life he cherished 
the affection of his youth. When prostrate with illness during his Glasgow visit, he wrote to his friends at Lessudden, that if he died they were to bring his body to St Boswells churchyard, and lay it beside his Nannie. The sad duty alluded to in the closing stanza fell to be performed by John, his wife's death having preceded his own by several years.

There may be sweeter spots afar

That I have never seen,

And lofty towers and rivers clear

With flowery vales between:

And fairer faces too may grace

The garden and the hall :

But there's a place, and there's a face

That's dearest of them all.

And $\mathrm{O} !$ our cradle spot of earth-

Where light first took our e'e,

And mother's love our infant heart-

Where'er that spot may be :

Tho' it were even slavery's soil

And we got free to rove,

-Yet wander how or where we will,

'Twill claim our latest love.

The swallow dreams on Afric's shore of Scotia's summer pride;

And plumes her wing, and knows her hour

To hasten to Tweedside.

The cliff or skaur she kens afar,

And towering ruins grey,

Where she was nursed-in Dryburgh's bower,

The lap of flowery May. 
The salmon gray of Tweed or Spey,

Returning from the sea, Seeks to its native river stream,

Whichever stream it be.

Even spirits 'mong celestial orbs,

In glory roaming free,

May own to earth, their first abode,

A soul-felt sympathy.

And there is yet anither bield

That ne'er can be forgot-

Tho' in his age from thence expelled-

My Nannie's father's cot.

In memory's light, like glow-worm gleams,

My fancy yet recalls

Love's youngest hopes, and downy dreams.

Still nestling round its walls.

MY NANNIE.

Its now full twa an' forty year,

Since nestling in wi' Nannie; As weel my part, I held her dear, Sae faithfu', young, an' bonnie. Her tocher was a trifle sma,'

A hard-earned weel-saved pennie;

But o' tocher could I think ava,

When in my arms my Nannie.

Nae artfu' wiles, plied e'er sae fain,

Could move the mind o' Nannie;

Hal courtiers wooed 'twould been in vain,

Her heart was held by Johnnie.

Of cares we've had our world's share,

Through stormy days and sunny;

My part has been the less to bear,

I've had sic help o' Nanuie. 
A welding heat o' strong young love Will last through winters many; The frosts of years but tend to prove The links that bind to Nannie.

Though teeth are fled, and locks grown gray, She's yet sae kind and cannie-

Love that outlasts young life's hey-day Is the love I bear my Nannie.

'Mid a' the thoughts that trouble me, The saddest thought of ony Is wha may close the other's e'eMay it be me or Nannie? The ane that's left may sairly feel, Amid a world uncanny; I'd rather brave auld age mysel' Than lanely leave my Nannie. 


\section{REMARKS PRELIMINARY.}

It seems to have been an early practice with anglers, which is yet much followed in books written on the Art of Angling, to face up the subject with pretensions of its being an amusement above all others conducive to religious contemplation. This is silly, either as a notion or a pretence ; and on the other hand it is equally pitiful to read the frivolous sarcasms by which this pursuit is in turn assailed.

Dr Johnson and Lord Byron, these famed fondlings of their age, have said some smart things to render angling ridiculous as a pastime. Having acquired no taste for it themselves, they wished to make believe that they stigmatized it from a moral sentiment ; and this, not so much perhaps from an inclination to

"Compound for sins they were inclined to By damning those they had no mind to,"

as from an opposition to the whimsicalities of early writers on the subject; such as old Isaac Walton, 
and the religious sportswoman of 1496, Dame Juliana Barnes, who mixed up their descantations with pretences of its being favourable to holy meditations, from the rural quietude of the pursuit. This must have been alleged by these early anglers and writers through a sort of mental defence against a superstitious suspicion, that it was not perhaps the most christian way of spending the sweet summer days of a brief probationary term of an eternal existence. Hence the struggle to the present hour of a hundred-and-nine scribblers on the subject to maintain a point, of the propriety of which they are by no means thoroughly convinced : only, finding the pastime a kind of exercise agreeable to their propensities-like that of cats to hunt mice, and lords foxes-they make a specious pretence of considering its gratification, not only as no sin, but rather in the light of a duty. Now the truth lies in this as in many disputed points, midway between the two extremes. No one who inclines to go a-fishing can reasonably suppose the pursuit any way very particular in point of morality-let him allege what he may, we believe that the angler foregoes such considerations. We view the matter simply in this way, that every man is so much of a boy (which may often be the best part of his character) that he goes 
out a-fishing because he had got into an early habit of so going, and finds amusement in it preferable to walking, or even to riding, should he be master of a horse; or else he pursues it, fain to find recreation in that in which he perceives his neighbour so well pleased, just as he would go a-quoiting, a-cricketing, or a-curling. To talk of following it on a principle of love or admiration of field scenery, the wood-skirted grandeur of cliff or stream, is surely either a pretence or an illusion of his own mind; because every staunch angler may be said to leave his admiration of the picturesque, the beautiful, and romantic in nature, as something to be particularly kept in mind, returned to and enjoyed "at a more convenient season" - as governor Felix did his taste for the most sublime doctrines of Christianity. I have felt that I could admire the beautiful in landscape as much as my neighbours, perhaps any of them, yet never could find either taste or time for the disposition of sentiment while sallying out on a fishing excursion ; and however romantically beautiful the branch overhung its shadow in the water, I no sooner hanked my hooks on it than, if within reach, crash down it came, whilst a wish hurried over my mind that all river-skirting trees were removed. I would hardly 
except the bordering willows of Dryburgh, or those skirting the rivers of Babylon, where the Israelites hung their harps in the days of their captivity.

By no poetical feeling whatever should the free swing of line be ever interrupted. Let sketchers put imaginary trees in their landscapes as they please, yet such are ever the true angler's real feelings, disguise them as he may: KEEP TREE, ROCK, AND IVY FULL LINE-SWING FROM THE MARGIN OF LAKE AND STREAM. One truth is worth fifty of these fishing authors' sickly preachments. If our tractates on the subject should never sell, let us not heap disgrace on our own poor head by feigning sanctity we never feel. Such would be worse than prevalent superstition or common hypocrisy. I can see no more sentimentality in angling for fish than in the rural sports of Fox or Otter hunting.* The excitement is kept up by the solicitude of success, and this the same in fishing for reputation in the sport, as in fishing for a dinner; the true angler being always intent in the pursuit, however passive he may appear.

The fertility of Isaac's imagination, and the ingenuity of his mind, would have made him to excel

* There is at least a charm, a romance, felt in the prospect or the remembrance of angling which almost every one feels, and which John himself must-have felt hundreds of times. - [EDR.] 
in whatever his hand might have found to do. A mind too versatile to have been confined within the critical rules of any age or art had excited him to write out his mixed thoughts, feelings, conceits, . songs, and sermons, on all favourite subjects, just as they occurred to his fancy-hence all are found pouched up together like his fish baits. Had he not fallen madly fond of angling pursuits, I have no doubt but he might have been one of the greatest devotees of his superstitious age. Or had he turned to "the breeding of the fighting-cock," like several of his angling predecessors, he would likely have crossed on till he had produced midden fowls to have beaked it with eagles; but luckily he had not the cock-fighting propensity. And what, after all, was fishing in the Dove and Stowr, with paddock baits, for geds and gudgeons, to the run of a salmon in the silver Tweed? I wonder how he would have looked if he had been brought here by rail, and set down below our Hare Crag with a twenty feet rod in hand, and seen and felt a twenty pound salmon snap down his fly to the bottom, and there hold it as firmly as if it had been fixed to the rock in the deep, with only a little tremulous indication of life at both ends : and then, again, when the sudden bolt up thestrong current took place, with the dash out 
at the top, showing the broad, silvery, and glancing side to the light of day! T'o imagine the odds between old Isaac and Ur Johnson, brought perforce into that particular position is ludicrous enough, and can only be exceeded by the next supposed image of seeing both snug at supper in their Inn, with the same salmon presented in his next glorious altitude, welldressed, and set round with sprigs of parsley and piggins of sauce. Who of the two would have said the grace? I think that duty would have devolved on old Isaac of necessity, as the doctor's mouthwatering would have prevented articulation. The doctor, on returning thanks, would assuredly have acknowledged the blessing as sent by God's merciful providence to his maw, by whatever method of stick and string it had been captured.

* * * * * * * *

Since publishing the first edition of this dissertation on River Angling in 1840, I have written out some recent observations and corrections, which will be found under their proper headings in the present edition; as this will likely be the last opportunity I can have of doing so, or of noting further experience. My remarks will be found truly practical-a description of my own successful practice and personal observation, regardless of other eyes and au- 
thors. Indeed, I hardly quote another author, as the late ones possess nothing new to me, and the old are hardly at all applicable to our Scotch rivers.

I conceive it better to make particular mention only of the best standard flies, with the manner of dressing and using them, than to give a detailed description of infinite and inferior varieties. I will, therefore, give only useful directions, divested of all the unnecessary discussions and superfluity of frivolous anecdotes, which have hitherto tended to swell the bulk of treatises on this subject. Thus will also be avoided all insignificant and endless enumeration and invention of names to flies, which rather tend to bewilder the reader's imagination than prove instructive to the individual desirous of practical information.

Should the style of language be considered not sufficiently perspicuous, the reader will be lenient when assured that he has got the very best style the writer can possibly afford from thirty shillings' worth of scholastic education. 


\section{S A L M ON F LIES.}

Salmon will occasionally take any fly of a hundred shades of variety; and often, in the most promising hour of weather and water, will, without any understood cause, disregard all kinds whatever. They are therefore accounted more capricious creatures than we might consider them, were we better acquainted with their appetites and habits, their incitements, and likely other sensibilities dependent upon certain unknown combinations of atmospheric influence, by which we ourselves feel often affected, yet cannot, with all our boasted philosophy, define how or why.

No one can say that he has ever seen any insect or fly frequenting the surface of our waters which in any respect nearly resembles those with which we angle most successfully for salmon.* Therefore, an

* One insect that occasionally frequents river margins occurs to us as resembling some salmon flies-the dragonfly; only it does not appear till about mid-summer, a season when almost no salmon are in the fly-casts. Dragonflies show all the colours of the rainbow, and the largest are as long as a medium sized salmon hook. We do not mean to say, however, that salmon ever take the artificial fly thinking it the dragonfly; but the insect decidedly resembles some of the lighter dressed salmon hooks. - [EDR.] 
imitation of nature is not in this, as in general cases, the ground on which the salmon-fly angler can possibly proceed; since, in this pursuit, he is left in a great measure to his own fancy; until from long experience he has discovered the combinations of fur and feather with which he finds himself, or perceives others, most generally successful.

From experience in dressing flies for other people, and frequent angling for my own recreation, I have long ago decided on the flies which the salmon seems generaliy to prefer. These I have reduced into six distinct kinds; and on investigating why these should generally be more successful, they will be found to embrace all the clearly marked distinctions of the leading character of the flies in common use. For instance, suppose you were to collect all the flies generally used on the Tweed, they would, at first sight, present the appearance of an endless confusion of variety; yet I am convinced you could not classify them into above six, or at most seven distinct kinds, in which the decided principle of all the vague variety of colour in fur, wool, and feather, would be found to concentrate, Consequently, the best known materials, wrought into the best practical combinations for proper effect, will be found to constitute the half dozen flies I shall here endeavour to describe; and 
this upon the same principle as the infinite variety of lines diffused throughout the floral creation may be referable into the pristine colours of the rainbow.

\section{FIRST FLY.}

First FuY.-A black body of fine soft cow-hair, or other fur (in consistence like that from the flank of a cow or kyloe), with a tuft of yellow floss, silk, or fine worsted wool, for tail, and a little red, green, or deep orange twisted close round the root of the tail-tuft. Then roll gold twist thread round the body, about an eighth part of an inch distance between the folds, and prick the hair out with a pin, and shade it as equally over the gold thread as possible, giving it a fine soft hackle appearance; and give a turn or two of dark orange, or rather red, round the shoulder, close below the root of the wings. A grey or bright mottled turkey feather use for wings, either from the tail or from behind the quill feathers in the wing of the fowl, according to size and circumstance, and have the mottle or speckle equally bright on both sides of the feather.

If a smaller sized hook:- where the pile of the feather is sufficiently long to extend the length of the fly's body, take one of four feathers from each side of the back of the drake immediately above the wing. 
Some prefer the mallard, insisting that its feathers are softer. I prefer the tame drake, as its feathers are soft enough, far more distinctly mottled, and more varied in light and dark shades of colour, to be used according to the state of water and other circumstances. The grey feather of the argus, or that of the silver pheasant, with its fine white bars across, is perhaps as good as either turkey or drake. A small feather lies below the wing of the snipe, about an inch and a half long, of a beautiful light grey, very well adapted for a large-sized fly, by tying the two corresponding feathers on entire for the pair of wings, adjusting the length by the body of the fly. The wings should never be so long as to project over the tail-tuft, and they may be put on unbroken, with the upper sides of the feather kept outermost, and lying along not too widely expanded from the body of the fly. Slight variations may occasionally be used with effect. As, for instance, dark blue wool for body, or water-rat fur, over which roll a cock hackle, preferring the kind which are black half way along from the root and red towards the top, the colour as bright on both sides as can possibly be got. In low water and bright weather, the light grey wings should be supplanted by others of a bright brown hackle, even as deep as the colour of the woodcock- 
wing. The bittern's is an excellent wing of this kind, and large enough for any size of summer fly.

\section{SECOND FLY.}

The second fly has in all respects the very same body as the first, the only variation being in the wings, which have what we technically term a whitetop. This is a black or dark brown feather, with a little white on the top, from the tail of the turkey for the largest size of fly, or from the rump above the tail for the smaller sizes; the feathers being smaller every row as they ascend upwards from the tail to the back of the fowl. Of this last rump feather, which is alike in length of pile on both sides of the stem, you have the advantage of furming the pair of wings with the greatest facility, by cutting with the point of a pen-knife the stem of the feather at the exact breadth of the wings intended for your fly, which are thus more easily tied on unbroken, as most wings had best be. Those white-topped feathers, the lower part of which are of a glossy black, are preferable; and the white top had best not exceed three eighths of an inch, and even three sixteenths make a fine fly of a small size; and if the hook is a large size, I would not disapprove of three colours in the wing - say a dun white below (as they often are 
found), black in the middle, and the white-top nodding over above.

\section{THIRD FLY.}

The third fly has the same body and tail as the former, with white wings; but prefer those of a pale or French white, that is of a light buff or yellowish tinge. This feather is got also from the white or cream coloured turkey's tail or rump. But the wings of such a fly should by no means be broad or full, only a few piles of feather in each wing being requisite.

This fly is preferable in cold spring fishing, particularly in heavy water. It is likely that this wing catches the salmon's eye more readily in deep or sullied water, as he will come up to it boldly when he will rise to no other. If the wings of this fly are too broad and flashy, you may readily raise a fish; but on a closer sight he will reject it and pass it untouched. Therefore give only as much wing as will render the fly perceptible to the fish from the bottom of the deep water; anything more will give it an unnatural appearance to him on a nearer inspection.

\section{FOURTH FLY.}

The fourth fly, in many cases the best, is altogether of a dun colour, body and wings. Although fox 
and other furs and mohairs, may be used for the body of this fly, with a hackle rolled over it, still I prefer fine woolly cow hair from the flank of a duncoloured cow or outfield kyloe. This, with a little gold twist rolled round the body, to give it an insect appearance, and the hair picked out to fall softly in a half shading over it, is, when well done, on all colours of fly, better than cock hackles. The proper dun colour is not easily described. It seems to partake of brown and white, a shade of red and yellow, with the slightest tinge of silvery grey, and a yellow tail tufted up with a speck of red. The wings are best when of the same colour, or at least as nearly so as possible, but prefer such as have a tendency to whiteness on the top. These may best be had from the tail or rump of a dun turkey, a fowl precious to a Tweed salmon fisher.

\section{FIFTH FLY.}

The body of the fifth fly is made of the dark grey fur of the hare's lug, mixed with the least quantity of bright red or deep orange mohair, or rather fine pig's wool (if fine pig's wool can be got with a tuft of yellow), over which, at the insertion of such tail or tuft, give a turn or two round of red worsted, mohair, or pig's wool. No hook requires the dresser to be more painstaking in dubbing the body. The 
fur used is the fine dark grey on the front of the hare's lug, where the fur is below a quarter of an inch long. This fur requires to be pirled* with the thumb and fore finger, along with the waxed thread. This gives it a sort of felting-on with the thread when you are rolling it round the shank of the hook. Still continue the motion of twisting while rolling it round. As you cannot come over the hook again with a second coat, it requires the necessary thickness to be done up at once over, and afterwards adjusted with pickings and trimmings, which can be better done with a small awl, having a handle, than a pin. If the hook is of a large size, I approve of a fine gold twist rolled around it, and a short bristled hackle laid in the lee of the tirsel. But as this is a fly more adapted to summer waters, and therefore seldom requires to be dressed on the largest size of hook, a hackle may be dispensed with. I have had best success without a hackle, when the short fur was neatly picked up to shade a little over the tinsel, the tinsel only a one-third ply of the gold twist. For the largest size of this fly, the ears of the roe-deer are, by my friend elsewhere alluded to, preferred to the hare's lug, as being a beautiful grey, and making a lovely body, either with or without a hackle. Of

\section{* Angiice Twisted.}


course these furs, like all others, ought to be gathered while the animal has its winter coat on.

The long tuft feathers on the head of the lapwing make a first-rate hackle for this, or for any low-water fly, as the feather is long enough to lap often round, and very fine and short in the bristle. A wing from the bright mottled feathers of the drake is the best adapted for this body, taking those of the lighter shade for the heavier water, and darker struck ones as the water falls into clearness, until on the smallest summer fly you may prefer a clear brown woodcock wing, which, from an old bird, is decidedly preferable to that from a younger one. But, as the woodcock wing will answer only a very small salmon fly, apply to the bittern, or to a beautiful, dark, drake back-feather for wing.

I recommend here nothing but what I have personally proven to my full satisfaction.

\section{SIXTH FLY, OR THE MAULE FLY.}

My sixth fly I will distinguish by calling it the Maule fly, which, though not much different from my first fly, yet is in some points peculiar; and principally in this, that Mr Maule hardly ever used any but this one kind, only varying the size of it 
from the largest size of hook (generally used on heavy water) down to the very smallest, little above the size of a large trout fly, say No. 9 or 10 of Adlington's. From the least to the largest size this fly was made up of a medium colour of sky-blue fine wool, with small pallid tinsel, or no tinsel, and a very peculiar cock hackle: to wit, black from the root up along the middle stem to fully half the length, then running into red out to the top-and a yellow or light orange tuft for tail-the wings of a soft mottled turkey tail feather, dark grey. A wing feather, however favourably mottlèd, he considered too stiff and unpliable. $\mathrm{Mr}$ Maule in dressing this fly differed from my mode of dressing. Instead of cutting off the pair of wings from the feather, and putting them on unbroken in the web, he tore them from the stem, then equalising their points, pirled them between his thumb and finger till well mixed; then tied them on with their tops laid back, adjusting the roots with knife or scissors. He then folded them forward and divided them equally; and next, by several crossings of the fine thread, tied them solidly in position, and trimmed off the fly. This fly he sunk by means of a blue silk casting line, which he had pointed off with five or six lengths of gut. In throwing this line he beat everybody; and 
from his art in sinking it, he brought it to near the fish on his lair at the bottom; and by these means he was more successful generally than any other fisher. I had long heard of Mr Maule and his success, and always with the warmest admiration, as a first-rate fisher, and a first-rate man; but I never met him till some years after my publication on angling had appeared-then I found him the man in every true sense of the name, and the gentleman in its every legitimate sense.

We have lost him now, several years since. Why should the true lovers of angling and worth not have him monumented at Boldside Boathouse, where he often lodged with the fisherman? I dare say the laird of Gala would not refuse the stance, were the idea respectfully represented. Were the rocks yonder mine, I would invite the monument; because we have had no fisher since the time of old Walton and Cotton characteristically comparable to the late Mr Maule. 


\section{MISCELLANEOUS OBSERVATIONS ON SALMON FLIES.}

For occasional variation of the three first flies, the body may be made of peacock's herl, using as many piles rolled round together as will produce the proper thickness of body. In this case a fine dark hackle is necessary to give it the proper appearance. Such hackle laid round close in behind the gold twist, produces a neat effect, besides being thus saved by the gold thread from the teeth of the fish, which are apt to cut the hackle unless so protected. I prefer all hackles rather short in the bristle than long. Those fine half-black, half-red hackles, so common with us forty years ago, seem now to be out of fashion among our barn-door fowls; few of the present colours are bright throughout; the inside is generally of a dirty pale yellow. Also, the real black are now changed to white near the root; still, with some trouble proper ones may be here and there found. Cocks of the game breed produce the best hackles for fly dressing, yenerally being longer in the feather, 
and shorter in the bristle, than those of the common fowl.

I am not fond of broad shining tinsel in any case, except occasionally in deep, dark, cold, winter water, and then I prefer gold to silver twist, as it is not so showy ; and, except on a large hook in dark water, a silk thread, or a piece of gut rolled round the body, to give the fly a maggot appearance, is perhaps preferable to any twist or tinsel. In very clear water, and fine weather, I consider all sorts of tinsel unnecessary.

Pig's wool when it can be got well dyed and of various colours is preferable for tails and tufts to mohair and worsted, being of a brighter dye and more determined colour in the water.

Much has been said of late of Irish flies, made (like butterflies) of parrot, golden-pheasant, and other bright fancy feathers; and even broad clear tinsel, with rough, red, blue, and white hackles, has been occasionally used on the Tweed with success. Hence, inexperienced fishers are very unwilling to believe in the general propriety of sober coloured flies. Yet, if the matter be observed and considered, it will be found resolvable into the principle of light colours for deep clark waters. Partial success in high or agitated waters is an exception to the general rule, 
and does not constitute a gaudy fly a standard one for ordinary pool and stream fishing. Besides, people often decide hastily in approbation of those flies with which they raise salmon, whether the fish touch their hook or not, thinking he has missed his bite. I think very differently in such a case. The fish lies quite at ease in the water, even in the gullyrush of a cauld dyke-slap, and on a glance of a fly moving over him, will sweep up in soft easy motion, and follow it round the curve it describes with a discerning eye; and on resolving to seize it, he will not miss his bite once in twenty cases; but when not pleased with the fiy, he will shy off, at which instant you may often perceive a back-fin, or half the web of his tail flap above the surface, or he will throw himself indignantly out of the water, and sinking back with easy motion, return again to his old lair, his chosen spot on the rock at the bottom of the river. By overlooking an angler from an eminence, we may see many fish rise coolly and examine his fly, of which he himself has no perception, not being in a position to perceive any that do not touch his fly or come up above the surface.

In regard to flies generally, either for salmon or trout, I have in practice found it beneficial to attend principally to a natural proportion of parts, which it 
is not easy to give or to receive a very proper idea of by mere description, and of which an individual can only acquire a correct notion from personal experience and attention to those in general practice. For instance, instead of a full dress, starched-looking fly, give it rather upon the whole as much of a modest, maggot appearance as possible. The wings should lie at seeming ease, less than half extended from the sides of its body, which body is the better of looking somewhat caterpillar-like.

I do not allege that the materials of fur and feather here specified, are the very best of any to be found in the range of nature for the effects $I$ intend to be produced : they are only the best I have found convenient, being our own local product. What I advise relates more properly to the general combinations of the colours, shape, and size of the fly, as suitable to the high or low state of the water, than to the particular materials by which such a combination may be best effected. For instance, several foreign birds and fowls-such as the Bengal and other kinds of bustard, the pencilled and silver pheasants-produce beautiful feathers, particularly of the black-and-white, barred, and mottled kinds. There are many English fowls, the plumage of some hundreds of which I have seen (preserved by a gentle- 
man in Warwickshire), and several of which I noted as being of a superior kind for wings to my favourite flies. The drake of the pocheral, or great red-headed widgeon, I would prefer as wings for my first fly. The gadwall or greywill - the saddle feathers of his back, and those over his groin, are also excellent for the same purpose.

The web or sheet part of the wing of the great grey gull, as well as his tail, is splendid for the wings of very light salmon flies, grey in place of pure white - this for my third fly. The greater gull and common sea-maw have beautiful feathers of an azure white still rather superior for the same fly. Then the cock shoveller has feathers on the saddle and over his loins charming for a fine dun fly, and his tail is valuable for beantiful light speckled wings. The buzzard and kite are alike excellent for light dun wings for a large fly; and for a duller shade there is a speckled feather in the spread of the pea-fowl's wing finely adapted for a hook of large or middle size, and easily tied on without separating the pile; but with a little trouble in the selection, the turkey produces nearly all the varieties of mixture and shades really necessary.

In collecting and preserving feathers, I would recommend to select merely the feather, or that part 
of it that is of positive use, stripping off the refuse which tends to foster moths, by which three fourths of all the best collected feathers are generally soon destroyed. In a box two inches deep, and eighteen long, by twelve broad, I can preserve all the feathers useful to dress, say ten thousand flies. To preserve them clean and right, tumble them all out frequently, say every three months, on a newspaper, brush out the box, and then lift every feather singly, clean it by stripping it between your thumb and finger, and replace it in the box. This will prevent moth-bites, and keep all tight and clean.

I consider it unnecessary to vary these flies in hope of success; only, be particular in adapting the size of the hook to the state of the water, as from the time the water has fallen in from a flooded state to a fishing size, and thence down to the lowest size of pure summer clearness, it requires not the colours or the form of the flies to be varied, so much as the size, which gradually diminish from the largest salmon hook down to the smallest, even to the size of a trout bait-hook, No. 10 of Adlington's; and, when trouting in low clear water, a salmon will often take your large trout fly, such as a March brownafter all forms of salmon flies have floated over him in vain. With my spring trout fly, No. 7 of 
Adlington's, I have killed a fish fifteen pounds weight. They feed in the low water exactly as the trout does, and with caution and patience these flies often yield amazing sport.

But the point most essentially necessary to be clearly understood in angling, and which, howeversimple, seems generally to be overlooked even by writers on the subject, although the most easily perceived in the practice, as well as on the slightest glance at the philosophy of the case, is this :-The salmon lies the whole day stationary on his chosen spot on the rock, at the bottom of the water, four, six, or eight feet deep, from which situation he must perceive the fly on the surface before he ascends to seize it; therefore, it must be of size and colour to catch his eye through that medium of water less or more agitated, as well as discoloured by earthy particles. Hence the main difficulty of ascertaining the exact size of fly, wing and body, first to catch his observation, and excite him to rise, and yet not to exceed the appearance of nature on his nearer approach. I have often known a fish in deep water rise three times successively at a fly of a very full white wing without effect, and when I diminished the breadth of each wing by half, he seized it greedily on the fourth rise. On this principle is grounded the main reason why every 
fisher succeeds better on his own water than a stranger, from his local knowledge of the depth and eddy, rock and gravel, of every cast, pool and stream. He knows from daily experience the size and colour of the fly requisite for each, according to the state of water, whether or not he is at all able to explain the matter.

Deep water, either in pool or rapid, generally. requires a fly of a larger size than more shallow pools and streams, even on the same day; and that without change of sky, wind, weather, or water. In heavy water, or in fishing over a deep cast, I prefer going over it first with the largest or brightest fly I suppose at all likely, say a large size of my third fly ; this may catch his eye and engage his attention. Should this not raise him, or should he rise and pass the fly, then try hin with one a size or two smaller, or a little more sober in colour, which he will likely then take. On the contrary, in low pure water, when beginning to go over a cast, use your smallest or sober coloured fly first, and if he do not rise to it, then go over the cast again with one a size larger, or a shade brighter.

An experienced, good fisher, even on a strange river, may conceive pretty nearly the spot where a fish will lie, according to circumstances-the state 
of the water, or the curve of the surface, in pool, rapid, or eddy; but no description is of avail in giving an idea of this, as the skill can only be acquired by experience.

Since Irish flies were first tried in the Tweed, that is within thirty years back, * they have been, if not gaining in favour, at least keeping a distinguished place on "the face of the waters," and have got a standing amongst the fly fashions of the age. This certainly shows that they are somehow cognate to our old legitimate Tweed flies. Yet that the success has been greater with them upon the whole, than in a corresponding length of time previously with the old flies alone, may be disputed. That more fish were caught in the thirty years before they were introduced is no argument against them, all other casualties duly considered. We are, therefore, obliged to hesitate in a decision for or against preference of either. On a broad view, my own conception of the matter is this, that Irish flies may be found preferable in muddy, dark waters, being constructed of bright colours-golden pheasant, yellows, oranges, \&c. - and that newly come fish see them more quickly, while the water is yet a little discoloured from the soil in a flooded river, and from this cause take them 
more briskly than flies of darker hues. New run grilse certainly prefer them, as I have found those always fonder of a bright fly (with glittering tinsel and showy colours, even white hackles) than heavy old-run salmon are. Heavy fish keep more in the deep water, and never take the fly well till the river has fallen low and clear, and then sober coloured flies please them best, as likely agreeing better with the low clear state of the water. Clear or coloured water will account for one half of the whole phenomena. In discoloured water bright feathers appear as dim as sober colours appear in the clear.

It is long since we were satisfied that the living type of what we call our salmon flies is not found in fresh waters or produced there, either on the land or in the river. For what, then, the salmon take our flies has been the continued unanswered question.

From a late brown study on this subject (perhaps the fiftieth I have caught myself in in as many years), I have been pleasurably aroused by the present of a valuable book, from a kind gentleman, entitled "The Earn, its Legends and Fly Fishing," by the Rev. Henry Newland, rector and vicar of Westbourn. In this book, among a variety of pleasing observations and well told anecdotes, the author, supposes the shrimp to be the natural prototype to which our 
artificial salmon flies form an accidental resemblance, in the structure as well as in their jerking motions, caused by their attachment to the line in the current of water.

Having never then seen a shrimp, dead or alive, I could not blame myself in not having detected it as decidedly the true prototype which I had so long been in imaginary search of, being always convinced that it must be a marine production, and very common on feeding shoals in the sea Had I ever seen a shrimp, I think I might have caught up the idea at once; and now what a variety of proofs come in on the mind in support of the opinion, which is no longer an opinion with me but a decided fact, as all past observation, from experience and analogy, rushes in, confirmatory of the truth of the parson's observation. One point which goes far in proof of this opinion, is this, that every good fisher must have observed that his fish bites surest at the fly when well sunk in the water, say to mid-depth or so ; and it is also a sure sign of a fisher knowing his business from experience when we see him endeavouring to sink his fly well, in place of making a novice-like effort to keep it on the surface. In fact, I think I may be correct in advising to even add a little weight occasionally in a deep and strong current, say a grain or two of shot, a gut 
length or so from the fiy, the same as is used in minnow and worm fishing.* This is one of those conceptions of which we feel certain without having put it to clear proof. Whoever will try it I am convinced will succeed. Large old salmon do not readily take the fly in heavy or soiled water; the main reason is likely this, that they keep low in the water, resting frequently, like other heavy old creatures. This rest they take on the bottom rock or gravel, and do not prowl in mid-depth as the grilse, being young, sportively do. Hence, the grilse meeting with your bright fly, see and seize it, while it is not seen by the salmon below. By the time the water has again fallen in to the low fishing size, the dull flies, what we call the legitimate Tweed flies, are again found bright enough, and mainly in request. I have only twice in fifty-seven years seen something

* We may mention a case favouring Younger's idea on this point. Some years ago in the Tweed, a few miles from Kelso, an old and experienced salmon angler found in the early spring that the fish would not rise, though he tried them with all sorts and sizes of flies; and it occurred to him that perhaps the salmon in dull and rough waters might not be able to see his flies, or that they would not move or rise from the coldness of the atmosphere. He therefore got the fisherman to dress him a large fly, on the shank of which he had strapped small beads, with hackles between. The weight of beads made the hook sink deeply in the water, and the result was that the gentleman for a week or so had first-rate sport, although anglers on other neighbouring waters were doing almost nothing. In summer waters, however, this gentleman, like other anglers, sinks his fly by its own weight and the manner in which he works his rod.-[EDR.] 
apparently the reverse of this, which might at first sight have posed a fishing philosopher to account for. In a heavy late autumn flood, in the second week of October, a run of large grey schule fish came up, literally stocking the river, while yet running black and full. For three or four days they seemed all keeping near to the surface, tumbling up everywhere incessantly, to near the very bordering grass, and seizing at sight any large fly you might throw in; but yet [being] on the run upward, they would not settle till the water should fall low. This does not fully account for the whole phenomenon, as more were still moving on from the sea, till in a few days they became sobered down and would not rise to a fly; but when the water had fallen to a mean fishing size, they fell to be fished for in the ordinary way. We may observe that if our parson's bright yellow fly-which he names from his own profession, The Parson-is his studied initation of a shrimp, copied from the type (and we say the salmon take it for a shrimp), then what do the salmon take other flies for? certainly, as well all for shrimps-black, blue, brown, and dun as well as yellow. This holds at all points to our purpose, in proof that it is the shrimp that salmon flies of all colours are taken for. The bright golden flies of the Earn, and the darker flies of the Tweed, 
must all be imitations of shrimps, though unwittingly so designed.

The living parson has copied a fly from one bright yellow shrimp, found it a killer, and named it after himself; but from a handful or two of shrimps I shall pick out a dozen, in which his six pictured favourite Earn flies and my half-dozen of Tweed ones, will be found a resemblance as near as if imitated intentionally; and these may be even more like when moving in the water. And shrimps are as varied in their colours as are a flock of fancy pigeons,* and of all sizes too, the same as we make salmon flies.

It would appear then, that all along in making up our salmon flies, we have, by a repetition of experimental trials, been arriving at effect, without adverting to the proper type as the cause. Who of those who in primitive ages "cast angle in the brooks" would first conceive the notion of what we call the salmon fly (like no living fly that has been seen), or what might suggest such idea to their imagination, must remain, as it has hitherto been, undeclared, and unremarked, even in tradition. It would be a curi-

* We doubt if John is entirely correct as to the colour of shrimps. We have many a time caught thom, both on dull and sunny days, and their colour al ways seemed the same or nearly so. When the sun shone we occasionally noticed a light or faint shade of steel blue upon some of them, but so faint that the natural colour was still the predominating one, namely, that of sea sand.-[LDR.] 
ous experiment for some one-how amused he would feel at his first success. Whether an ancient philosopher, or a neat herd boy, is of little consequence. And now when we do believe the shrimp is the small marine creature to be imitated (instead of some unknown fly of the air), and in consequence, in making up our deceptions, strive to copy that little fish more closely, yet in this we may not succeed better than by holding to our old experience.

From examination of the shrimp dry in our hand, along with the best imitation we may be able to make of it, we might be misled in our judgment on the matter, from the want of being able to examine it with the eye of a salmon thrcugh a salt water medium, where the effect of colour, shape, and motion, may give a very different appearance; and hence, after having acknowledged our conviction of the exactitude of our similitude, may yet be led to prefer our old fashion from the mere accidence of eventual success. This is to say that our chance imitation, formed upon the principle of success in repeated trials, may be as true a resemblance as a more closely designed imitation might ensure. Yet still it is a curious consideration that, in this case, so much imagination has been letloose in conjecturing what living type these flies might be the imitation of, 
and no one till now should have stumbled upon this salt sea shrimp. We are now making as renowned a fish of him as if he were actually the great "saltsea shark." He is a most active little fellow, with his score of limbs, arms, oars, feelers, and feathered tail, all spread in action. On minute observation our salmon flies resemble this shrimp more than any other creature we wot of, either on land or in water : their various size, indicating youth or age, the form of body with its appendages, and the different colours they assume, agreeably to the reflection in light or shade, like the pheasant's or pigeon's neck. Then, observe this creature in its own element moving through the variety of its exercitations, its limbs thrown abroad like a bird's wings in air, and feet moving as swimming in mid-depth of water, its contractions and expansions, as it draws in the hinder part of its body, and strikes back with its horizontally spread tail in acceleration of progression. Then see the salmon at ease below, his ever-awake eye alert on the watch for prey, as well as against surprise. Now he shoots forward like a feathered dart, or, nosing out on the prowl, snaps up the shrimp as the swallow takes flies in the upper element.

What a picture does nature everywhere present, 
if we had eyes calculated to see through her grand media and take in the minutiæ as well as the expanse of her canvas.

These shrimps are everywhere acknowledged a very nutritious, as well as a savoury dish at table. No wonder then, that the salmon which leave our rivers in the spring in a poor meagré state should so soon again get into grand condition; and that the slabby white muscle of his body grows red, rich, and incomparable, as the digested substance of five hundred shrimps a day may make it in a month.

Be this as it may, we are certain that salmon take our fly for something that must nearly imitate what they know to be their food. Or suppose them to have been confined to a situation where they have never seen such species, they would yet seize our fly on sight, as a cat would a mouse, from an intuitive impression that it is their natural prey. We may rest assured, however, that it is not a fly of the air, nor a fresh water production that the salmon take it for, as such have never been observed by the fishers of late generations, nor recorded by any of the former; yet, we may not even now alter its name, but call it still the salmon fly. 


\section{TROUT FLIES,}

\section{NATURAL AND ARTIFICIAL.}

Before proceeding to give my selection of trout flies, I would wish to observe how these flies are bred, and the successive appearances they present in their change from one state to another, which will assist you to account upon philosophical principles for various phenomena occurrent in angling, which tend to confuse the ideas of superficial observers.

If in the middle of winter you lift a stone from the bottom of the river, you may perceive on the under side of it numbers of small cases, formed of mud-particles, cemented by a glutinous substance into a consistency like brown paper; by pressing this case you will see that it contains a dark green maggot, or chrysalis of the future water-fly.* These are

* We have lifted hundreds of stones both in winter and early spring for the pnrpose of examining the water flies in their maggot state, and even to very small pebbles they are often sticking numerously. The family is greatly varied, both in size and shape, and each kind has its own peculiar covering or outer skin. One or two of the kinds have a somewhat uncanny look, and few but Waltonians would care about handling them. - [EDR.] 
in myriads, and constitute a portion of the food of trouts throughout the winter, as they do in their more fully developed state when winged in the summer. On 23d November, 1837, from the stomach of a trout about half-a-pound weight, I counted out three hundred of these maggots all in the skins, many of them still retaining the appearance of life.

The genial fine weather in early spring brings forth a portion of these maggots every fresh sunny hour, just as they come into a state of forwardness toward the maturity of their existence. Having left their habitation on the stone, they float for some time enclosed in a second tough film, within which their wings lie in one single fold, and from which they creep out by degrees, leaving this last vestment a floating wreck. So soon as extricated, their wings spring erect, shewing them off the finished, lovely, gentle denizens of air.*

Not a more delectable half-hour's amusement have

* A friend who has been a keen angler for fifty years, gave us the following information :-An old man of his acquaintance (but not an angler) came to him one day and said he had something to tell him that he thought very curious. He had been sitting in the sunshine close by the river, when he saw what he thought a small bit of brown moss rise from the bottom of the water to the surface. He kept looking at it for a few seconds, when he thought it began to move. Presently a small fly stood erect upon it, then spread out its wings and flew off; and one fly after another continued to do the same until the brown speck disappeared, it having been a cluster of water-flies.-[EDR.] 
I ever had in my life long (except in sweethearting when young), than in lifting one of those aurelia from the stream, and sitting down with it on the palm of my hand in the sun, till it put out its feelers, and drew itself by degrees from its envelopment. Then its wings sprang erect, shewing it off as tenderly-pure as a vision of thought; and when dried, it mounted in its new element, to delight its hour or its day in the pleasures of a new state of joyous existence.

Though some species of the water fly have been considered ephemeral, I do not think any of them are exactly so; as they continue to flutter about the bushes, where you may beat them out in thousands in a cold morning, and when brought home to the windows they will live for several days. After they have risen from their maggot state at the bottom of the water, to the most perfect winged portion of their existence, they swim and flutter on the surface till they have gone through all the operations necessary to the continuance of their species, dropping their eggs on the surface, which, being of more specific gravity than water, sink gradually: and wherever the current of water may leave them at the bottom, which is most generally on a ford, they settle and adhere by an emitted gluey substance to the under 
edges of the stones, where they are carried in by the current; and where, from the sediment of the river, they attach the material particles proper to form the case in which we find them there contained, and which, by some operation of the insect, is formed into a proper fitting sheath for its body. Here it lies snug, with its black head and fore feet, or feclers, peeping out on the sweet light of life, ${ }^{*}$ dining like a young emperor on the rich, delicate, minute animalcula of which the water is pregnant.

Trout angling is very different from salmon angling; because, the trout when feeding on flies swims about in middle-water, or rather nearer to the surface, picking and choosing the fly most agreeable to his taste. Fror instance, in a summer flood, when the river begins to subside, you may perceive on the yet brown muddy water a variety of flies, of many kinds and colours, floating down the current, and the trout rejecting all the gay profusion as they pass, and selecting one kind (probably a dark coloured midge fly), no doubt just as carefully as he does in the clearest water-when circling round his pool with an easy motion, you may observe him darting forward to scan the coming fly, which he

* The cradle-skin of a large number of these maggots is quite close, and these can, of course, neither put out head nor feet. - [EDR.] 
likely may reject, springing aside to seize another of a kind which he approves.

As the trout are feeding on these insects in all states, both at the bottom and as they ascend to the surface, no wonder that people sometimes catch a few trouts with very ill-formed flies, even without wings altogether. Yet this is not a sufficient reason why you should not have a fly formed to give as much as possible the shape, colour, and appearance of the natural fly in its state of fullest perfection; and, for this purpose, I will here briefly give you my selection of trout flies, imitated so as best to promote general success throughout the season. I shall reduce them to only a few in my description, as I hare found only a very few really necessary in my general practice.

But first allow me to observe, that if you go out a-trouting about nine or ten o'clock on a mild March or April day, you may thrash away perhaps an hour or two without seeing a natural fly, or a trout rise. At last, unexpectedly, you will hook a trout with your flies carelessly half-sunk in the water; and before you have landed it, you will perceive the trouts all in a plunge-nothing but heads and tails flapping amidst myriads of pretty large flies, which, according as the light strikes them, may cause the 
surface of the middle current to assume a reddishbrown appearance when seen in the distance. On a nearer inspection, you may conceive that they might be best imitated by the dark grey of a hare's lug for body, and brown speckled woodcock wings-which most fishers positively decide on using in preference to other material, never considering that hare's-ear fur is darker coloured when wet; and of which, therefore, from experience, I disapprove, preferring the body rather of the shortest, or belly part, of watermouse fur, teased up together with an equal proportion of yellow fine wool or mohair. This mixture shows of a tarnished green colour, and when in your hand looks too light for the body of the natural fly, but when wet, must to the trout have the nearest resemblance, as with it you will have most success throughout the spring months.

First take of Adlington's hooks (round bend), No. 7, to form your pair of flies (or whatever maker's hooks you may approve, but let them be of that size); make the wings of the one fly of the lighter coloured part of the woodcock wing feather, or rather prefer the softer and lighter coloured feathers from the middle of the web of the partridge wing. Make the other fly, the blae one of your pair, with either a starling wing, a bunting, or 
mistletoe thrush. I cannot decide as to which of all these is the best. Let the body of both flies be made of the shortest of the water-rat fur, that which grows nearest the belly, and has a yellowish grey lustre on the surface; this mix up with an equal proportion of yellow worsted wool or mohair (dyed pig's wool is preferable, when it can be got fine enough) well teased together. With this make your fly, body and wings, fully as large, upon the whole, as the fly you imitate (in earliest spring I sometimes use No. 8), and fish on with this pair, using no variation whatever, from early spring down to the setting in of fine weather, about the end of April. Then the fly of which this is the imitation is succeeded by one of a size smaller, or rather more slender, and the least shade lighter in colour of body and transparency of wing. In England the first of these flies is called the March Brown, the second the Pale Yellow Dun.

In ordinary seasons, this last fly comes up about the end of April, or beginning of May, and continues for a month or more in main request, making still a secondary fly all down the summer; and when it comes first on it is the chief object of trout, in preference to the former fly, of which a few are still seen straggling on the surface. My usual imita- 
tion of this fly is with the same mixture of blue water-rat fur and pale yellow, inclining to white for body; and for wing, the most transparent feather to be got from the wing of the bunting* or the mistletoe thrush.

As these flies are tender, you may perceive them in breezy weather all dishevelled by being blown in from the ruffled surface to the sheltered eddiestheir wings being dashed asunder, and spread on the water like shivered oars. In this state the trouts devour them; and from this circumstance, as well as another which I shall presently describe, a hundred vile imitations of this fly meet with partial success; while those who use such, often ignorantly aver that it is of little consequence to be nice about flies. The next best imitation of this fly (or it may be even a preferable imitation to mine, as I never used it) has the body the same as described, but small and gentle, and the wings of a small body

* Buntings are a numerous family; but from the fly he speaks of, he must mean the yellow bunting, the yorlin. To an angler with "music in his soul," the black-headed bunting is a river-side pest. In the early morning it follows him from bank to bank, with its whit-o, whit-o, whit-o, bringing him in mind of saw-sharpening. We once saw a brother piscator lay down his rod and commence stone-throwing with great vigour, into a bank of trees. On coming up and enquiring what he aimed at, he said he was trying to drive off a sickening bird that had " wheetled-zheetled there for the last half hour." This was the black-headed bunting. Strange, we have more than once seen this bird classed as a British song bird. - [EDR.] 
feather from various birds (say the body feather of the grouse, of a lightish fine freckle, stripped off the right side), and rolled round the head, or rather neck of your fly, in the manner of a hackle. This imitates the dishevelled wings of the natural fly, and is technically called a spider fly, and some aver that with it they have great success, of which I have no doubt, as I have long known it much in vogue.

I discovered my imitation of the Pale Yellow Dun to be a killer thirty years before I really ascertained its proper archetype or its name. At that time, fishing along with a dear companion, now long in his grave, on opposite sides of the Tweed, a little above the Doup Roads, on the head of Mertoun water, we, to prevent entanglement, took cast about, our flies (though contrariwise) both alike sweeping the same centre spot of heavy water ; and, in a circle of within twenty yards diameter, he caught three trouts, while, with one of the flies of my pair, I caught fifty-four, which weighed twenty-four pounds. We then examined that individual fly, which, in the dressing up, I had accidentally varied from the rest of our early spring flies, and we afterwards adopted it as a first favourite-a successful one. It was nearly thirty years afterwards ere I learned that this fly (accidentally on my part) proved to be the "Pale Yellow Dun" of English anglers. 
About the middle or end of May, sooner or later, according to state of weather, a small dark blae fly appears, which may be best imitated on a small hook, No. 1 of Adlington's, or others of a similar size, the body rnade of the belly fur of the water-mousewhere the fur is shortest, blae-coloured, and tipped with dun-and tied with fine silk as near the same colour as possible. The wings should be made from the tip of the back feathers of the starling wing, or from any other bird's wing of a fine texture and blae colour, though I have often used those of a sparrow wing, and with success. This small fly appears on the water before the former (the second spring fly) is retired. I have preferred using one of each to form the pair, making the small blae fly the trail or end one, and the former, larger, light-coloured one, the bob or dropper, upon the consideration that the smallest fly of a pair should always be the out-end one, giving it the open chance. For days or weeks after you will take trouts alternately with each; and observe, that though trouts may occasionally be taken at this period with flies of other descriptions than these, yet no trout that would take any other would reject these if gracefully offered. I have always hated the confusion of fishing with more than a pair of flies, and would rather nip off 
the dropper and fish with only one than fish with three, and be sure of more success too, as through a day or night you have no hankings or hindrance.

\section{CURIOUS PHENOMENA.}

Some curious phenomena occur in angling which may come well enough in place to relate here. In fishing either for salmon or trout, more I think depends upon the state of the atmosphere for success or non-success, than on any other single circumstance, or on all other causes taken together.

In the salmon department, we may passively observe, that often when all seems fine, and you know that salmon are in the pool or stream, and might suppose that they would just be lying ready watching for a fly; you may cast over it with all the blandishments of your art, try all known means of temptation, and even supposed new means-as well try to raise the rock he lies on! Say that this occur twice in the day, morning and middle; yet go back about sunset, when you may likely have him up at first sight, fit to tear the rod from your hands. Now, whether he had been asleep, or had 
not got digested his nightly or early meals, or had merely felt lazy from some oppressive feeling, allied to an indigestive state, such as is frequent with ourselves, is not understood ; but I rather suspect that the real cause is from the electric state of the atmosphere, disinclining him to motion, as well as promoting a dulness of appetite.

Again, in the case of the trout. We have a fine middle April day, we go out say at ten o'clock, the glass at $50^{\circ}$, a medium state, having been pretty steadily so for days past. Everything looks favourable-the river just beautiful, not too much cleareddown from the browning of a recent flood-the atmosphere neither spiringly dry, nor drowsily heavy. Fit up, lay on your flies, be ready for the first movement (and be alert while the movement continues), for they cannot choose, but be all in a stir in a little. Well, you go on, throwing out softly and dexterously, till you have gone over a hundred, or may be three hundred yards, up or down, of the finest water you ever cast line on, yet not a bell or small circle ever forms on the beautiful surface, except what the soft falling of your own flies and line occasion. You look up and see the light clouds hardly moving on sunwards, and scarcely even whitened on the sunny side, the least indicative sign of frost-every- 
thing in perfect consonance with our notions of a good day-our own blood in free circulation to and from the heart, bearing elasticity and comfort to the nerves, and inducing even generous sympathiesthe lark overhead sailing beside the light cloud, the thrush and blackbird on bush and tree, and the titmouse in the hedge below, swelling their little throats in the joy of love: why are there no flies come to the surface-they are half an hour later than I expected? While you turn and move and stand in suspense, down floats a shower of flies literally thatching the middle current, multitudes of them whirling into creeks and eddies (say beautiful March Browns, bred up from the grub state on the bottom stones of the ford above the stream), and not a trout seen to flap a tail amongst them! Why are all in motion but the fish? No answer to this our question of thought, no solution found, the pride of our philosophy humbled. Even old father Walton and Sir Humphry Davy were aback as far as I find myself, having no reason to render for such a phenomenon. But we feel, we fret to stand inert, so keep casting on, regardless of breaking the wings of fifty living flies at every fall of our lumpish line and sham fies, on the surface, though supposed by us comparatively fine ; and having come to fish, fish we will. 
I who write have gone on in this style for hours, and till nearly at the sinking in disgust of all idle earthly pursuits; and the water-carpeting of flies having imperceptibly vanished off, I could take no account of the least perceptible change of atmospheric influence, when at last a good trout would startle me with a tug at my line, half sunk from inattention. Ere I got that drawn ashore others would be plopping up here and there all around. Then I became alert and diligent, and just as I had got one carefully taken off the hook, another would have nipt down a natural fly; my flies are over the spot in a moment, up, down, or across-but a yard above his nose-and he is got fast and flouncing. No stop now takes place till my basket is full with nineteen pounds weight, just what the lid would tie down upon, and a dozen more half and whole pounders hurriedly thrown on the grass, or stuffed in my pockets with their tails flapping over. Likely then, they begin to rise more transiently when I begin to relax in persistence, getting even sick of the water.side, fresh, fish smell; and, bundling up, I turn for home to see and get something of a salted taste to satisfy a well-earned appetite.

This is the description of one effect: I should like to meet with him who could give me a satisfy- 
ing natural cause. In the meantime, I conceive the cause as somehow allied to electricity in some state of its negative, positive, or veering motions, but how balanced so as to produce the particular phenomenon of the flies covering the surface, and the trouts not owning them, I know no more than a philosopher.

Another morning at ten o'clock will look much the same as last in all respects, only that the first rise of flies to the surface will stir all the trout into motion; a complete flapping of heads and tails and yellow bellies tumbling up, cuffs the flies to confusion. In this case we may get a few, and only a few, for, though in feeding mood, they have such a choice before them, that our best imitations are overlooked or rejected on sight. In half an hour the hurry is over and all stilled again into a dull calm surface, till another rise of flies from the bottom, when a similar scene takes place for another half hour or so ; and so on alternately down through the middle part of the day. The best thing to be recommended to an angler in such a case, is to take his place on a proper station, where he previously knows the trouts will be principally congregated; to be ready and active in picking out half a dozen or so whenever these bestirs are going on, and they 
are common on every fishing day in April, for halfhours alternately, from nine or ten till two or three afternoon. If it continue fresh and fine, though even sunny, they will rise and take singly on till four, when you may pack up and toddle homeward, with hope of sound sleep and a still better day tomorrow.

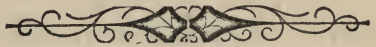




\section{MISCELLANEOUS OBSERVATIONS}

ON TROUTING, TROUT FLIES, TACKLE, AND RODS.

When in bright weather and clear unruffled water you cannot succeed in throwing your flies across, or rather at a considerable angle upwards, and letting them swim down of their own accord, with no visible pull upon them, then turn your face up the water, and whether in stream or smooth pool, there throw straight up, or at such slight angle from straight up as circumstances of depth or other impediment may permit. In this way, your fly falling lightly above the feeding trout, he is apt to snap it the instant it alights; your quick acknowledgment of feeling him being down against his mouth and body, he can hardly miss being hooked; then lead him gently down towards you, which action alarms none above. Then proceed a step upwards, and in the next throw, breaking new water, you have a new chance.

It is easy to conceive how readily a trout is hooked in this way; for when the fine gut is wet and pliant, the moment the fly is dropped on the 
surface the action of the water folds it inwards, bringing it to the trout's mouth like a natural fly afloat, and not seemingly held as hanging against the current. It is thus slack when he sucks it in, and you have only to give the slightest pull, which, being against him, gives advantage to get such a hold as settles his concern with existence. In the common way, fishing from above, the thing appears to the trout out of course, and this he perceives, from an instinct, more quickly than Sir Humphry Davy could have reasoned it from his best philosophy and knowledge of angling. Indeed, in fishing downwards in thin clear water with flies hanging against the stream, it is a wonder one should get a rise of a trout at all; and if you should, you are more likely to scart the mouths of nine, than to get hold of the "tongue or lip of the tenth, which would be a chance next to a miracle. Without the method here recommended, in thin clear water, where trouts, if unalarmed, are sure to be feeding, you cannot have success-at least coming splashing down upon them in the coarse common way of proceeding in heary water. In the fine light they fly from your line or the shadow of yourself, shy off and disown your acquaintance, and you come home like an idler, if not like an idiot, with not a trout to grace 
the meal for which you are hungry after such exercise.

The method above recommended of throwing aslant, or even due upwards, may to some old anglers appear sheer innovation upon old standard habits, as much so as railway trains are to their old notions of wains and carts, stage-coaches, \&c. But those fishers who still adhere to the old system of fishing down or across the water, let them match themselves for a day with fishers who fish up the water, and on comparing baskets, the follower of "old saws" will gape with due wonder and dumb astonishment when he finds how much he is outstripped by the followers of " modern instances."

On the falling in of a flood the trout soon perceives, and sets out on his foray, first on the easy eddies, and sucks in the small flies in thousands, filling his stomach on dainties to repletion. Cut up a trout of a pound weight in such a time, and see in his throat and stomach ten thousand blae midge flies going into a mash amongst six or eight pars and minnows, and find that he has also been so greedy as to take your fly or minnow over all; and then don't be sorry for having nabbed him, and saved a million more of flies and small fish, each life as precious as his. From the stomach of a trout, of about the above weight 
I have cut out six small trouts, pars, or smolts, averaging five inches long : the one first swallowed digested nearly to the bones, the last, whole and entire, still stuck in the gullet for lack of capacity in the stomach equal to the voracity of its nature. This trout took my imitation fly, over and above this gorged bellyful, by which it was caught.

The trout is not the capricious creature he has so often been represented to be; every motion and appetite of his being as exact to taste as that of any creature, bird or beast, that we wot of. There is not a mistake in the constitution of his nature and habits; all things seemingly so arise from our own misconceptions, through ignorance of his true characteristics; and be it also particularly remarked, that waterflies arise from their grub state on the bottom not at all according to months and terms, but agreeably with the state of weather. Any, and all of these kinds of flies, the spring and early summer kinds particularly, may be three weeks, or even six, later in one season than another; and the trouts are not waiting for these flies coming to the surface, as they are always, summer and winter, helping themselves to them in the grub state, and to any particular kind of them, agreeably to their seasonable tastes, and following them to the surface as they arise, 
feeding upon them there also. When the flies come up thickly to the surface, as formerly described of the March Browns, and no trout takes them; for a trial of skill mutilate the wings of your flies by picking them off about half-middle (not cutting them); or rather by tying down the top of the wings to near the tail of the fly, which makes its appearance something like the maggot released from its first case on the bottom stone, and on its ascent to the surface. Then, as much as you can, let them sink low in the water, altogether below those flies on the surface, and you will most likely succeed in getting a few trouts, as then they take them for the grub newly come out of its case on the ground stone, and not yet quit of the silk-like film in which it is bound up-with its wings laid up in one fold, like a man with his wrists tied to his arms below his oxter, with the arm-pit joints having free motion. These pellicles, or second skins, which the flies cast off, you may see lying like chaff, covering the water edge, as drifted into coves and eddies, about the end of April and beginning of May.

When you find the trouts decidedly preferring the small fly of your pair, it being newly come on while the former is fading off, then discontinue the large bob one, and constitute your pair both of the small 
one on very fine gut. Whatever other flies appear on the river throughout the succeeding months of July and August (nature in these months sporting her summer hues in all shapes of tinted variety, befooling our imbecile attempts at description or imitation) still continue, all along down through these months, with the same small dark flies as herein stated, with only the following occasional variation :-Let the body of one of your pair be made of a pile or herl of the peacock tail-feather, rolled round very closely to form the body in place of the blae fur, and with these you may succeed, less or more, every breezy summer day.

Although in salmon fishing we recommend a large fly for rather a heavy or dark water, that the salmon may see it from the bottom where he lies, and be tempted to rise to it, the case is completely reversed in trouting, as trout do not lie on the bottom like the salmon, but when fly-feeding, in muddy water, swim so near the surface that a quick eye may often detect their back-fins kithing above water. This they do as much for respiration above the floating mud as for seeking food. The smallest fly they take in its season is sought by them on the surface of the most flooded water; and as to the fly itself, it ascends to the surface in its proper time, day and 
hour, whatever state the water may be in. Nature does not work in the vulgar manner of making larger flies for flooded waters, and finer and lesser ones for the low and clear.

With regard to certain states of water (dark or clear), and the colour of the fly showing more sober or bright, as the shades of light may strike and tinge it for the time being, we should not stand too stiffly upon a crotchet of opinion. We may find success though we cannot well account for it, and therefore our imitations should perhaps not be held too strietly opinionative, either in point of size or colour. We therefore may not err in sometimes holding our fly a size larger,* or a shade lighter

* This must, we think, have been an idea, not an experience of Younger's, otherwise he would likely have written more decidedly. He also elsewhere recommends a spring fly to be dressed larger than the fly imitated; but the summer months are not, in our opinion, favourable for angling with flies so made. The rivers are larger in March and April than in summer, and the feeding trouts also lie in deeper water, and are ever hungry and extraordinarily fond of flies in early spring; and the large fly may, trom these circumstances, be more easily seen, and readily taken. But unless in early spring, or in water still very dark or muddy from a recent flood, we never knew an angler who preferred fishing with flies made larger than the natural insect. If different at all, and for clear-water fishing, most anglers like the dressed fly a trifle smaller than the living one; and we, ourselves, have many a time found a fly made up on this principle a good killer. In the streaming rippling waters, generally fished with fly in summer, the small hook cannot so readily show the cheat. The males of some of the kinds of water-flies are smaller than the females, and the difference is nowhere more noticeable than 
coloured, as comparing it with the living fly when both seen together dry on our hand. In such case it may be advisable to yield to what we may find conducive to our success for the time being, rather than to stand starchly to a general principle, however supported by our ordinary philosophy.

The grand mistake of all the authors I have seen on fly fishing, is their supposition that the flies are alighting on the water from above, whereas, could they catch up the idea, or be persuaded when told, that the flies arise to the surface from the bottom where they are bred, sheets of useless speculation might be saved; such as about making your cast of flies alight softly on the surface, like living flies alighting from the air above, \&c. Water flies.do arise from the surface occasionally (as well as for sexual contact, like midges, bees, and birds — such as snipes and swallows,) and sometimes alight on it after. One of a thousand may do this, and on alighting be met by a ready trout; but this is rather an accidental alighting than a general case, as the trouts are really rather feeding on those arising from

in the March Browns; and from this circumstance a person dressing from a male pattern of this insect might make the artificial fly a good deal larger, and find it a killing one, but the same result, we are certain, would not follow with other flies, and in clear summer waters.-[EDR.] 
the bottom upwards, while those ascending into the air are done with the water, not requiring to return.

Flies on which trout principally feed are such as are bred in water, and these having passed their ten or twelve months, in the grub state, and arisen into the full flush of their aerial term, very quickly perform the functions necessary to the continuance of their species, and leave the water as a band of newly fledged locusts leave the desert sands, flying off as may be seen, particularly in the months of April, May, and June, in myriads. I often see them on all the breezes, arise from the water and take to flight over the 'Tweed's banks of seventy feet high-of course unreturning. The millions of trout devour millions of flies each, still myriads are left, these flying out to the bushes and broad open downs to disport their hour, day, or term in other situations.

It must be understood that all this time, under my above receipt, you are using very fine tackle, a well balanced rod, with line to match, of a rightly calculated weight for the throw-as too light a casting line is a more grievous mistake than even too heavy-and fine gut of a water or window glass colour. The rod should be about thirteen feetthrowing out a line under easy command, say of from twenty to thirty feet, as found necessary. With 
this fine light hand-piece you will nip up eight of every ten trouts that take a pook at your fly thus offered.

Touching rods we may here further observe, that in regard to length and weight of rod and line, the grand point is to find balance, by having one thing adjusted to suit another, and all combined so as to answer the use and habit of the individual. A person may fish a lifetime with a short rod like a coachman's whip, and shorter still, in such small streams as the Ale and Kale, the Gala and Leader; and by perseverance, and lurking about bushes and going on his knees to hide himself and shadow, he may be pretty successful ; but still this is like shooting partridges with a pistol in place of with a fine fowling piece.

With a rod of about fourteen feet, large enough for having command of water, even when fishing in the Tweed, you will also have most success in these small streams; as with a rod well balanced, of equal spring from hand to top, and a casting line of suitable weight, you will throw to the point you wish with ease and softness-and walking upright, like the "Lord of the Isles," disdain to crouch or hide. Thus, too, by throwing out only half the length of line you could do if necessary, you will in small streams 
nip the trout up as he rises, and be more successful by open means than by hidlins; and why bind to fish with one hand only*? If you have two hands left from the Crimean or Indian wars, use both, except when you require to scratch your lug. Thus make your angling easy, pleasurable, and man-like. The balance of rod should be thus-when you hold it by the butt, in a horizontal position, it should not droop in the top, though on the point of doing so ; and it is an observable fact, that a well-balanced rod, always feels one half lighter in the hand than an illbalanced one, although both of the same weight, upon the whole, if weighed in scales. This occurs from being top-heavy, or too yielding in the middle, where it should stand stiffest, yielding rather more both below and above the centre. I approve also of the extreme top for two, or not exceeding three, inches being very pliant, such as whalebone rendered finely small will make it; as in fishing on the stream-water, say on a summer evening, when good sized trouts are feeding on small flies, a stiff top will strike the grip from their mouth as fast as you hook them; than

* We have always found a one-hand rod the pleasantest to angle with, because it fatigues less than a two-hand one. A light one-hand. fly-rod brings more trouts to the creel too, because the angler can. cast oftener with it than a two-hander, and the oftener the flies fall on the water the more chance for trouts, of course.-[EDR.] 
which nothing in all my experience in angling has been more provoking, and which this thin, pliant, two or three inches at the top will thoroughly prevent, without making any observable difference in the general spring of the rod. It is also serviceable in making a large trout, when hooked, keep down in the water, and not spang and spatter on the surface, beating the hook from his mouth; and this (over and above your necessary means in lowering the fore part of your rod to near the surface) at a slanting angle to right or left as may be, to keep him down in the water till he get accustomed to be led tamely, like a horse in breaking - tackle, after which he will keep sleekly below, and come ashore resignedly.

This, recommended from our own practice, is upon the whole more pleasant fishing than wading five or seven hours even in boots, not to say in stockings, and sometimes to middle waist in cold spring days, or early summer weather, as I have often done, labouring with a longer rod than here recommended, to throw far out to where the trouts were resorting, endeavouring to fill a basket with twenty-four pound weight. This you pursue with your limbs benumbed, till coming home, you require to be rubbed down like a hunting horse an hour in your stall, or rather before a fire, till you find the circulation beginning 
to prinkle over your benumbed joints, when you again venture to conceive yourself safe from the seizure of rheumatism for a month or more to come. I have luckily escaped rheumatics to a long age, which to myself is a wonder, and matter of particular thankfulness, for what I have described is not rational treatment of our corpus.

\section{ON THE DRESSING OF FLIES.}

Despairing to give any practical idea by mere description of the manner of dressing flies, it might perhaps be as well to refrain from attempting it, as the methods of holding the flies while dressing, and the opinions as to where you should begin and finish are so various, agreeably with taste and habit, even amongst the best practitioners. For instance, my son and I laugh at each other's method of holding the salmon hook while dressing it, whilst we contend for the best finish-he holding it loosely in his hand, while I keep it linked to a hold-fast. Briefly then : tie on the gut, beginning at the head end of the hook, lapping it firmly along till nearly opposite the point of the hook, where tie down the end of the tinsel, and if a hackle is intended, there also tie the point of the hackle; then dub the fur for the body 
on the waxed thread, and lap it solidly in a regular progression upwards to nearly the head end of the fly, and there fasten the thread till the tinsel is rolled forward, and the hackle beside it; which of these is the first rolled on is of no consequence, providing the hackle is laid close in to the wake of the tinsel, to be as it were guarded by it from the teeth of the fish. When all is brought forward, and neatly fastened down by the tying thread, rather less than a quarter of an inch from the end of the shank, then add whatever bright tuft of colour you choose to put below the wing; again fasten the thread, and pick all the body of the fly with a small awl or pin, and adjust it.' Lastly, lay on and tie down the wings unbroken, crossing them with the tying thread as often as may be scen necessary to adjust and hold them fast, and then fasten your thread by a few knottings around the head of the fly.

Trout flies I dress the reverse way, beginning at the tail end of the fly to tie on the gut, lapping it up to within a little of the head, and putting the wings on first. When these are properly set and adjusted by the crossings of the thread, I choose my fur, and dub it on the thread, rolling it round for body, and fastening the thread. The fly is thus produced in a twinkling. 
To dress trout flies in a superior style:-When the hook is tied to the gut and ready for the wings, cut with a pen-knife two wings close from the rib of the feather, lay the one piece upon your left fore finger, and the other exactly upon it, with the two insides together, then close your thumb upon them, and place the hook below, pressing it up close to the wings ; and while held in this position, lay the tying thread round over it, press the point of your finger closely on the tying thread, and while in the act of drawing tight, also cause it to draw the wings straight down together on the hook so as to prevent its ruffling or twisting them to one side; then lap the thread. once or twice more round on the same place to secure the wings, and letting the wings escape from your fingers, divide them asunder, and cross them round between with the tying thread, and they will stand up unruffled in the texture, a beautiful model of the living water fly.*

One may even go the length of cutting the two wings from the two corresponding feathers of the pair of wings from the same bird, but this is extreme

* John says truly, that to give any practical idea by mere description of the manner of dressing flies, is a difficult matter; and though his description to a dresser may be pleasant and intelligible, to a novice it cannot be so. An angler will learn more in the art of dressing by a half hour's lesson from a regular hand than a half day's reading of clear English on the subject. - [EDR.] 
nicety, which may only be resorted to as a trial of skill.

I may observe, however, that not above one of fifty to whom I have shewn this method of putting on the wings has ever succeeded in doing it well, but this I consider proceeds only from want of practice.

I have often thought that in the trade of fly dressing there is too much of show and variety, and tinsel-glitter, even for any river. Such flies I deprecate, and I suspect those who make them do so merely to increase their sale, as inexperienced anglers are apt to conceive that they ought to provide themselves with every variety of hook exhibited to them in a tackle shop.

As to the question of dressing salmon flies on whole length threads of gut, or on loops, I consider it merely a matter of taste or convenience, as they may be neatly and effectually done either way. Looped hooks are perbaps more convenient to pack and carry, and also require a less stock of gut on hand, either for the dresser or the purchaser. If looped, I would recommend the loop on small flies to be rather of three-ply twist of small fine gut than of one stout thread, as the three-ply is tougher, and it should be kept so short that the double eye may barely admit the single stout gut to which it becomes 
attached, after being opened by inserting the point of a pin, so that the last fastening running knot may form what may be considered a small head to the fly. For regular fishermen on the water, who generally dress or repair a fly or two every morning as their principal dependence for the day, perhaps the plain gut without a loop may be as well; it is as neat and efficient, and quite as convenient.

\section{ON THE CASTING OR WHEEL LINES.}

In either salmon or trout angling I do not like too light a casting line, as it does not throw so well, particularly in any breeze of wind. I prefer a casting line of three or four lengths of good horse hair, firmly twisted with the fingers (not plait), and not looped to take off and on the wheel line, but neatly lapped to it, so as to remain and be rolled up along with it. The first length of twisted hair should be nearly as thick as the wheel-line, suppose eight, ten, twelve, or fifteen horse hairs; the second length some two or three hairs smaller, and so on downwards, until about the fourth or fifth (according to the length of the hair), forming between five and six feet in all. Let the last be six, eight, ten, or twelve hairs thick, according to the strength of the hair, or the weight 
of the line wished, for salmon, trout, or both occasionally, as I generally have used them.* Then begin with three equal hairs of hand-twisted gut, choosing the hairs finer as you come downwards the four or five lengths, till, if for spring salmon fishing, the last is small enough to be next the hookgut, to which it should be attached by a neat loop. In clearer, summer weather, when single gut becomes necessary, have three or four additional lengths of good gut along with you, ready knotted and looped, to link on in addition to the former, which can be added or removed agreeably with sircumstance or fancy. Let all the knots be well tied, both of hair and gut, and the ends neatly lapped down with waxed thread, so that you can roll all up through your rings without rag or hinderance; and when done with fishing, unlink the hook, and roll in all at once.

Wheel lines last best that are made entirely of

* We venture to state that very few anglers indeed would use the same wheel line for salmon and trout fishing, because to most anglers it would prove either too light for salmon or too heavy for trout. We do not know of anything more fatal to fine casting when trouting than a heavy bagging wheel line. It is as bad as a too stiff rod. The late James Baillie, the fly fisher, was very particular in this respect; and he could throw, with a rod cut from a hazel bush, the longest and finest line we ever saw fall on the water. The wheel line should be tapered as well as the hair and gut casting lines. - [EDR.] 
horse hair, as silk, or a mixture of it, rots readily when wet. Even hair lines are not long in rotting if carelessly left wet on the wheel. If drawn off and hung up whenever they are wet, until dry, they will last very long, except the short piece of the end used in casting, which should be renewed frequently. I had a good wheel line, of my own making, that lasted me twenty-five years, fishing occasionally, both for salmon and trout, besides lending it often; but I never suffered it to lie wet on the wheel.

A salmon wheel line for the Tweed here, at St Boswells, should not be shorter than at least seventy-two yards; and all below Mertoun water about a hundred.

\section{ON FISHING RODS.}

[Very few anglers now-a-days think of making their fishing rods, and very few of those who do make them can produce rods to fish so well as those produced by regular makers. A good maker can adjust the spring and balance of rods to suit any angler. The woods now used by the best makers are : ash, sapling, or hickory for butt, and greenheart for middle and top, with sometimes a few inches of whalebone at the point. The best point we ever used was made of a bit of old brier, twelve inches in length, whittled into a taper and adjusted by James Baillie."-EDR.]

To produce the best fishing-rod for use and durability, take a billet of good hard red hickory, well seasoned (as it generally is before it reaches us here), of about three or four feet long, and have it ripped 
down into slips of various thickness, proper to form the whole rod, butt and top. Joint up as many pieces as will produce the length you wish, say eighteen or twenty feet long for a salmon rod, and from fourteen to sixteen for a good trout one. Make these into splice-joints of sufficient length, the splice being seven inches at least for the butt-joints, and tie them up well glued, leaving them so until the glue is dry ; then lay the rod upon a straight plank, and have it planed up all in a piece to a proper thickness-a person of skill standing beside the joiner, trying and adjusting its elasticity to the proper spring, till he find it please, recollecting to allow something for the weight of the tyings of joints and rings. If the planing could be so managed, the perfection of the rod would consist in having it to taper properly the whole length, from butt to top, and the wood being of the same piece and growth, the spring must be equal and correct throughout. After it is properly planed and smoothly polished with sand paper, cut it across into two, three, or four pieces, as you please. Have your brass ferrules straight, not tapering, but alike wide at both ends and sunk just a little in the wood at the under ends, and left full and flush over the wood at the upper ends, and either with or without screws, according to pleasure. 
These all adjusted, then roll up your wood-glued joints with good silk, or, what is preferable, very fine lint thread, using varnish on the thread rather than wax. Begin at the top to tie on the rings, which have large enough. Make them six inches apart at the top, and lengthen the distance between them as you come down towards the butt. Then have the whole slightly varnished.

If a rod is made up of various kinds of wood, or even of different trees of the same kind, you can never have the same equal degree of fine elasticity; whereas, by making the whole rod out of the same short piece, you not only improve the proper spring, but also find the best precaution against its twisting-to prevent which professional rod-makers often render the wood short and fragile by the application of heat, and other methods calculated to damage it in this most material respect. I prefer hickory, as it combines all the essential qualities, without the inconvenient weight of lancewood : only, great attention is necessary in selecting the hickory, as very much of it is unfit for rods.

To those who reside near the water, I would recommend a rod all of glued and tied joints,* as best

* Rods of this kind are in general use about Galashiels; and many anglers thereabouts uphold that these rods cast better than those made with ferrules. We used one of them for a season, a short one for fly fishing, and liked it.-[EDR.] 
in point of real use, and not so liable to break in the moment of action: or, indeed, even for travelling, I would prefer tied joints, as, wherever a person has time to stop and fish, though only for a day or two, he has at least five minutes to spare for tying up his rod in a sufficient manner.

Rods are often breaking at brass joints, and those who use them, instead of bringing in a back-load of fish, are often arriving home from the water telling you, "I've broke my rod !" Such sickening news may generally be prevented by tied joints.

A one-hand trout rod, between thirteen and fourteen feet long, is very convenient and pleasant to use, even when wading deep in the Tweed. But in moderate wading, we cannot command much water with a rod of less than fifteen or sixteen feet. I would recommend that a rod be made soft and pliable for about three inches on the top, much more so than is generally done, as a hard springy maintop readily twitches the hook from the trout's mouth.

\section{ON SALMON ANGLING.}

The greatest requisite in an angler is the art of throwing his line properly. Though some attain this more easily and with less effort than others, yet it 
is a point which can only be gained by practice, even with the best rod; but when once learned, it is done with little comparative exertion. And besides that, in casting a good deal depends on a finely balanced rod, yet as much depends on being accustomed to the use of any particular one. I have seen a fisherman in daily use of a rod so heavy and unyielding, that any person else could hardly suppose it intended for the purpose, and yet I have stood amazed at the length of the line the owner would throw with it, from the mere force of habit, whilst he in derision would pronounce a fine soft springy rod "a mere "wattle." A stiff rod requires great force and quick motion in bringing it back to give the requisite impetus to the forward throw, while one of an opposite description of make, from its tendency to yield, requires a very slow motion to bring the long line fairly round with it and communicate just the necessary quantum of force to impel it again outward. Of course a medium is best; and if we cannot possibly have a perfectly equalized spring from hand to top (which, like perpetual motion, it may be impossible to produce), then let the stiffest part of the rod be about its middle, the rest of it softening below and above to the extreme top.

Practice with such a rod will make the best throw- 
ing, and such a rod is also best for holding up the fish in the run, without any tendency to jerk the hook from his mouth on any sudden fling.

Indeed, the art of casting seems to depend on a free motion of the body, and there seems to be a kind of innate feeling, a delicacy of touch necessary to throw a good line, which some may never be able to acquire even by practice. And though we have known instances of gentlemen having killed salmon on their first start out, when they could not throw a good line, it has generally been under proper guidance and direction on a favourable day, or on protected water, where fish were numerous and undisturbed, and "with all appliances and means to boot." Such instances are, of course, no way indicative of superior skill in the individual.

When the river is low and clear, then is the time to prove the abilities of the angler. Then a long line is required; and great skill is shewn in making the fly light like thistle-down within an inch of the spot intended, say twenty-five or thirty yards from the hand, and three or four at the least above and beyond the spot where, from previous knowledge of the spot or general skill, he knows for certain the fish must lie.

I recommend a beginner to practice throwing the 
line on a broad smooth pool, where he can see that it is delivered out properly, and falls lightly without splashing. In such case the practitioner will perceive something which he cannot easily account for: and that is, that after he has even attained a great degree of perfection in the art, he will not be able to distinguish how it happens, that in one throw his long line will proceed tightly out, his fly alighting first on the water, and in another throw the middle of his line will fall first, while the farther part, still obedient to the general impulse, will proceed out the full length, the fly falling the last on the surface. This last throw is not so good as the former, for the reason, that the main current having caught the middle of the line first, it carries it too quickly down, leaving the fly lagging and forming an awkward curve ; for, before it comes over above the fish, the fly should lie on the water, so as to have the appearance of plying at an angle against the current. And the angler should so manage his rod that, while he lets his line float round at its full length, his fly should come as slowly as possible over the main spot. In this case the salmon will sometimes rise at once, rather before you expect him, but more generally will follow the fly to the eddy, or edge of the deep, where, if on examination he feel disposed to seize the hook, 
he has it before you perceive a head, fin, or tail above the surface. Indeed, before you perceive the web of his tail he generally has the hook in his jaw a foot below water, as in descending he goes, like other divers, head foremost.

The angler's next motion is generally termed striking, which, to my taste, is a wrong word to express that particular action by which a true angler retains his already hooked fish. This motion is rather a retentive hold than a start, or a stritie. Your tyro, keen and vigorous, is for ever striking, as the weakest part of his tackle, or a shred torn from the mouth of the fish will often abundantly testify ; while the true angler will go through the whole process with perfect ease, or rather, in what an inexperienced onlooker would account a careless or slovenly manner; in short, as seemingly easy and unrestrained as the step and manner of the savage in his native forest,- - so nearly do the accustomed habits of art approach the perfect ease of nature.

But I believe that in fishing, as in other things, example is more instructive than precept, and therefore a beginner would do well to set himself to observe with attention an experienced fisher begin and go over a stream or cast: his easy positions of body, method of casting, and manner of leading his 
line; and above all, should he hook a fish, the way he manages him, until he is laid "broad upon his breathless side," a rich and beauteous prize. For instance, he will not drag his fly across the stream, neither pull it against the current, which is a common error with beginners, and quite absurd. But in salmon fishing, he will, in throwing his line, direct it so as to make the fly alight on the spot desirednot straight across the current, but slanting a little downwards, so that it may form as gentle a curve as possible; he will move it as slowly as the current will permit, over the spot where he expects the fish to be lying; he will make no perceptible motion to keep his fly on the surface, except on a sluggish pool, but will let it sink a little, depending on feeling rather than on sight; and though apparently keeping no pull on his line, yet all the while he will be able to detect the touch of even a minnow. On a boil, or other appearance of a fish, he pulls up his line, not twitchingly, but actively, steps a yard or two back, rests a minute, to let the fish resume his lair and attention, and perhaps feels inclined to alter his fly to a shade darker, or a size smaller, before he anuoy and disgust, or alarm his fish, when he will probably come up and seize it in earnest. Should he not rise again, or rise and pass it thrice, 8 
leave him quietly alone for the present, and return to try him some time afterwards. On taking the fly, the fish means to return with it to his precise select spot of lair, on rock, stone, or gravel, at the bottom; and the fine angler, holding him gently, often in the first instance allows him to do so, but soon the fish, too surely feeling his awkward predicament, bolts off, "indignant of the guile." Then is the time when the fisher is attentive. W.ith the butt end of his rod resting on his thigh or groin, he keeps the top nearly erect, never allowing it to fall below the proper angle of forty-five degrees, as relative to the situation of the fish ; and in this position the elasticity of the rod never allows the line to slucken in the least degree for a single instant, however the fish may shake, flounce, jerk, or plunge. With two or three fingers and the thumb of his left hand the angler holds his rod, while the wheel-line runs out, regulated by the first, or first and second fingers, relieved or assisted, as occasion may suggest, by the right hand, when it can be spared from its necessary occupation of rolling up the wheel-line, as the fish settles a little or returns inwards. In this manner the fish is allowed to run up, down, or across, as he may choose. But if, when the fish makes an outright dash of thirty or fifty yards aslant, ending 
in a fling above water, the inexperienced angler should feel flustered (which he is very likely to do) and by some involuntary twitch of the running line let the top of his rod be pulled down to a level with his own head, then the tug of the last plunge will assuredly break his hook or line, or tear the hook from the mouth of the fish : or what is as bad, a sudden jerk or turn of the fish will give the line a momentary slackening, when the hold being already so strained as to have widened, the hook will fall out, and your fish is gone for ever.

More hooked fish are lost in these two ways than from all other causes put together; and this can be easily prevented by a little self-possession, simply by keeping up the top of your rod and letting the lino run with ease, regulated as above described by tho feeling of your fore finger. But if the matter is properly managed the fierceness of the fish is the angler's main sport. The faster he dashes on, the sooner is he exhausted. Sometimes you may see him on the opposite side of the river, with the web of his tail above the water, and his nose struck into the gravel, in an endeavour to dislodge the vile little instrument of his ruin. The fish will then again allow himself to be led at ease to the angler's side of the river, like a bridegroom to the altar, when, on finding the 
water shallowing, he will again make another desperate effort, probably a new dash into the middle current; but, too much exhausted to resist the still continued pull upon him, he will soon again fall into the shallow, where, on a sight of his enemy, he is again alarmed into a new effort, and again exhausted , by turning his outward-bound head down into the water again and again, and again, until his own last efforts to keep swimming are made subservient to the cautious angler, who moves him by degrees into the shallow, where, half dry, he must at last yield to his fate, and fall panting on his side. The angler should by this time have his line rolled up to within rod length, and the rod should be held with its top landwards, without slackening. The fish should then be seized with the fore finger and thumb of the right hand, across by the root of the tail (which is by far the surest method of seizure), lifted, or rather slid out head-foremost, over gravel and grass, and in mercy felled with a blow on the back of the neck.*

After going through this process with a twentytwo pounder (and the process would be the same

* The natives of Australia are said to drown the fish they catch by seizing them with the grip above mentioned, and holding them with the head below water. The gills then open, and let in the water, which drowns them in a minute.-Younger. 
with a forty-four), the writer can aver, that he does not conceive that from the moment he has hooked such until he was laid on the grass, he ever, for an instant, had three ounces of more or less pull on the fish; for in all circumstances of run, regularity of pull is the sure test of true skill, and it leads to final success. Indeed, I have seen many a fine fish laid on the dry gravel, when the hold of the hook in the lip of his mouth was so slight as to be smaller than the steel of the hook : so much for equal pull and cantious management in the run. In short, a man is never a master angler so long as a desire to have his hooked fish to land excites in his feelings the least agitation, as the matter should be managed with that cool philosophical ease of mind, which is alike above the paltry calculations of loss and gain, and the common ridicule which often tends to stir up a degree of childish fretfulness. This perfect ease is absulutely necessary to first-rate excellence and ultimate success. 


\section{GENERAL OBSERVATIONS}

ON

\section{SALMON ANGLING.}

The very perfection of the fly fishing art is to feel enabled to say, that you will take a salmon with fly, when, from the low clear state of the summer river, the regular fishermen, as well as the amateurs, have all given up the case as hopeless. To effect this you should take the smallest salmon fly, neatly dressed on a fine round thread of blueclear, not white, gut. I dislike dyed gut; its natural colour, which I call blue-clear, is the colour of water, as may be seen by putting it into a white basin of water. The dark or blue colour of a river is the reflection of the sky, as seen on the surface from above. Such gut gives the same reflection when in the river. And what is still a better argument, the fish seem of my opinion, as they always take best with it.*

* When stating that gut in its natural colour is the colour of water, John was safe to add- "as may be seen by putting it into a white basin of water." If the white back-ground of John's basin could conveniently be held between the fish and the firmament, the gu $t$ 
As already said, for a low clear river take the smallest salmon fly; and choose also the cloudiest or dullest hour of daylight, and cast in the manner formerly described over the deepest part of the stream or pool, where fish then lie, allowing your line and fly to sink deep in the water; for though at this time the fish will not rise to a fly skimming on the surface, he will yet venture on a bite as it quietly passes near him below. In this way I have often succeeded to the admiration of even the fisher who rented the water; and of late $I$ have been delighted to hear a friend mention it as a point of his own discovery, and assure me he has often killed fish in the northerm rivers, as well as in the Tweed, by following this plan, when not one old

under such a canopy would of course have little chance of being seen by the finny tribes. We have tried a number of experiments to find out how best to render gut invisible in the water, and we now decidedly prefer having it dyed (with logwood and copperas) of a blae or faint sky colour. Here are our reasons for preferring it : first, we have more difficulty ourselves in seeing it in the river than we have in seeing gut in its natural colour, and as trouts, at least, must ofter have it between them and the same back-ground-the river bottom and overhanging banks-we conclude that they will resemble ourselves in this respect. Next: the gut is generally between the fish and the sky when in the water, and being of a blue tinge, and suen against a klue sky, it must necessarily be more difficult of detection. Though dyed too, it remains transparent, as may be seen by holding it against the light. Gut in its natural colour may be almost invisible to the denizens of the deep on cloudy days; but for successful and pleasant trout angling give us the "glad sunshine and the laughing sky." - [EDR.] 
hand, who knew every pool and stream, could stir a fin, or be persuaded to attempt a trial.

My friend writes thus :- "In these small waters, or tributary streams which run into the large rivers, you may fish with great success with what is commonly called a sea-trout hook. In several small salmon waters in Argyleshire, and other island streams in the west, I have fished successfully with hooks of the above size, when I could not stir a fin with a common sized salmon hook. And it may not be generally known, that in these smaller waters, salmon, grilse, and sea trout, will take the fly greedily when the water is in such a state of foulness, that those who have only been accustomed to the Tweed, Tay, \&c., would suppose it the next thing to madness to attempt trying a fly of any kind." I may remark here, that if my friend had thought of observing carefully, he must have found this would not happen in the swell, but in the fall of such flooded streams, when these fish, like natives in an inundated district, were thrown out of their usual spots of habitation, and were still moving about in an unsettled and shifting manner. In this way, salmon occasionally take the fly in large, though more particularly in smaller streams; as the sand and mud are gradually subsiding, the fish driven into 
the shallows ascend to the surface, the water being purer there, and thus take the fly on the same principle that trouts feed generally. But trouts will not take the natural flies in the rising swell of a river. When it has begun to fall they attack them greedily even in the white muddy water.*

In regard to the different kinds of salmon flies applicable to the different rivers, he further states a curious fact:- "In no two rivers that I know of," says he, "do they angle with flies which at all resemble each other in point of shape and character. In the Spey, Findhorn, and Ness, rivers not above thirty miles apart from each other, the style of their hooks is nearly as opposite as possible. In the Spey, common drake, or mallard wing, with yellow or orange body, and black hackle from the breast tuft of the heron, is one of their principal hooks; and another, a hook dressed altogether from the heron-namely, a blue or slate-coloured wing with hackle to match. In the Findhorn, again, nothing but Irish flies, or imitations of them, seem to succeed. And in the Ness, the flies used are of a much more quiet and modest kind, somewhat resembling

* This remark as to trouts not taking natural flies when the river is rising, we can testify in favour of, having on many occasions put it to the proof, both by throwing the flies into the water and watching them, and by angling with them. - [EDR.] 
those used in the Tweed in point of materials, but not generally so large in size, and the form is shorter and thicker. In both the Spey and Findhorn the hooks are much larger than for the Ness.

"I am not able to say how far one might be successful in any river with a common Tweed fly, only varying its size and colour to the state of the river at the time; I think the chances are that one might kill fish in any river with them, just on the same principle that in the Tweed many are successfnl with the bright gaudy Irish flies, which are so opposite to the legitimate Tweed hooks. But I do not think this has ever been properly and fairly tried, for one is apt to adopt the hook commonly used on the river he goes to, without giving himself the trouble to inquire into the cause for such a form or style being adopted. For myself, I have hooked and landed good fish both in the Tay and Findhorn with the common Tweed fly,* and I am sure they would do also in the Spey; although I allow that I would not have the same confidence in fishing with any other than the common and well known hooks for each respective river."

An old friend of mine, John Haliburton, formerly

* Tweed flies are not nearly so much used now for fishing the Tweed as Irish flies. - [EDR.] 
fisher on Dryburgh water here, and afterwards at Craigo'er on Mertoun water, who removed to a farm near Hamilton about fifteen years ago, once accompanied three or four gentlemen on a day's stroll to the Clyde, where, with his old Tweed hooks (exactly such as I hav described) he saved the credit of the party by personally killing the only five salmon seen that day. But then I have never seen any man who could excel Haliburton in laying a fly to the eye of a salmon; and yet his is the only instance $I$ have known of an angler becoming excellent who was not bred to it from boyhood;* for John had never once thrown a rod at the time he took a lease of Dryburgh water, being then a labouring man, a husband, and a father. But then he was one of the few amongst the sons of men who could calculate on the nature of things as they are, without regard to fashion or general opinion. While in Craigo'er, in the year 1816, I knew him, in five days of one spring week, kill with $\mathrm{y}$, with his own hand, ninety-nine salmon (mostly foul fish and kelts of course), and on one of the days he caught twenty-four, many of them about and above twenty pounds weight. But, except John

* With due deference to John we may state that we know a number of very good anglers who never caught either a trout or salmon in boyhood. Perseverance and observation might, in our opinion, make ten men out of twenty fair anglers. - [EDR.] 
Thomson, once in Newstead, or the Kersses, the Purdies, and Johnstones, who, on the Tweed, could ever throw a line with Haliburton?

But not to multiply instances bearing on the point, I find, from my own experience, and that of others in whose skill and judgment I place full confidence, that the matter is resolvable into this general leading principle-that large or showy flies suit best in deep, dark, or drumly waters, and the finer modest shades of variation, such as I have here endeavoured to describe, are necessary to entice in the settled calm of summer pool and stream.

But it is seldom difficult to find arguments in support of exceptions to any general rule, and I am aware that in no instance could it ever be more easy than in the very limited selection of flies I have described; because almost every fisher prefers a particular style of hook, and I am quite aware an angler might fish successfully for a life-time, and yet never use a fly that could be proven to be an exact type of any one here described. At the same time, I am certain that unless some of my principle can be detected in his hook, his general success will be far from coming up to his wishes and expectations. 


\section{ON TROUT ANGLING.}

In Trout Angling, the whole process, like the casting, is of a lighter character, in proportion to the lighter implements used, and varies considerably from the salmon principally in this respect, that, as the trouts lie or swim about in more varied situations, according to the state of water, sometimes in the main streams, sometimes in the eddies, and in still heavier waters on shallow gravel beds, the angler will perceive that on spots where he might be successful yesterday, not a trout will be found to-day; for in heavy flooded waters they fall into easier situations, and as the water clears and lightens, again seek the deep for food, pleasure, or security.

On the subsiding of a flood, great takes are often made in eddies, where all the finny breed are driven in shoals to quiet nooks, creeks, and cairns; and where the frothy scum of the agitated surface is seen collected and wheeling in circling motion, great slaughter may often be made by any one who can simply throw a fly ten yards out before him. This happens after the fine fresh spring, and early summer floodings, in March, April, and May, and sometimes 
later, according to the wetness of a season; but, of course, only on the first day of the ebbing flood.

Hence, throwing the line for trout does not require the same regularity of plan and manner as the casting for salmon, since it is often more necessary to throw aslant, upwards, or straight across, than downwards. And, indeed, in trout angling generally, it is very improper to hang the fly on the stream, far more so to pull against it, as the natural fly never floats in that direction.

In fishing either stream or pool regularly over, cast the fly across, or slant it considerably upwards, and let it float down the current of its own accord till it come gradually full round, managing your rod so as all the while to keep the line and flies under such command, that should a trout touch the hook unseen below the water, you can detect him on the instant. This action is simply a tightening feel, as the trout is generally previously hooked from the natural resistance of the floating line. If he is not felt to be hooked, then it is necessary to pull full up and make another throw ; but never let the first pull in feeling for a trout be so decidedly forcible as to be called a strike, for it ought not to be done with

* Younger is against striking, yet the force be would allow to be used, wbove and elsewhere, appears quite strong enough for good and secure striking; but anglers know that every one has faith in his 
a third part of the force requisite to lift the line clear off the surface, as is necessary when making another throw. Indeed, in casting generally for either salmon or trout, the angler should never snatch bis line quickly from the water, but give it first a gentle pull, and let the lifting it be a second and brisker action; as a large trout, or sometimes a salmon, may be following the fly, and may readily, at that particular instant, be just seizing it; and if you lift it with foolish force, the fish is struck off from the gut in his

own method, if by it he can generally angle successfully. There are many points that successful anglers differ keenly upon, which, in our opinion, but simply and reasonably proves that there are more ways than one of capturing salmon or trout. To strike, as most anglers know, is to make a quick turn of the vrist-a sort of slight twitch-very like the movement made by the wrist when a person opens or shuts a lock quickly with a key. This movement causes the hook to give a slight but sudden jerk, which secures the fisb. If properly managed the fish will not be struck off, because the wet line yields as well as the top of the rod to any gentle movement of this kind. The mode of striking we here describe must be understood to refer to trout angling. As regards striking, in salmon angling, many flrst-rate anglers do not strike when they feel the fish, but merely make a sudden steady hold; while other equally good anglers strike, some of them firmly, the moment they feel the fish take. When learning salmon angling we had a "blowing up" more than once for not striking when a salmon happened to touch our hook and get off unscathed, and we have also repeatedly brought censure upon our unfortunate head for striking when a salmon rose and touched the fly, and disappeared as we struck. These unpleasant lectures (for it is something dreadful-and a little odd, perhaps -to lose a fish and "catch it" at the same time) we received from old experienced anglers, who simply differed in their mode of hooking a fish. Most anglers strike, we believe, when fishing with a very large hook, - [EDR. ] 
mouth. In low waters, $I$ have in such a way caught many salmon with the trout fly, on which, at such times, they occasionally feed; and therefore, in Tweed trouting, I have always used a wheel line long enough to secure any salmon accidentally so hooked.

The manner, too, of angling for trout, as a driver lashes stage-coach horses is ridiculous, as if a large trout were foolish enough to take a fly so offered. The angler is still more foolish to strike the fly from off the gut in a fish's mouth, and come home with a tale of sad mishap that a great salmon had broken his tackle. An amateur angler here last season came from the water with a sad complaint against a monstrous salmon that had robbed him of his bait houk and gut line; and what a weight he was to be sure! My son, who had happened to tie on the angler's hook in the morning, trouting a little next day with the same roe bait at the spot, caught a trout not half a pound weight with the identical hook stuck in its stomach, and the thread of gut hanging nine inches from its mouth.

But constant and successful trout angling in the Tweed, or other pretty large rivers, requires the fisher to trash himself rather unmercifully, as to secure general success, it is absolutely necessary often to wade deep and long to get to where the trouts may 
be lying; for to stand on shore and see them tumbling up in the $\mathrm{m}$ in current of broad pool or stream, or on he opmsite eddy, is of no aviil t: fill a large basket; besides, he must wait with Job's patience, and shift about, often for hours, till the time when they are pleased to feed, which is various and uncertain; and more particularly so in the Tweed than in the smaller streams, according to the circumstances already described.

When a lad, I have often fished patiently for three hours without the appearance of a fin; and in the two or three succeeding hours have filled my basket, which held nineteen pounds' weight. This happens often under circumstances to us unaccountable, but frequently on a fine forenoon, when the natural flies are floating down, and not a trout stirring; and after a break of thunder, or a slight shower, sometimes of hail, or even a fine breeze of wind, they will get all into motion at once, and feed voraciously. Much depends on the state of the atmosphere, of the influence of which we are yet ignoraut.

But the perseverance neces ary to gener 1 succass requires the angler to strive and labour diligently, to wade in awkward situitions in a kind of halffloating way, to creep on the narrow ledge of a shelving rock, under pendent tree and briar, and perhaps over 
hanging dripping precipices, jutting and shiverysuch as the Dun-Hare-Crag, Hawkslee Scaur, the whirlpooling Fatterdon-Pot, or the black drowning Gibson's-hole below; to fish sometimes on his knees, pulling in the hooked trout by the line in hand, as in such unfrequented situations the large onepounders are not yet acquainted with the hook, and are therefore keen and ready.

But these were the sports of greener years! The slippery foot on the loosening stone, or the tremulous grasp, with the deep below, is not the task for lusty manhood, or the stiffening bones of age. If ever now, once in a season, I do try the trouting, I must get on more in the way the old trout feeds, rather lazily and shyly.

It has a sobering effect, to feel the play of youthful muscle torpescent! Yet, though, like a well-hooked fish, we must succumb at last, there is still a certain pleasure in the reminiscences of some of our early starts in such pursuits.

It is now forty years since I, then a boy, so poor as not to be master of a hook or a ha'penny, sallied out to the small burn (which, at that time, yet unrestrained, like myself, chose its own vagrant way from Elliestown House to the Tweed, circling through the low rushy leas, forming dimple, pool, 
and ripple), and yumped* out half a stone of speckled trouts, where my neighbours never suspected such a thing existed.

The poet is in error when he says-

The trout within yon wimplin' burn

Glides swift, a silver dart;

And safe beneath the shady thorn,

Defies the angler's art.

This the trout cannot do, for his clammy nose is ever protruded, and clear round eye ever on the alert for a fly or a worm, and well the angler knows where and how to drop the line into the pool before him. When a whale is not safe in the Polar Ocean, talk, forsooth, of a trout in a burn! $\mathrm{O}$ dear shade of Burns, the poetical portion of your earthly feelings might have been too fine for an angler, as well as that of your grand successor Byron, or perhaps it might not, for all the fascination of song. I grant you, however, that even I, when a hungry laddie have often enough got into these fits of extreme sensibility, returning the small trout to the stream -

As piteous of his youth, and the short space

He had enjoy'd the vital light of heaven.

And, indeed, I have often felt the full force of Byron's

* To gurnp-to enpture tronts with the hands, beneath the lanks and stones-generally done in burms : nil small waters. - [Eve.] 
satirical remark on anglers long before he wrote it; $\mathrm{ay}$, and occasionally got into such qualms of reluctance, that I would suspend my angling pursuits, and admire the trouts tumbling up in the streams, suppressing the desire to cast a hook amongst the freebooters. And the same sympathies have at times unfitted me for some necessary employments of life, yes, even to the length of requiring an effort of $\mathrm{my}$ strongest philosophy to bring me to prune a rose or pluck a flower! This was nursing the poetical temperament to an unnecessary tenderness. "No angler can be a good man," says Byron; yet, I believe these sensitive gentlemen, the poets, could all eat lamb, veal, and oysters, as heartily as trouts can snap up lovely innocent flies, or gobble the small fry of their own species with all the mischievous appetite of cannibals. And, alas ! the sensibilities of genius give no sufficient guarantee for that consistency of character which would justify us in bestowing the designation of a good man, on any human being. 
ANGLING WITH WORM FOR SALMON.

Angling with worm for salmon is practicable only when the river is very low and clear, and in all dry and frosty weather.

In January 1814, when the Tweed was frozen on both sides, leaving only about a fourth of its entire breadth still spen in the middle, John Haliburton fished with the worm, walking on the ice (a lad attending him with a long gaff), when he made great slaughter, until the ice closed over. His greatest difficulty was to keep the freezing line running. Worm angling, however, can only be practised most successfully in the very lowest state of the river, after the fish have set up, as the fishers term it, and will not take a fly. In the summer season, the best fishing hours are very early in the morning, from daylight till the sun has become too bright, or in a day grey throughout.

The worm used in this angling is called the large dew worm, from its being found in the spring and summer nights among the dewy grass. They may be seen in a morning lying liuked in couples all 
along the pathway sides, or on old leas, where. on the least disturbance or tread of foot, they sink into their respective holes in an instant. Fishers generally gather them in candle light, stealing softly along, and seizing them before they can escape. When required in cold seasons of the year, they are dug from the earth in certain places where found in greatest plenty. They are kept in moss for some days previous to being used; and if long kept require to be fed with a little cream or sweet milk, and red earth or brick dust.*

Anglers differ in their choice regarding the size of the two hooks proper to be used for this sort of bait, but those most generally preferred on the Tweed are large sizes, Nos. 18, 19, or 20 of Adlington's-the other Nos. 15 or 16. As they require to be shorter in the shank for this purpose than for the fly, it is requisite to break a piece from the shank of each. The larger one is tied to the end of the gut, the other us much farther up on the gut as to allow its point to be turned round to the shank of the first hook,

* The brick dust for worms, we should think, must now be an exploded notion. It has no effect whatever on the colour of the worms. It is too dry to be swallowed by them, and this is the only method by which the clav could redden them; and we know to our cost that it destroys them if kept anything long amongst it. The dust being too dry for the worms, is the means of taking the sliminess too quickly off, theroby causing, first numbness and then death.-[EDR.] 
and a little of the shank of each should be left untied for the purpose of catching into the worms, and preventing them from slipping down from their proper positions. The first worm is then put on by inserting the hook at its head, and running it up over that hook altogether, then turning the uppermost hook round, and inserting it also at the same incision; then run the worm up over this hook also till the tail of it is fairly above the bend of the hook, and the upper part on the line above. A second worm is taken, and the hook entered about its middle, running it up also to the second hook, which is entered at the same incision, and run round in the loose end of the worm, which covers it over the bend and point. The remainder of that worm is pressed up till it appear contracted and thickened on the short piece of gut intermediate between the two hooks; then a third worm is taken and run on the first hook head foremost, leaving its tail to cover and project over the point. This is called a full and proper salmon bait. Some use only two large worms in the manner of the first and third, with half a worm, or a small whole one put on the second hook to cover its head and point.

A few large grains of shot, ready nicked half through, are kept by the fisherman very conveniently 
in a quill for the purpose of adding an additional sinker to his line, as the strength of a stream may require, and from three or four to ten of them may be ured as considered necessary. They are easily closed on the gut line by a little pressure of the teeth, and may be opened with a knife, and taken off at pleasure, according as the angler requires it to sink, or move on in the various strength of still or rapid water. These are put two or three together, or some inches apart at pleasure, none within a foot, nor exceeding thirty inches from the hooks.*

Thus equipped the angler will commence at the head of a stream or cast, arid proceed downwards in the very same manner as if fishing with the fly, taking a full step between each throw. He will throw well over the fish-lair, and let his line and bait travel gradually round, just making as much motion as to prevent it sinking and hanking at the bottom, and always lifting it gently for the next throw, in case the fish should seize it on the instant. But generally the fish will follow it, and commence nibbling at the bait, quitting and seizing it alternately. Sometimes he will run off with it a few yards, then quit it, return, and seize it again, all which time the angler

- Drilled shot, which some consider preferable, can be had of most tackle makers for this purpase.-[EDR.] 
will cautiously give way to his motions, which appeur very capricious, allowing the line to follow him freely, yet never permitting him to be altugether unfelt.

Sometimes these motions will be continued for a considerable time, five or even ten minutes, when he will quit and leave it altogether. But more likely he will attempt to swallow the whole bait, which he generally at last succeeds in doing; and this motion is understood by the angler from the particular twitching the fish makes in gobbling it. The angler at last feels that he has it pretty fast, and by a sudden resistence fixes him, when he is then run and landed in the same manner as if hooked with fly.

Salmon are very voracious in regard to the worm bait. I have known two fishers, each of whom has, at periods more than twenty years apart, met with the self same occurrence in the very same placethe Bayhill Cast, at Dryburgh Chain Bridge. The fish took the bait, and was run sometime from near the head to the foot of the stream, when by some accident the line was broken, or cut on a rock, within a foot or two of his mouth, when the fisher coolly put on a new tackle and bait, went up and began again at the head of the cast, and exactly on the same spot, hooked him again with much less ceremony than at the first, as the fish seized it this last time with 
great eagerness, and was run and landed with the first bait, hooks, gut, worms and all, hanging in his throat.

When the water has fallen very low, in drought, the first trial of this worm bait is a searching thing for the river. I have asked Haliburton,-_ "John, are there many fish yet left in the water ?" "I cannot just say," he would reply, "as the water has fallen so low they have been set up to the fly for some time past; but I will inform you to-morrow night how many are in the Caul-pool, the Broom-ends, . and Back-brae, as I mean to be on them very early in the morning with the worm, and every one you know must have a passing pook at the first bait." I went down to the Caul-pool once about five or six in the morning, after a conversation of this kind, and found that John had already eight lying on the gravel.

\section{ANGLING WITH WORM FOR TROUT.}

The worm preferred for trout bait in the Tweed is what is commonly called the black-headed small tailed worm. In manured and fat clay soils, this worm is found of gross habit and dark colour; and 
where the soil is light and sandy, is of a bright colour. On digging any earth in dry weather, it is found rolled together resembling a mulberry or a cherry. When got in this state, they may be fished with as soon as gathered; yet, in general, to have them in proper order, they ought to be kept some time before being used, a few days at least, amongst moss, and the moss occasionally changed. If kept over three weeks or a month, they require to be fed with a little cream or sweet milk, and brick dust or red clay,* but always replaced into moss a day or twobsfore being used, which renders themclean and tough.

Although trout may be taken with worm in any state of water, yet the most proper time is in the very lowest and clearest state of the river, from the end of May to the end of July; and the best hours

* We have no faith in either sweet milk, brick dust, or red clay, as food or colouring matter for worms. Abundance of fresh moss (Scottice fug) will keep them fresh and clear for months; but a few drops of watershould now and then be sprinkled overit, and it should be frequently changed. The worms are always ready for angling with when kept in this way, and their natural colour, when scoured of the clay within them, is reddish. They should be kept in some very cool place, and the dead and sickly worms removed daily. We are in the habit of keeping them in a wooden box sunk in our garden, the box of course rainproof; and we have on many occasions astonished our friends with a sight of many hundreds of worms all fresh and clean in the scorching July. Tackle-makers in large towns supply worms at reasonable rates, and the worms thus sold are generally in prime condition for angling with. - EDR. $\rfloor$ 
of the twenty-four are from the first break of daylight to six or eight in the morning. If the day is what fishers term "a grey day," dull, with the sun shaded, or a little breeze, they will continue to take the whole day. And although considerable success may sometimes be had under the bright sun, which often indicates a degree of frost in the atmosphere, yet a day of alternate cloud and sunshine is considered the very worst that can occur.

The rod proper for worm requires to be a little stiffer than that used for fly, and the casting line within five or six feet of the hook should be of very tight round gut, with the knots well lapped* down to prevent catching the stones. One grain of lead shot. No. 3, should be fixed on the gut above the first knot, or about eight inches from the hook. No. 11 of Adlington's is often used, but No. 12, or even 13, are better sizes.

Anglers differ in opinion about putting the worm on the hook, but the best practice is to enter the hook at the head of the worm, and run it down till the worm is brought up all over it, and leaving the tail of the worm to curl over the point, which should always be kept covered, as the trout is so extremely

* For angling in clear water, no first-rate anglers of the present day lap the line-knottings, either for worm or fly-fishing. - [EDR.] 
suspicious that he will hardly take a worm where the hook's point is seen.

Thus equipped for a start in low pure water, the angler lets out a line only about the length of his rod, and entering at the foot of a stream, contirues to wade upwards, throwing his line nearly straight up before him, or occasionally only a little to the side, as the run of water in regard to his position may require, or where from habit he believes that a trout may likely be lying on the watch for a floating worm. As his worm and line travel down towards him, he keeps a continued check upon it by a perfect management in raising the point of his rod, and on feeling the least stop, he can generally determine whether it is a small or a large trout, the small one continuing to follow and nibble, while on the seizure of a large one the worm is stopped at once, when the angler gives a gentle pull, which_being downward, against the trout, generally gets a secure hold of him.

In this way great slaughter is made of the very best trout; and this by a dexterous hand is accounted the most masterly mode of all trout fishing.

As it is necessary in very clear water to keep out of view of the fish, coming from below and fishing upwards in this manner gives the angler decided advantage. 
By a skilful and diligent fisher, in our smaller rivers, trout may be taken with worm all the autumn in almost any state of the river; and as in the colder part of the season trout generally leave the streams, seeking the more easy current of the pools. they will there also take a worm dropt near them; in which case it is necessary to give the worm as much of a nice motion by the management of the rod, as to prevent it sinking and settling at the bottom. One man, I see daily (an old gamekeeper, in present lack of other occupation, and who "maun do something for his bread") is so excellent at this method, that he kills on an average about half a stone every day, in the Ale water; and to-day (September 16, 1839), after yesterday's very high flood, while Ale water is yet white and muddy, he has come in with nine pound weight of beautiful trout, taken there with the worm. For harvest wages-half-a-crown-a-day and victuals - I dare say he could teach any active man to do the same in the course of a fortnight's diligent apprenticeship.

So far as regards fishing with worm in drumly or flooded waters, except by a knowing and dexterous angler, as above alluded to, I consider it merely a boy's amusenent, generally done without art, and it is not worth further description. 
In the Teviot, and all the streams between that and the Cheviot range of hills, particularly in the pastoral districts, where the Oxnam, the Kale, and Coquet waters glide through amongst sheep farms, great execution is done with a red and bright yellow freckled worm, called the Brandling, or Bramble Worm.* This worm is found in very old dung heaps and when taken out emits a strong smell, felt at a considerable distance. I have heard it affirmed that my grandfather, in the olden time, killed thirty-six dozen of trout in one day, in the Kale water, with that worm. I believe this the more readily, as I know that a nephew of mine killed half that number in one day with the fly, in that small stream. And a Jedburgh amateur angler assured me to-day, that

* The Brandling is still held in great repute, but not so mueh by clear-water anglers, as by those who angle when the water is subsiding after a flood. In pools the trout seem to gather about the sides wherein this worm is being angled with in the manner they do when roe is used. We met an angler of our acquaintance some years ago with a large number of trouts taken with the Brandling, all from one large pool, which was slightly muddy. On a bit of string he had twelve trouts that weighed 12 lus. On another string he had nearly as mueh weight, though the trouts were rather smaller, and be bad also a small gamebag full of the smallest he had taken, probably in weight about $8 \mathrm{lbs}$. The Jed was the river in which the take was made, and the angler's remark to us was that he believed he hadn't left a decent sized trout in the pool. His rod and taekle were of the coarsest description. He at one time fished so much with this bait, that he kept his supply of seasoning worms in a pretty large barrel. When a boy we on one or twn occasions had a reep at the "barrul o' worms."-[EDR.] 
he once killed the same number, eighteen dozen, in one day, with the Bramble Worm, in the Teviot.

Yet though these worms have been brought and bred here in dung, I have never known much success with them, nor heard that they were at all to be preferred to the common worm in I'weed fishing.

\section{FISHING WITH MINNOW.}

Minnow is a very good bait for either salmon or trout, although a very small trout or par, put upon the hooks whole, in the manner of a minnow, is a preferable bait for salmon. For trout the minnow may be fished with in any state of water, flooded or clear. It is best, however, in the evening, particularly in the shallow of a ford or the break of a stream. Some use three, four, or five hooks on the minnow bait, and put it on various ways; but the best practice is with two hooks, the largest. No. 14, the other, No. 8 or $9 ;$ these are tied distant from each other the full length of the minnow. The large hook is entered at the mouth of the minnow, and

* The upper hook (the lip-honk) should be so formed as to keep the lips of the minnow close, to prevent its becoming destroyed. Tackle makers have hooks for the purpose.-[EDR.] 
brought out at the root of its tail. The small one serves principally to hook its mouth and hold it on ; or the minnow may be reversed, with the same chance of success the large hook entered at its tail and brought out at its mouth, and the small one hooked through the gristly part at the root of its tail. As many lead shot are put on the line, a foot or two above the minnow, as will make it keep half sunk in travelling. Swivels are also necessary on the line, to prevent it twisting, although what is called "spinning the minnow" intentionally, is nonsense. It is just thrown in nearly straight across, and allowed to travel slowly round, like the silmon worm-bait, in about mid-depth of water, with only as much movement of the rod as to prevent it sinking and catching at the bottom. The trout seizes it sometimes with a dash, but more generally fo!lows it slyly, and snaps it, getting himself hooked before the angler actually perceives him, which renders any idea of striking him absolutely ridiculous. The natural retention of the hand in fishing is generally sufficient to fix the hook in any fish without intentionally striking; and in all angling it is proper to depend more on feeling than on sight.* For salmon,

* In angling with fly for trout, especially in clear water, we cousider sight of much more importance than feeling. The expertest fly anglers we know " hook" the trouts as they see them rise.-[EDR.] 
the principal mirnow hook should be a size or two larger, say No. 15 or 16 . And in fishing with this bait purposely for salmon, you go over the salmon cast with it just the same as with the worm or the fly, hanging it as long as possible, with a gentle motion, over the spot where you suppose him to be lying. But, as formerly mentioned, a whole small par, or young trout, is a preferable bait for the salmon. Sprats, or garvies, as they are called, which I believe are young herrings, are excellent bait for salmon. The first time they were tried in the Tweed was in the spring of 1837, at the first breaking up of the river, at which time I accidentally saw these sprats, and conceiving they would be good salmon bait, procured a few, and recommended them to a Mr. George Brown, then here on a fishing excursion. On his first trial with them he made great havoc amongst the salmon in Dryburgh water. He then took a few to Kelso, and there introduced them, where they became a favourite hait for the season, till, at last, the fishermen prohibited their use, from a supposition, that the daily use of such a large bright bait scared the fish from their waters. 
FAR-TAII.

\section{PAR-TAIL}

Par-tail is seldom used for salmon, but is a capital bait for trout. Two hooks are also necessary for this, the same as for the minnow, only of a larger size. No. 15 or 16 is small enough for the end one, the upper one No. 9 or 10 . Measuring from the bend of the hooks, they should be tied about two inches and three-quarters apart, or a little more than half the length of the whole par, or trout, to be cut and used for the bait. Half an inch of the large hook should be left out untied, for the purpose of being run back and fixing the bait, to counteract its tendency to slip off. Any very small trout, par, or smolt, may of course be put on whole in the manner of a minnow ; but when too large for this, it should be cut across to the proper length, to suit the distance of the tied hooks, slanting the cut from above the back fin to a little below the middle of the belly. The fins and web of the tail should then be nearly all cut off, and the large hook inserted a little above the tail, and brought out at the cut end, leaving it to hang freely and clearly out. The other hook is put through the solid gristly part, above the root of the tail. The hooks thus left out have a fair chance 
to get hold when a trout bites. Swivels are necessary on this, as on minnow tackle, also shot to make it sink half-depth in rough water; and thus prepared, it is fished with the same way as the minnow.

Though trout will take the par-tail occasionally in any state of water, exactly as they do the minnow, yet the best time for using it is on the first swell of a flooded muddy river, and then best in the shallow, just above, or on the break of a stream. In this case I prefer using drag hooks - that is two hooks, No. 9 or 10, tied back to back on a strong gut, attached to the line an inch or two above the other hooks, and projecting three or four inches out heyond all. The first trial I made of this was when I was one day obliged to give up fly-fishing by a sudden flooding of the water from a thunder shower. 'l'his was exactly on the spot where the Merton Bridge is at present founded. Of a dozen good trouts then caught in a few minutes, eight were hooked outside the body by these trail hooks. I have consequently preferred them ever since in coloured water, and with them have been always proportionally successful.

In minnow and par-tail fishing, however, one cannot succeed well every day on the same spots of water: the reason is quite obvious. 
Minnow and par-tail are excellent baits in the night throughout the summer, in all states of water. But night fishing cannot be recommended; it is so baneful to the health.

Minnow, for bait,* are caught various ways, with nets or with worms; but boys will always provide them for a trifle. And the moment they are caught they should be dropt in a box overhead amongst salt, for preservation, unless they are to be used that same day.

\section{ROE BAIT.}

[By Act of Parliament, angling with roe is now prohibited, but we deem it proper to let the following chapter stand, as it records the method by which trout were captured by it; and besides, Acts on fishing are changed almost annually. Roe-fishing in muddy water, in autumn and winter, we always considered should have been beneath the notice of proper sportsmen: to capture trout in such water requires no skill, and the fish in such seasons are thoroughly out of condition. In summer floods, however, when trouts are in their prime, sometimes heavy baskets used to be made by roe-bait. -EDR.]

Salmon roe has, of late years, become so fashionable as a trout bait for all seasons of the year, that those who profess superior methods of preparing it have generally a demand above their means of supply.

* Small minnows for trout angling are best, and they should be white-bellied. The reddish minnows, commonly called "streamers" are not taken readily by the trouts. $-[$ EDR. $]$ 
After all, I must confess I have never seen much success with it, except on the first of the autumn or winter floods, when, for a day or two in the subsiding river it is most deadly.

One thing that particularly recommends this bait to so many is the simple method of its application, being level to any capacity.

Receipts for preparing the roe are held as secrets by individuals; but the object of all and each is to preserve it clean, and near the natural colour. Some prefer it broken into paste; others preserve it as whole in the roe as possible. One receipt I can here give:-Take the roe from the belly of the fish, and put it in water, a little more than milk warm; stir and wash it till the roe leaves the netting and runs like shot; clear away the refuse, then drain it, and hang it in a flannel cloth to drip, for twelve hours or more; put it then in a vessel, and salt it, adding a small quantity of saltpetre, and set it in the open air to dry, or before a fire, not too near; then pack it in small pots, and run a little suet over it, to exclude the air, when it will keep for years. But at the same time, I must confess, that the best success I have ever seen with the roe bait has been with it simply salted as taken from the salmon's belly, even unbroken from the netting, laid on a board or slate, 
set in a sloping position, to let the blood and wet run from it while absorbing the salt. When balfdry it is best for use; but if long kept, till dried hard, it should be dipt in water, to soften it a little before being used.

The hook used is No. 9, 10, or 11, just tied on the gut like any other bait hook. The only great error in this fishing is using too large a bait; the size of a pea of prepared roe is always sufficient; any larger piece prevents the hook from catching, in which case the hook is pulled from the trout, generally leaving the bait in his mouth.

The proper places to angle are on the eddies of strong or flooded water, on some fine gravelly bottom, where the trout have come in shoals to the quiet water ; and there it is only necessary to drop in the bait, and wait till a trout is felt or seen to move the top of the rod; then pull up, lead it out, and throw in again for another.

The best time is the morning. I have seen a lad bringing in at breakfast time seven dozen, which would weigh above two stones; and a boy lay down beside them half the number, which would overweigh one stone; and these had been eaught with the plain roe, simply as salted from the belly of the salmon. 


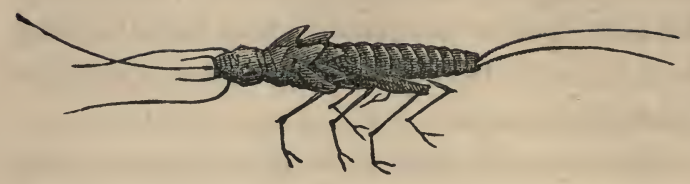

CREEPER FISHING.

BY THE EDITOR.

Its head was covered wi' a black airn ladle, It had black legs, and tail as sharp's a needle, A great red e'e stood stairin' in its breast, I'm like to swarf-0, 'twas a fearfu' beast !-

Tannahill.

Though the creeper has long been known as a deadly bait to the knowing ones who have used it, so conservative are anglers in general, that it is only within the last year or two it has been much used on the Borders, especially on the lower parts of the Tweed, and on the Teviot and its tributaries. Younger himself was influenced by this feeling, and said he "couldna be fashed to write aboot it; it was sic a short time on." Cotton knew it, and calls it a Jack, the name, by the way, of a fish common in the 
English rivers. He never mentions it as a bait; but he knew it as a deadly one in its winged state, and says that the fishes "will gorge themselves with those flies till they purge again out of their gills." Hawkins, writing a hundred years later than either, had never seen it, while his "learned and ingenious friend" knew it as a stone-fly, but not as a creeper. So far as we are aware no books on angling treat of it as a bait but those published in the present century. Barker is known in angling history as the first who found "following the roe" a successful expedient for filling the creel; Smail as the first who found the minnow to be a salmon bait; but the name of the originator of creeper-fishing must have been "written upon water."

The creeper is not such a short time "on" as the trusty John imagined. The insects are in the river all the year round. We have seen them in almost every month of the year, and of all sizes, from an eighth part of an inch in length to the full-grown insect. But it must not be imagined that the season for angling with the creeper extends over such a period. In general we have found it a good bait from about the middle of April to the middle of June, when it merges into the stone-fly. One of the largest takes we ever made with it was on the 
20th of the latter of these months. Stone-flies were in abundance at the time, and we tried both these and the creeper carefully for an hour or two, but finding the latter by far the deadliest of the two, we stuck by it to the end of the day. We have tried the same baits in a like manner several times since with the same result; but of this more hereafter.

"Up in the morning early" must be the angler who would be successful with the creeper at the beginning of the season; for, frosty or fresh, it is then most deadly before the first glimmer of the sun strikes the water; only that is generally an hour or two after sunrise. After the sun is up a fair number of trouts may be taken down to about 9 or 10 a.m., when the artificial fly is preferable. By the beginning of May, however, a change in this respect gradually begins to establish itself, until, by mid-May a tctal reverse has taken place. From that period until the end of the season, the best time for creeper-fishing is from about 9 a.m. to 5 p.m. For success, however, the water must be low and clear, otherwise the creeper will prove useless. A two-inch swell, though the water remain quite clear, will cause the trouts to stop taking it; and this we have found to be the case over and over again, both in the Tweed and 
elsewhere. Under a brilliant, steady, June sunshine -a great fishing help-by a low clear water, with a dozen or two of creepers, and cunning in the fling of his arm, he is but a sorry angler who does not for the time forget friends, home, and country.

The creeper is fished with in the same way as worm, by throwing up-stream; but in place of fishing the comparatively smooth streams that worm is used upon in April and the beginning of May, the creeper during that period should be fished in, or rather upon the edge of, very rough water. The best conditioned trouts only can lie in such water at that early season, and in general, only the best conditioned trouts take it, - a consideration. Indeed, at such a time, we do not recollect ever capturing more than two or three, or so, in any other than pretty rough water. Whereever an eddy is brushed by a strong and moderately deep stream-a place where good trouts, if they are in the water, are sure to be lying - the creeper should be applied, and, if possible, dropped just between the eddy and the stream. All broken water where trouts lie, such as that below mill caulds, and large stones, is favourable for creeper-fishing, especially during the first few weeks after the insect comes in as a lure. When the trouts begin to take it freely through the day, however, the sport becomes more 
pleasant; as in all the common feeding-streams, rough or rippling, but especially in those streams with pebbly margins - the haunts of the insect-the lightly thrown creeper will prove a surer giant-killer than Cotton's "most deadly killing fly," of which he sings. When May bas given place to June, and

"When the sun gallopes in his full career, And gildes the streames with heavenly Alchimy,"

the finest and thinnest streams covering good trouts may be fished with success. By now and then casting to the very edge of the water, large trouts at times may be captured, as they prowl about the edges of the pebbled streams on the look out for vagrant creepers and water-worms. We know that they poach in such places, and remove the fences that protect these unfortunate little animals. We and others of our acquaintance, have several times seen trouts-especially so when the rivers were very small from drought-turn over pebbles with their noses; and but for the food they procure in this manner, when the rivers are low, we do not see how, when taken, they could so often have large numbers of creepers and water-worms in their maws, and also such large quantities of water grubs, which are well known to lie beneath the stones. I'he water-worms 
(a species of the earth-worm, with black heads and reddish bodies) we do not recollect ever seeing, though they are numerous, either in the water, or at the edge of it, unless we turned up the stones under which they were lying.

In a very bright June day--if a curl on the water all the better-a few good trouts may be captured in still-water by throwing the creeper into the edges of overhanging banks; and large trouts may also be taken in water just gathering itself to form a stream, or in other words the hing of the stream, which every angler knows who can pronounce Auchtermuchty. We would not, however, advise the angler to dwell long on such places, as the streams are certainly the preferable parts for sport. Nor should he dwell long on one stream if he have another unfished above him. It is not good policy to cast half-a-dozen times over the same trout, or even twice, when trouts are lying a step further up that may not have had a line over them for an hour or two, and may therefore not be so wary.

In all kinds of clear-water fishing, it is almost needless to say that very fine stained gut should be used. No doubt, in the early part of the season, when the trouts are somewhat green, gut of a heavier stamp may be angled with; but, for our part, we 
prefer fine gut at all times, unless in muddy water. We may mention that horse-tail hair is a very good substitute for fine gut when the latter cannot be bad. This is like taking a step backward, because gut superseded hair; but now that much difficulty is often experienced in procuring proper gut, the angler will find hair both easily got and a capital substitute. We often use it ourselves, and always single, and we find no difficulty in landing trouts with it, saving that it takes more time to land large trouts, and as a whole, a little more caution when striking and landing than gut. Hair when wet is very elastic, so that a trout making a sudden bolt is not apt to break it; and if it be good hair trouts up to about half-a-pound may be lifted out of the water with it. If of a blae colour, it is also nearly invisible in the water. Hair frnm the tails of white or grey nags is best, horsehair being generally too coarse, and that of mares too brittle. When we have gut to our taste, however, we prefer it. It is more clever among taking trouts.

Some anglers, rather innocent ones we opine, make up their lines of any sort of gut, and bait the creepcr upon a common worm hook-passing it through immediately below the head, and then back again through the head's antipodes. This is a vague way of making a line, and a clumsy style of baiting; 
and shows moreover like the hidalgo's dinver-very little meat and great deal of table cloth. The general mode of baiting the creeper is on two hooks of size about No. 4 Addlington, which are tied about half-an-inch or so apart. The upper hook, which some anglers prefer a size smaller, is passed sideways through the shoulders, and the other in the same way through the lower part of the body-rather lower than the middle. Though many first-rate anglers use the two hooks, we cannot say we have a liking for that style of baiting the creeper. We consider that two hooks cannot be sufficiently hidden in the body of such a small bait. We use only one, a No. 5 Addlington sneck-bend, the point of which we enter (see illustration) just above the breast bone, and carry down the inside of the body, and bring out at the beliy, immediately below where the legs protrude, taking care not to bring out any of the interior of the insect. The hook, besides being fixed in the strongest part of the insect, is thus almost hiddenthe tip of the shank being almost flush with the nose of it, and the point protruding from the bend only; and by baiting in this style the creeper is made to come down the stream on its back, and the protruding hook-point is thus rendered invisible to the trout. The hook itself is a ken one, and very few 
trouts are lost by it if they once take hold. The best angler who ever thrashed water-James Baillie of Lauder-baited the creeper in exactly the opposite manner to that we ourselves practice. He, knowing that trouts sieze all live provender by the head, inserted the hook below the legs and brought out the point above the breast bone; but the insect when baited in this way is apt to slip round the bend of the hook after the first cast or two is made; it is also more difficult to bait it so without injuring it.

Great care must be taken in casting with the creeper, otherwise it gets destroyed : and those who find that they cannot make a cast sufficiently soft for the preservation of it, should use the two small hooks just mentioned, as they keep it in better preservation; moreover, the two small hooks have been the means of filling many a capacious creel. As the creeper is soft and easily destroyed, it is difficult to throw a long line; so that to keep out of sight the angler must stoop at certain places. Should he turn creeper himself here and there he may find it profitable. When fishing with this bait we almost never use a sinker, as the trouts rise and take it about middepth, and often within an inch or two of the surface, even in heavy streams. In very heavy streams, however, a single shot, No. 3 or 4, may sometimes be used 
advantageously. Without a sinker there is little danger of the hook getting fast on stones or the like; and when the angler sees his line stop, he should strike almost on the instant.

We have many a time been amused with the timidity shown by anglers, even anglers, when they took a creeper in their hands for the first time. The poor animal is generally thrown to the ground as if it were a livejcoal, and often with a profane ejaculation accompanying it. It certainly is not a pretty animal, and its nimble legs tickle the palm of the hand; but the angler soon gets over his timidity when he finds the reptile-looking innocent a deadly troutbait.

The stones, large and small, under which creepers are to be found, are embedded loosely among clean and generally pretty coarse sand; and where the insects lie the water is always running, and that, from one inch to five or six inches deep; and when the river gets less as the season advances, they retire with the river, but still keep under stones of a similar kind. Places abounding with stones and sand, as described, are in rivers generally plentiful ; and in such places, in a dry spring season, no difficulty need be experienced in procuring abundance of creepers. When taken, they should be kept in a perforated tin box, dry 
and airy, and in this way they may be kept living for some days. A number of anglers gather what serves them when fishing, but we prefer having a goodly number to begin with; and we use only the largestsized when we have them to pick and choose from. In a wet spring, sad to relate, when the rivers keep swollen, the sport from creeper-fishing proves a dead letter; and at the end of such a season the disconsolate angler may sorrowfully exclaim:

They lived unknown, and few could know

When creepers ceased to be:

But they are in their grave, and oh,

The difference to me!

Mostly all the streaming rivers running over loose gravel beds are adapted for creeper-fishing; such as the Tweed, the Leithen, the Gala, the Leader, the Rule, and the Teviot, the latter being better for this kind of fishing above Roxburgh than below. Trout taken with creeper in the Gala and the Leader are of a heavier arerage than those taken in the same rivers by worm or fly when the water is clear, and we have found the same result in the Tweed. To give an idea of the size of trout taken in the Tweed with creeper, we way mention the weights of some we captured in 1859 in that river. Out of twenty-seven trout 
captured in an April morning, the best half-dozen weighed 5 pounds. In another morning in May, out of twenty-one trout, the best half-dozen weighed $5 \frac{1}{2}$ pounds. On a bright afternoon in June, also in the same year, we went out for the purpose of fishing a single favourite stream. There were half-a-dozen anglers on the stream when we began, and we only got eight trout, but these weighed 6 pounds; and on a May morning in 1861 we killed a dozen, the best half-dozen of which weighed $6 \frac{1}{2}$ pounds. In Leader Water, in June 1863, we caught three dozen and nine, which weighed 14 pounds. The largest trout we ever killed was with creeper, and it weighed $3 \frac{1}{4}$ pounds. Indeed, we do not know of a bait, except the minnow in flooded water, that can fill a creel with larger trout than this insect; and those who angle with it know that they are but little troubled with the small trout and fry that sometimes almost pester a man's existence out of him when using the artificial fly. 


\section{THE STONE-FLY.}

[OR BORDER "MAY-FLEE."]

BY THE EDITOR.

I am the daughter of earth and water, And the nursling of the sky.

Shelley.

STONE-FLIES come into existence-we mean numerously so-generally about the second week of June, and continue a good bait for about three weeks or little more. We have found clusters of flies, however, beneath large stones in the end of March. They are found under the dry stones at the side of the water wherein they live in creeperhood. For a day or two after merging into stone-flies they arc tender and somewhat helpless, and many of them perish when exposed to cold east winds. Great numbers, too, are blown into the river before their time when the weather is windy - their wings being so large that they act like sails, and drive the insects in all directions in such weather. The flies are therefore most plentiful in mild seasons; but in all seasons they are most numerously to be gathered in places where the banks of the river shelter them from the wind. But a single flood, if 
high and of long duration, will sometimes sweep off the whole flies of a season.

When the river is falling in, and is of a porter colour, it is in first-rate trim for fishing with the stone-fly; and the streams and eddies are the best places to fish with it; but a number of trout may at same time be taken with it in the pools. When the water is clear the only places worth fishing with it are rough streams, and in such places it is sometimes very deadly. In swollen rivers of the porter colour above mentioned some of the largest takes have been made with stone-fly that ever were made in the south of Scotland; but it very seldom happens that the porter-coloured river and an abundance of stone-flies are to be met with in a state of co-existence. The trout taken with this bait are large and of the best quality - better on the table than those taken with worm during the same season. Indeed, we never saw a trout taken with it in any other than good condition.

The stone-fly must be fished up-stream, like the creeper, and it is baited in the same way; and only the large yellow-bellied flies, the females, should be used, if they can be had, as they are much more deadly than the little black-bodied males. Some writers on angling recommend fishing with two of the 
male flies on the same hook on account of their smallness. This we have tried often, but never with anything like success; we therefore prefer using one fly at a time, however small. A successful stone-fly angler of our acquaintance, who has used it as a bait for more then thirty years, is also against using two of the male flies at a time in place of one.

As the fly is more easily destroyed and jerked off the hook than the creeper, a shorter line should be used, which should be thrown very gently out; and common sense will, of course, tell any angler that no sinker should ever be used with it. When thrown into streams, the tumbling of the waters generally takes the fly under the surface, and we have mostly found it more readily taken when so placed, than when floating on the surface, especially so in slightly muddy water. In pools, however, we prefer having it floating; and in these the stone-fly is generally most deadly about nightfall. Quick striking is necessary when angling with this bait.

We mentioned in our remarks on creeper-fishing, that from experience we found the creeper more deadly than the stone-fly when both were co-existent. This, of course, was in clear water; the stone-fly being as deadly, if not more deadly, in swollen or coloured water, as the creeper is in clear. Here is 
a method we have found successful when both insects were to be had : we used the creeper on ordinary and thin streams, and when we came to very heavy water, where a shot might probably have been needed on the creeper-line, we used the stone-fly.

Lord, what a stoun'! a glorious stoun'; My saul played dirl against my croon, My feet near loupit frae my shoon

When first I heuk'd a saumon.

But dearly tho' sic sport I prize, Wi' eager heart $I$ aften rise As dawn lichts up the simmer skies

To fish, an' no for saumon.

For whiles I dance wi' vera glee, When, wi' the deadly bait or flee, The mornin' brings some troot to me As big as mony a saumon.

An' when the troots are takin' fine, The deil might try to clutch my line, The sun an' mune forget to shine-

I'd trail them oot, like saumon. 


\section{REMARKS ON}

\section{WORMS AND WORM ANGLING.}

BY THE EDITOR.

LAIRD (bawling across stream) - What are you doing there, Jock?

Jock (with difficulty)-Fiffin !

LAIRD-Fiffin? Oh, fishing you mean. And what's that in your mouth?

Jock-Wo'ms fo' bait.

LAIRD-0, you brute!

Jock-Weel, I might as weel have carried the brutes in a flannen bag, maybe. Jest Book, 1760.

WE have successfully practised worm-fishingthe surest of all fishing-in clear water for many years, and as our ideas on the subject differ somewhat from those of Younger, who does not appear to have angled much with worm, we shall herein note some of our experience: merely premising that on a subject of this kind the tyro may find the experience of two anglers of more benefit than one.

Worm-fishing generally may be practised most successfully from about mid-May to the end of July. 
Trout in good condition may however be captured earlier or later in the season, according to the piscatorial "earliness" or "lateness" of the respective rivers. For instance, the Till and the Eden are early rivers, and the Rule and the Oxnam are late. Burns and upland streams in general are late, and may be angled in successfully after worm-fishing is almost over in such waters as Tweed and Teviot.

From the middle of May till about the middle of June, the early morning and forenoon is the best time for worm-angling; and from that periodbut the change of course takes place by degreesthe best time to the end of July is from seven, eight, or nine o'clock, till about four or five in the afternoon.

From mid-May to mid-June the trouts take worm greedily on very fresh or dull mornings, or when very light rain is falling; and in the sunshine of early June they also take greedily. But they are not constantly in taking humour, and the angler must cultivate patience if he wish to make a good basket. Trout often do not take, as Younger says, at a time. when even first-rate anglers think, from all outward signs, they should be feeding; but a good angler bides his time, knowing that they must have their "grub," and that is perhaps one of the reasons why good 
anglers can always bring home a weighty dish, if not a basketful, after a day's sport. In the latter end of June and in July the worm is most deadly in sunshine; indeed, it is generally during that period deadly only in sunshine; and when the sun glares all the water it is most deadly of all. The reason of this, we are of opinion, is that trout cannot see the angler so well when the sun shines on the water as otherwise; and when it causes the streams and pools to glare or shine, the angler may capture them even in shallow water at a few feet from his rod-point, so difficult it would seem is it for trout to see under such waters. When the water is shining thus, the angler, if walking on the river bed or on a level with it cannot see the river bottom; hence it may be assumed that trout may have the same difficulty to contend with when trying to observe objects on the land or in the upper element. Through the medium of the water, refraction will we know soften the brilliancy of the sun's rays for the finuy tribes; but as trout have no eyelids, we are of opinion that the rays that reach them from strong sunlight, however much modified by refraction, must to a considerable extent favour the angler's approach to their haunts. We know, however, some good anglers who hold 
that the reason why trout take worms so freely in midsummer sunshine is, that under the pleasure of basking near the edges and in the shallows of stream and pool, they become somewhat forgetful, and-being like charity children, always ready for "some'at to eat"-readily gobble the angler's bait.

The worm-fisher must cast up-stream, and keep well back from the place in which he expects to make a capture; and to enable him to do this he should have a 14 or 15 feet rod. If he cannot keep out of sight of the trout he tries to take, he may as well go home at once. He should also learn to throw a long line-and that without causing the worm to slip down the hook or break on the tackle-hooks -because in all large waters, and often where banks are awanting in small waters, unless he throw a long line he cannot make his lure reach the trout without being personally seen by them. When a trout is felt, after allowing a second or two to pass, the angler should strike down-stream, or as near as he can against the direction in which the trout is thought to be lying. With the tackle worm-hooks he should strike the moment he feels a touch, as in fly-fishing. Streams are the principal places in which to fish, but the angler should remember that in June and July the trout are 
scattered over all the river, and are plentiful in odd corners and side streams where the water is often not more than four or five inches deep; hence no places of such description should be missed by him; indeed, they often yield most sport, as trout mostly all feed at the sides, where worms are always most plentiful. If a wind should happen to be blowing up the valley, the worm-angler reaps some benefit therefrom, as he may then angle in pools as well as streams. The least wind-ripple on a pool partly prevents the trout from noticing the accompaniments of the angler's bait, which so often frighten them from taking; and they often, when the surface is rippled, take the worm as they take fly, the moment it alights on the water. For pool-fishing of this description the angler of course requires to throw a light long line, and to have fine gut in use.

An ordinary bait hook for worm-fishing does very well at the beginning of the season, when the trout are still unjealous of the worms coming to them in such a stiff form ; but in July, when rivers are at their smallest, and trout are extremely wary, many of them having been hook-nipped, we prefer using a tackle of three small hooks, upon which we stick the worm in such a way that it can wriggle about in a quite natural style; and we find the liveliness 
of the worm always makes up for the visibility of the small hooks used, for trout take the worm in this form fully more freely than when bent round a common bait-hook. The tackle form does not answer in Tweed so well as in the smaller streams, because the larger worms generally used in Tweed often, from their liveliness, turn and twist themselves and tackle into a knot, in which shape no trout will have them. The tackle breaks and wastes more worms than the single hook.

The best angling-worms for the Tweed are the black-headed worms, the size of which varies much, and the angler may use the size he finds most deadly. The black-headed worms are also good for small stream angling, but it is often difficult to procure them small enough-about four inches or so in length. We always use smaller worms for fishing the Tweed than are used by the anglers we are in the habit of meeting on that stream, and they are numerous; but we have sometimes, though seldom, found worms of a larger size than we use taken when smaller worms were refused. This was generally on days when the weather was changeable. For Teviot and the smaller waters, such as Kale or Leader, we prefer the marsh-worm. This worm is 
often abundant in dampish stackyards, and in old rubbish heaps, and if in a breeding state, has a white knot some distance from its head. If not amorously inclined, the white knot is represented by only a whiteish ring. These worms when scoured are beautifully pink, and they are seldom too large for the angler.

Brandling worms require much longer keeping than other worms in order to toughen sufficiently, to allow of easy baiting; and for clear water angling in small rivers, our experience leads us to consider them next to the marsh worm as a bait. Anglers who keep a stock of worms should note too, that brandlings are much more easily kept alive than any other kind of worms. Even should the moss in which they may be placed for toughening become mildewed or partly rotten, a slight sprinkling of water over the moss will keep them quite lively. Remembering where they are bred, this is not to be wondered at.

It has often been wondered at how trout and other fishes have such a greedy appetite for worms, land animals; and none of our naturalists try to account for it. Knapp, in his delightful and often quoted Journal of a Naturalist, even writes as 
follows:- "Secured as the worm appears to be by its residence in the earth from the capture of creatures inhabiting a different element, yet many aquatic animals seem well acquainted with it, and prey on it as a natural food whenever it falls in their way."

Within the last two or three years we have made many investigations in the river-beds of the Tweed and Teviot and other smaller waters, and from these we have learned how it comes that fishes have such a relish for worms. We found that many more worms reside in the river-beds, under water, than could be found by digging in an equal surface of earth along the water's edge. We knew many years ago, as no doubt many anglers also know, that worms were not uncommon under the pebbles in river-beds; but not until a comparatively recent date did we know that they are so very numerous. We have often found two or three worms below a single pebble, and we got them from where the water scarcely covered the stones, to a depth of twelve or fourteen inches; and where the stones were imbedded in clayey soil we found at least a worm for every third or fourth stone turned over. Where the stones had clay beds the worms too were larger than where the stones were lying on 
sand. They are what are commonly called waterworms, but they are constructed like earth worms, and a novice would not know them from these. There are two kinds in the rivers ; one very blackheaded, dark on the back, reddish on the sides, and flattish : this is the largest of the two, and may be found from two to six inches long. The other is dark-headed, and inclined to yellow, and sometimes green, and ringed in the body.

Many anglers and authors think that the worms by which trouts get gorged in a flood are brought into the rivers by flooded drains and the like, whereas they get gorged from their own river-beds; because the floods generally turn over large numbers of pebbles and thereby dislodge the worms in thousands. On examining the worms in a trout's throat or maw, the angler will find that as a rule no other than water-worms are ever lodged there ; and after a flood almost all large trout on being captured show numbers of them, half-mashed and otherwise, in their gullets.

These worms too, along with numerous small water-grubs (most of which eventually become trout flies), are what cause ducks to gobble and plouter so much about the edges of drains, burns, rivers, and mill-ponds. What else could they cap- 
ture? Two summers ago, the writer and a friend watched the movements, for a considerable time, of a few ducks in the Jed. The water was so clear that the heads of the ducks were seen in all their movements under the water; and during the time they were watched they were constantly moving aside or turning over the pebbles over which they were swimming. From this it is evident that their food at the water's edge must bear a pretty large portion of water worms.

We have heard it alleged that trout will not take these worms when angled with; but such is not the case, as we have several times used them with success; but we fished with them of necessity, and would rather have had a supply of well-scoured earth worms.

The reason, in our opinion, why trout are so fond of worms in mid-summer is not, as many anglers say, because they are tired of flies, but because they have nothing else almost to feed upon. The grub flies have mostly all left the bottom of the river by midsummer, and the eggs of the earlier flies cannot, we opine, be grown so as to yield sufficient food for trout until the flush of summer is past; so that worms are almost the only abundant dish to be had at such a season. Another 
178 REMARKS ON WORMS AND WORM ANGLING.

thing that may tend to make trout prowl about the edges of rivers, and nose around and under the pebbles in midsummer is, that worms at this season are wriggling under the influence of Cupid, and when paying love visits to each other they all but leave their holes or cells, and thereby expose themselves to the watchful eye and ready mouth of the trout. Worms begin to meet about the end of April in mild weather, and breed all through the summer. 


\section{SCRAP.}

BI THE EDITOR.

WATER INSECTS.

DURING the last year or two we have endeavoured to watch the rise and progress of a pretty large family of water or river insects; and in order to try as far as possible to come to correct conclusions, we on several occasions and in several places col lected numerous grubs, and placed them in their native element, with a surrounding of pebbles. And as we always had these enclosures in private waters, where they were never disturbed by anglers or boys, we anticipated being able in a year or two to note the natural history of most of them. This, however, we have not been able to do: indeed we have just learned sufficient to make us remain silent. We find that instead of a year or two, it would require many years' careful observation, in order to note correctly the history of the grubs and flies inhabiting our running waters, for a number of drawbacks come in the way of observation. The water is always running pretty freely over the places where 
insects are most abundant; and we found that the stone enclosures in these places could not be made sufficiently close to keep in the grubs we lodged in them: even the putting together a considerable number of them, alone seemed to make them think something was wrong; and until their number was reduced to about the ordinary figure, escape seemed the only end in view with most of them. Sometimes, too, when we were on the tip-toe of expectation from noticing changes about to take place in the vesture of some particular grub, a sudden rising of the river swept both insects and enclosures away. Loaches (or beardies) often also thinned our preserves, and in this they were occasionally helped by small eels. Whenever beardies got within an enclosure containing only creepers and caddis worms, in a very short space of time the beardies alone were left, so rapacious are these small fishes. It is, besides, a very difficult thing to distinguish one grub from another of its kind, and whenever very few were encircled they always disappeared.

The "creeping things," and animalculæ and grubs fastened, like shell fish, to the river stones, are vastly numerous, and in the winter season when no surface food is within reach of the denizens of the deep, an abundant supply of food is thus always procurable. 
And before trout-flies leave the river bottom to sport in the upper element, they are full grown and complete, and we have often taken them thus grown and winged out of their semi-transparent cases, formed of a skin resembling gelatine, even in the late autumn. When we see trout leaping and feeding en masse on flies, the "take is on," as anglers term it. and thousands of flies may be seen floating and eddying on the surface, their wings standing erect like tiny sails. The sudden rise of the flies from the bottom to the surface is the cause of the "take," and from this it would appear that from the few minutes they inhale the air before being crushed in the maw of the trout, they acquire a richer flavour than they possess in the water.

It is believed that all trout flies are produced from eggs dropped into the water; and we can speak of one fly we have often seen in the act of dropping eggs-the stonefly. This fly drops its eggs near the edges of streams, not pools. The fly leaves terra firma, where it runs among the grass blades that float or overhang the river, and paddles into the stream a few feet, sometimes a yard or two, dropping its small black eggs the while, which by their specific gravity speedily reach the bottom and settle beneath stones. The fly repeats this process 
of egg-dropping for hours at a time. After every deposit it paddles to the shore, where it rests among the grass or pebbles for a short time, and then renews its labour. We have heard it asserted that a trout will not take a fly in the act of depositing its eggs, but we have witnessed something different; and we have no doubt but any trout will just as readily gobble an egg-dropping fly as a poacher will spear or net a spawning trout or salmon.

\section{BIOGRAPHICAL.}

As John Younger was a Borderer, and as his book refers almost solely to angling in border streams, it may not be deemed improper herein to record a few words on two noted border anglers now deceased. We shall begin with

JOCK SMAIL.

Jock Smail, who died about twelve years ago, was a Jedburgh man; and his principal angling streams were the Teviot, Rule, Jed, and Kale. He was for a long term of years looked upon as, and he no doubt was, the most successful angler in the district. His feats with fly on the still pools of the Jed are 
yet spoken of; and we have seen him fill a moderate creel out of one long pool where almost no other angler would have taken above half-a-dozen trouts ; and at this time he considered himself past his best, for he was an oldish man. He had a thorough knowledge of the habitat of all the finny tribes in the streams he fished; and his feats were performed with what would now be called very coarse tackle. $\mathrm{He}$ was also the most successful Teviot salmon angler in his day; and he it was who found out the minnow to be a bait for salmon. Early in the present century (about 1805 or '6), he was angling one day in the Teviot for salmon, in company with his father-"Auld Rob," also a keen and clever angler. The old man, after vainly plying his fly for an hour or two, came to Jock, calling out as he approached, "c'way, c'way, they're no gaun to take ; let's hame ;" but on seeing three or four fish lying grassed, he immediately ejaculated-"lord! how gat ye thae, callant?" Jock did not explain; but Rob, watching his "cast," cried out, "mercy, laddie, yer flye fa's like a stane, what are ye fishing wi'?" The minnow was shown, and the twosome kept the secret for a season or two, during which time they killed a large number of fish. The fish taken by the minnow were bull-trouts and salmon kelts, but 
in those days kelts were counted salmon. John Smail, like John Younger, was a shoemaker, respectable and respected, and like him he dressed flies, by which he eked out his living. Both father and son fished from boyhood to old age.

\section{JAMES BAILLIE}

Was, we do not hesitate to say, the best fly-fisher ever known in the Borders. We have mentioned him in some of our notes to the present work, and some of these were printed before he died, his demise having taken place in November 1861, at the age of forty six. He angled almost solely in the Leader and the Gala, and he seldom tried from spring to autumn any other lure than fly. In the hottest days of June and July, when these waters were at their smallest, and when almost no angler ever thought of trouting with fly, he could, every day, and in a few hours' fishing, kill from 10 to $15 \mathrm{lbs}$. of trout. For many years before his death he was in feeble health, and he could not stand the fatigue of fishing more than four or five hours a day; and during these years he had to refrain from wading, as wetting his feet would have prostrated him entirely. He fished always up-stream, and his principal flies were "spiders," thinly dressed. He spoke 
of shop-made spiders as "liker bottle brushes than speeders." His rod (not by choice, but necessity, for he was always poor, and had to live by his angling) was of unpeeled hazel : it was of two pieces, and when tied up it was well balanced and bent with every cast down to the hand. His mode of casting was a firm throw from the elbow; and he could throw a very long light line, and make the hooks fall on the very spot he wished. He did not like very fine gut, but when he had a choice he always picked the roundest strands. His gut, however, unless some one had presented him with it, was generally coarse; because he had to purchase it in pennyworth's in country shops, where little choice could be had. We met him on the Leader one April day, and we never saw a coarser casting-line than he was using. The strands had been knotted down and down until we are certain the longest did not exceed six inches; and with that line, which was of a milkywhite colour (for he almost never stained the gut he purchased), he had captured upwards of eight dozen trouts that day. A peculiarity of his angling was that he seldom caught very small trouts: this we noticed many a time when angling alongside of him. He was often in very poor circumstances during the winter season, especially of late years, as he was not 
strong enough to shift about for a living, in the way he did when in health. He called upon us two months or so before he died, in miserable health, and thinly clad, and we had the satisfaction of seeing him leave with a lighter heart. He was of gipsy extraction, we believe, and from anything we know to the contrary - and we saw a good deal of him during the later years of his life-he was honest and trustworthy. Let anglers note this: he blamed his incessant wading in his early years for his early death.

\section{HOMEWARD ROUTE.}

Perhaps the greatest drudge connected with angling is after a long and successful day's sport, to have to walk a number of miles before reaching home, under the pressure of a heavy basket and an empty stomach, accompanied sometimes with a burning sun and a dusty hard road. We have made this "weary pilgrimage" so often that in reflective moments, when that part of a day's sport comes into view, we sometimes break into a perspiration-the very remembrance of it is so overpowering. We shall narrate, however, the way we have found it most easy to get over the ground under such circumstances, hoping 
that it may at some time prove beneficial to some poor "unfortunate, weary of breath :"-We use tacketed shoes, of a size large enough to admit wading stockings when required; but when we wade without the water-tights, in order to keep the shoes firm and easy on our feet, we put a quantity of soft grass into them. After finishing our sport we take off our shoes, wash them out, and turn them up to drip. We then pull some of the softest grass we can find and put a layer of it into them, put on a pair of dry socks, which are easily carried in the pocket, and then put on the shoes. After this we can generally reach home without getting foot-sore. The basket (and note this, for it is of importance) we raise so high upon our back that it half rests on the shoulders, and we easily keep it in that position by twisting our rod once round the belt in front of us, and letting our arms rest on the rodone arm on each side of the belt; and the belt can be taken up a few links if found too long for this. The arms have thus a sort of lever power upon the basket, which makes it feel lighter, from the weight being more equally divided, and the basket shoulder being relieved from the dead weight. 


\title{
DESCRIPTIVE LIST
}

\author{
OF ALL THE
}

SALMON ROD-CASTS IN THE TWEED,

INCLUDING THE NAMES OF PROPRIETORS.

WITH very few exceptions, these, casts have been corrected by the proprietors themselves; and, barring the changes that floods may have caused since the corrections were made, they will be found correct. From anglers and others well acquainted with the Tweed, in different districts, returns were also kindly sent in, bearing lists both of proprietors and casts, and from these the Editor had thus the whole casts thoroughly checked. Some of the statements did not tally exactly as to the proprietorship of the first or last cast in some fishings, but in cases where two proprietors made a claim, enquiry was made, and the correct name placed against such casts.

The casts herein appear in the order in which they follow each other on the river. 
Thanks are herewith offered to the proprietors and friends who so courteously corrected the casts sent them for that purpose.

Salmon are occasionally taken with fly as high up as Biggar Water Foot; but hitherto poaching has been carried on so extensively in these higher waters, that the angler had seldom a chance of hooking a salmon unless immediately after a flood; but the better system of watching put into execution at the commencement of the close-time in 1862 may tend to improve the sport of the rodsman. Beginning about three miles above Peebles the casts come in order as follows:-

The Inch. In the middle of this pool there is a small island.

Barn's Pool.

Brown Knowe Goat.

Long, or Mid Pool.

The Wickers.

Eddstone Hench.

Manor Foot.

The land on the south side of these casts belongs to Barns and the Earl of Wemyss, and the north side, with the exception of a small haugh, also belongs to the Earl of Wemyss. 
Upper Poples. Fine spawning stream. Nether Poples. Fine spawning stream.

Stay Pool, or Wood Pool.

Toll Pool. .

Allery Stream.

Stone-Dyke Foot.

Castle-back. One of the finest casts about Peebles.

Dove Cots.

Howden. A fine spawning stream.

Little Wood Pool.

Minister's Pool.

Earl of Wemyss proprietor on both sides.

Cowford Stream, at Peebles Bridge. A fine spawning stream.

The Factory Stream, near Peebles.

The Drain.

Arthur's Putt.

Hay Side. Spawning stream.

Kerfield Pool.

Broad Stream.

Booner Staff.

Nether Staff.

Kerfield on the north side of the two last mentioned.

The Wheel, or Wire Bridge. A good spawn bed. Hunter's Stream. A good spawn bed. Eshielsback Water. A good spawn bed. 
Haystone Burnfoot.

$S$ cotsmill-back

Dog Craig.

Kailzie Throat.

King's Meadows on both sides.

Kailzie Pool.

Castle Pool.

Red Yett, opposite Kailzie.

Maggie's Tail.

Laidlaw's Heuch Cheek.

Kirkbank Boat Pool, Cardrona side.

The Rumbler.

The above on Pirn; anả Nether Horsburgh on north side, and Cardrona on south side, down to Traquair Water.

The Dirt Pot, three miles below Peebles, on Nether Horsburgh farm. Strong, rough, deep, rocky cast.

The Cragg, head of Nether Horsburgh nut wood. Fine cast from Cardrona side.

Wood-end Pool. Fine cast over rough stones.

Glenormiston property begins here, north side.

The Girley. A strong rough cast, deep on Cardrona side.

Fawn-burn Pool. Fine spring cast. 


\section{TRAQUAIR WATER.}

Lord Traquair is proprietor on the south side of all the casts to Kame-knowe-end, and on north side to Leithen foot.

The Whins. A fine gravelly pool ; fine spawning at the upper part of it.

\section{The Jawstane.}

The last two belong to Glenormiston on north side.

New Water. Beginning with a long ford stream, rough bottomed, a fine gravelly pool below.

Pirn from Leithen foot to Hollylee.

Cowford. A thin stream where fish spawn occasionally ; falls into

Traquair Boat Pool. A cast in heavy water -best for spring fishing.

Quair-Foot, opposite Traquair House. Pool, rocky and deep on south side; a good cast when the water is of proper size.

Upper Drown-Pouch, a little below Traquair Bridge. Good for spawning-good for troutingmiddling for salmon.

Nether Drown-Pouch. Good salmon cast.

Cadon-bank Pool. Excellent salmon cast, deep and rocky on south side.

Haugh-head Pool. Good cast-upper part spawning stream; the pool deep and rocky on north side. 
Mound Pool. Very good for salmon and trout.

Bishop's Point. An excellent new cast.

The Clure. A very fine cast.

Gazeling-Dale-upper and nether casts. The nether cast is the best.

Weaver's Pool-upper and nether casts. Both good casts.

Picklarny. Good for clean salmon.

Three Bold Throats. Three deep gullies-good rough rugged casts - the lowest the best; a fish hooked in the upper leads the fisher a dance to follow it down to the under.

Bold Burnfoot.

Barn Wa's-below Tweeddale Mills. Grand salmon pool.

Ashtree Stream. Not a fly cast. Below the stream is a strong throat, a good fly cast.

Litster, or Lidster-heuch. A deep pool on south side.

Caberston Rack, opposite Juniper Bank. Fine spawning stream; pool below a good cast for grilse.

For a good distance below this the water is thin and good for trouting. From this to Hollylee Boat Pool inclusive, the casts on the north side belong to Hollylee.

Bar Pool. A famed pool for salmon and trout; rocky on north side. 
Kame-knowe-end-mutual. A good cast from the south side.

From this to the head of the river the proprietors are lenient, and anglers generally enjoy their sport without interruption, looking upon the fishing as free.

End of Traquair Water.

\section{ELIBANK WATER-}

On the south side down to Nout Sykes inclusive.

Birky Throat, near to foot of Gatehopeknowe. A very fine cast.

\section{Hollylee Boat Pool.}

Howegate.

Belongs to Capt. Mitchell of Stow, and all the casts on the north side, down to Gleddie's Wheel inclusive.

Howegate, for about half-a-mile below this, consists of deep heavy water, with three casts at different places on the north side. It is a good salmon hold, and for fly-fishing when the water is full.

Elibank Wood Pool. A deep pool, famous for kelts.

The water divides here, there being a fine island in the middle.

Rough Haugh. Fine strong rapid stream, for salmon and grilse.

Nout Sykes. A spawning stream.

End of Elibank Water. 


\section{ASHIESTEEL WATER.}

The four following casts belong on the south side to Ashiesteel. On the north side the two first belong to Capt. Mitchell; then Torwoodlee comes in on the north, and goes down on that side to Little Caddon-foot.

Steel Pool. A fine cast both for salmon and trout; rocky bottom, water swift, trouting part of it rough but not deep.

Gleddie's Wheel.* A fine pool cast at all seasons Rampiheugh. Salmon cast. Ashiesteel Boat-hole. Grilse and kelts

End of Ashiesteel Water.

The Duke of Buccleuch is proprietor on the south side of the three following casts :-

Peel Boat-hole. A. fine cast for late grilse and salmon, lower part best for trouting; a mutual cast.

Peel Putt. A good cast for grilse and kelts. Peel Burn-foot. A good cast for grilse and kelts; a mutual cast

* It was in this pool that Sir Walter Scott, Hogg, and some of their friends had such a fine ducking by the breaking up of their boat when leistering salmon, which, as Hogg said, quoting from "Guy Mannering," were "turning up sides like swine." 


\section{YAIR WATER.}

Pringle of Yair is proprietor of the south side down to Russell's Rock, half-a-mile below Yair Bridge; but on the portion below the bridge the Fairnielee property has a right of fishing mutually with Yair.

Craig Stream. Good for a clean salmon.

Craig-on Gullets. Counted one of the best casts in the district; rocky on north side.

Moss Pool. Good pool cast.

Little Caddon-foot. Upper half on Torwoodlee; under half belongs to Major Scott, who has also the next cast.

End of Torwoodlee Water-north side.

Caddon Foot. This is a first-rate salmon cast. Gled Heugh. A good cast for kelts.

The following casts, down to Ettrick foot, on the north side, belong to Fairnielee:-

Blakie's Haugh. A very poor cast.

Needpath. Famous cast at any season.

Boglehouse Stream. A middling cast.

Yair Boat Pool. Famous for kelts, and in heary water in Autumn.

Elm Wheel. Fine for clean fish.

Yair Rocks, or Trows. Clean fish in summer or early autumn in small waters.

Gipsy Bog. For a clean grilse. 
Brander. Easy for kelts.

Burnet's Cairn. For kelts.

Raelee's House-back. Fair water for grilse and kelts.

Russell's Rock. For kelts and "late" big fish. A mutual cast.

End of Yair Water.

\section{SUNDERLANDHALL WATER.}

Howden Rack, or Pot Stream. A famous spawning bed, and a good late spring cast.

Arras's Putt. Fine for a clean fish; half a mile of trouting water down to the Tweed Bridge.

Sunderlandhall Boat Pool. Fine trouting pool. Black Strand. Spawning bed.

Tweed Bridge, at Ettrick Foot.* Spawningstream, and a fair cast.

End of Sunderlandhall and Haining water-south and north sides.

BOLDSIDE WATER,

Belonging to Major Scott of Gala (both sides).

Meeting Pool-junction of Ettrick and Tweed. Good cast.

* Salmon enter the Ettrick freely, and rod-fishing is sometimes very good in it; but, with the exception of about a mile-and-a-half of water at Selkirk, the only parts of the river worth the salmon angler's attention are preserved. 
Rink Stream. Excellent for clean fish. Hedging-end Pool. Principally a kelt pool, or salmon at backend.

Garden Back Stream.

Garden Back Pool. Salmon and grilse, excellent cast.

Boldside Wheel. Fine long rocky pool, good for any kind of fish.

Glen Mein. Good for salmon and spring fish, long and deep.

Hart-pool. A famous salmon cast; a spawning stream above.

Hind's-house Pool. Easy pool for a kelt.

Foghouse. Easy pool.

Dead Water Heugh. Easy water for kelts.

Gala Foot. A deep excellent cast, but exceedingly changeable from the floodings of the Gala.

End of Boldside Water.

LORD SOMERVILLE'S WATER.

Carey Wheel. A good salmon cast amongst rough rugged rocks.

Railway Bridge Pool. A small cast.

Glass-Wheel Pot-below the Railway bridge. A deep whirl, rocky on north side.

Knares. Fine east, half pool, half stream. 
Bridge-end Pool. Deep pool, the stream falling into it; a good cast as far as the run goes into the pool below Langlee, and opposite the hamlet of Bridge-end.

Quarry Stream. A rapid good cast.

King's Well Lees, or Big Brae. An excellent stream-cast, at the foot of Elwand, or Allan water.

Meg's Pool-a stream forming a pool below. A good cast opposite the fisherman's house.

Carre's Shot. A middling cast below Melrose Stone Bridge.

The Whorles, or Hallow Weel-a stream falling into a deep pool. A good cast for salmon and grilse.

Boatshiel. A small cast, but good.

Elm Weel. A stream falling into a fine deep pool cast.

Auld Brig. A cast in full water, opposite Gattonside House Lodge.

Sauter's Ford Stream. A cast in any water, nearly opposite St. Helen's House.

Cauld Pool. A fine hold for fish all the year, and good fishing from a boat. In spring contains great abundance of kelts.

Cauld-back. A cast, but often altering.

The Battery. A capital stream-part rocky.

Cowey's Hole. Mutual. A first-rate stream.

The under part of Cowey's Hole is on Drygrange Water.

End of Lord Somerville's Water. 
DRYGRANGE WATER.

Thomas Tod of Drygrange, proprietor.

Eddy Stream. Rapid, subject to alterations by floods.

Miller's Turn. Good cast.

Buller's. Rugged gully, ending in a pool-cast.

Lang Cairn. Good spring cast.

Fly-bridge Pool. Capital cast in a full water.

End of Drygrange Water.

OLD MELROSE WATER.

George K. E. Fairholme, proprietor of south side; John Meikleham of Gladswood, proprietor of north side down to Cromwell, half inclusive; then Miss Haig, Bemersyde, on north side, to end of Old Melrose Water.

Leader-foot Pool. Long cast, for spring and autumn.

Rampiheugh. Good, long, strong, stream cast.

Long-cairn. Stream, deep and very good.

The Coburns. Good stream cast.

Paddock-heads. Good, soft stream cast.

Cromwell. A splendid pool-cast-fine hold for fish.

Gateheugh Streams, in five or six breaks. All excellent casts.

Hally-Wheel Throat. Never "out of a tenant." Only the throat of this cast belongs to Old Melrose.

End of Old Melrose Water. 


\section{BEMERSYDE WATER.}

Miss Haig proprietor on both sides.

Middle-streak Hole. Pool and stream.

The Cradles. Long, half-stream, half-pool, rocky bottom.

Sangster's Point. Good on north side occasionally.

Between the above cast and the following one there are two good casts in spring and autumn, when the water is fuller.

Jock-sure, or the West Wood.

Buss aboon Traquair. Pool on south side for spring fishing.

End of Bemersyde Water.

\section{DRYBURGH WATER.}

This water belongs to Captain Riddell.

Battery. Strong good stream.

Toad-holes. Fine cast, stream and pool ; including the two following casts.

The Throat.

Mungie.

Beehill. Excellent long cast.

Wire-bridge Pool. A fair cast.

Dryburgh Boathole. Capital cast, but rather hurt by the ferry-boat.

Caul-Pool. A good rocky cast, opposite Major Riddell's house. 
Tommy Tulloch's Throw; below Dryburgh cauld-dyke.

Howden Burn-foot. A strong throat, and good cast for summer.

Harecrag.* Very good for all seasons.

Burn-foot. Stream and pool; a good throw for all seasons.

Brockie's Hole. Good for all seasons.

Gullet. A sure summer cast at the cairn point.

Birkicheugh. A cast of medium character; fair for spring fish.

Back o' the Stenhouse. A first-rate cast for kelts.

Lang Stream. Good all the year-salmon and grilse.

End of Dryburgh Water.

MERTOUN WATER.

Lord Polwarth, proprietor.

West Indies. For spring fishing.

The Caul Pool. A fine cast in all seasons-quite a hold for fish.

The Caul Dyke-back. A good stream.

Broom-ends. Spring cast.

Back-brae. Stream-a capital cast.

* From the overhanging Gray-crag, the author once counted in this cast forty-two salmon, all lying on the principal bottom rock, and held there for weeks in consequence of the lowness of the water. 
Strong Stream, or Jock A.-B. Summer cast. Kipperha' Stream. A fair summer cast. The Pot. Grand, deep, rocky cast. Gibson's Hole. A very good spring cast.

The following casts, down to the middle of The Webbs, belong on the south side to Sir Henry Fairfax.

Benrig Caul-stream. A summer cast, soft near the foot-kelts and salmon.

Haugh Side. South side for spring fishing. Kirk-back. 'Stream and pool-good.

Three Breaks. For summer salmon or grilse.

Cast above the Webbs. Good salmon stream.

The Webbs. A fine deep cast-excellent in all seasons.

Crago'er. A splendid cast, and a hold for fish in all seasons.

Stile-well. Stream-good-just above Mertoun house.

Stile-foot. Famous pool below.

House Stream. Good.

Willow Bush. Fine spring pool.

Caller Haugh Fine stream and pool.

Tou'er Stream (Littledean Tower.) Good.

End of Mertoun Water. 


\section{RUTHERFORD WATER.}

Sir Edmond Antrobus, proprietor.

This, as a whole, is most excellent fishing water.

Corseheugh. A fine pool-mutual between Mertoun and Rutherford.

Lang-stream.

Dub. Good in spring.

Stream between the Caulds.

Mill Stream.

Lover's Loup. Stream.

Corbie. Stream.

Clippers. Stream.

End of Rutherford Water.

MAKERSTOUN WATER.

Lady Makdougall Brisbane, proprietor.

Willie's Bank. Spring cast for kelts and grilse. Hirple Nellie.* Good for kelts and trout.

Orchard Head. Fine cast for salmon and kelts. Dark Shore. Fine cast for salmon and kelts. North and South Clippers. Good summer casts for clean salmon.

Laird's Cast. For salmon and kelts. Elshie Stream. Fair cast for salmon and kelts. Head of Blakeman. For salmon and kelts.

* An English sporting literateur lately translated the above name into "Help our Nelly." How he will relish his Dunbar !-[EDR.] 
Red Stane. Fine rising east for salmon and grilse. Side Strake. For salmon.

Doors. For salmon. Nethern Heads. For salmon. Runners. A summer cast for salmon. Kill Mouth. For salmon and kelts. End of Makerstoun Water.

\section{FLOORS WATER.}

Belongs to His Grace the Duke of Roxburghe.

[We do not consider it necessary to give a descriptive list of the individual casts in Floors Water, as it is always kept in the hands of the proprietor. The Duke of Roxburghe is one of the keenest and best salmon anglers on the Tweed, and he owns as fine a stretch of "quiet waters and unquiet waters" as the Tweed can boast of.-EDR.]

The Slates.

Black Stone.

Weetles.

Upper and Lower Huddles.

Shot.

Cauld-slap.

Dyke-end.

New Stream.

Hedge-end.

Shirk Stream.

Lang-rocks, or Dam Foot.

Skelly Rock. 


\section{Planting-end. \\ Coach Wynd. \\ Innes' Cast. \\ Income. \\ Garden Wall, or Cobble Hole. \\ Putt. \\ Back Bullers.}

Teviot Foot, or The Junction.

The Teviot, after a flood, often yields very good sport, and on application to $\mathrm{Mr}$ Darling of Broomlands, or to $\mathrm{Mr}$ Darling, Banker, Kelso, a free ticket may be obtained, stating that the bearer "has the Duke of Roxburghe's permission to fish for salmon on the north side of the river Teviot, from Ormiston March to Maxwellheugh Mill Cauld"-a stretch of nearly four miles of the best fishing-water in the river.-EDR.]

Cradles.

Mawwheel.*

End of Floors Water.

SPROUSTON WATER.

The south side belongs to the Duke of Roxburghe; the north, from Mill-stream to Eden Water-foot, both inclusive, to John Waldie of Hendersyde.

The water is held in lease by one of the Tweedside Kersses, and from him anglers can procure fishing on reasonable terms; and with such water and such fishermen no fair angler can miss a salmon if he will bite at all. The Sprouston water, as a whole, is first-rate. The Dub is the finest cast in the Tweed, and, from its dimensions and resources as a salmon-hold, yields a day's sport to more than one angler.

* The Duke of Roxburghe, a few years ago, killed 6 salmon and 20 grilse in one day in Maxwheel. 
Hempseed Ford. Excellent stream.

General's Banl. Stream at top, and pool below. Grain. Rapid stream-excellent.

Mill Stream. Long and good; rapid at top.

Mill Pot. A spring and fall cast.

Butterwash. Good grilse cast.

Bushes. Half stream and pool-fine rocky cast. Rock. Good, particularly in low water.

Prison. Very good and deep.

Dub. The best cast yet named; long, broad, and deep, admits boats all over.

Caul-back. Short stream, good and sure.

Mill-end. Good for big water.

Faulds. Long cast, rather a pool.

Eden Water-foot. A fine spring cast, half streamy, rippling, broken water.

Birgham Dub. Large, first-rate cast-south side.

Burn Stream. Good rough cast-south side.

End of Sprouston Water.

\section{CARHAM WATER.}

Earl of Home proprietor of north side, and J. H. Hinde. Esq., of the south side as far down as the Under Cairn Neb, from which to the end of Carham Water, Richard Hodgson of Carham is proprietor.

The casts in Carham Water, as a whole, are mostly rocky, and all are good.

Birgham Dub, north side. Grand cast. 
Wheel Stream, north side. Rough broken water - very good.

Carham Wheel. Good, especially when the water is low.

Ship-end. Middling-good trouting. Long ship-end-also called the Prison. Flummy, and Land Cast. Good. Kirk-end. Very good.

Dritton. Good.

Glidders.

Bluidy Breeks.

Under Cairn Neb. Capital cast.

Cauldron Pool.

Head of the Three Stanes. Fine cast.

Three Stanes. Fine cast.

Pikey. First-rate cast.

Three Brethren. Good.

Nether Stream. Good.

The Hole. Good.

The Hole Stream. Good.

The Neb. Good in full water.

Craw Stane. Good.

Merk Skelly Head. Good.

Bell Stane. One of the best casts in Carham.

Segg Bush Middling cast.

White Eddie. Good. 
Whin Bush Skelly. Middling.

Shaws Mere. Good.

Knowe Head. Good.

End of Carham Water.

\section{LADYKIRK WATER.}

The Snipe. Rod cast.

Lord Ossulton, proprietor.

Lord Home is proprietor of the four following casts.

Wark Dub. Rod cast.

Anna Side. Rod cast.

Cuddie's Hole. Good cast.

Black-mark. Middling cast.

Sir John Marjoribanks is proprietor of the four following casts.

Temple Pool.

Learmouth Haugh.

Battery Wall.

Deddo River-mouth.

End of Ladykirk Water.

COLLINGWOOD'S WATER.

Three miles of water below Deddo Burn-mouth.

Deddo Mouth. Excellent spring cast.

Trout Hole. Excellent spring cast.

White Stone. Excellent spring cast.

14 
Rabbit Nest. Spring cast-shallow. Monument Marjoribanks. Coldstream cast. Long Cairn. Good cast, streamy and heavy. Craw Hole. Good cast. Crook Bull. Good cast. Rough Stones. Good cast. End of Collingwood's Water.

SIR JOHN MARJORIBANKS' WATER.

Hell's Hole. Still, rocky bottom. Temple. Still, rocky bottom. Cobble. Still, rocky bottom. Cauld Slap. Ready cast. Bulwark. Good cast. Back o' the Wa'. Fine cast. Dead Eye. Good rocky cast. Cornhill Stream. Rough bottom.

End of Sir John Marjoribanks' Water.

CORNHILL WATER.

East Side of Lees' Haugh. Boat Hole-ferry before the bridge. The Craw. Long-net and rod cast. English Water. Rod and net.

Lennel Haugh.

Lord Haddington proprietor on the north side of this and Great Haugh Water. 
The Great Haugh Water ; fished by Robert Swan. Oxendean Burn, down to Tillmouth. Wellington Cairn. Good cast.

Cauld Slap Chapel Stream. Good cast.

Twizel Boathouse.

Chapel Stream, with part of the Till. Excellent down to Tillmouth.

End of Cornhill Water.

Putt Point, tail of the Chapel stream.

Scarsheugh Rock.

White Cat Rock. Deep and rocky.

Goat's-hengh. Nearly half a mile long-streamy and deep.

\section{Dreeper. Good cast.}

Sir Francis Blake and others proprietors of above cast.

Damford. Nearly half a mile long-streamy and deep.

David Robertson, Esq., proprietor of above cast.

Bendibus. Grand long-net shot.

David Robertson, Esq., and others, proprietors of above cast.

Glittery Heuch. From Norham Boathouse to Newbigging Burn, very fine cast.

Mark Young proprietor of above cast.

Westford. Good rod-fishing.

David Robertson, Esq., proprietor of above cast. 
Pedwell. Good rod-fishing.

William Mather, Esq., proprietor of above cast.

Blunt. Deep good cast.

David Robertson, Esq., proprietor of above cast.

Greenhill. Good; about half-a-mile long. William Mather, Esq. and others, proprietors of above cast.

Hallywell. Good cast.

David Robertson, Esq., proprietor of above cast.

Callerheugh. Good cast.

Sir Francis Blake proprietor of above cast.

Wilford. Good cast.

D. Macbeth and others proprietors of above cast.

Watham Water. Upwards of a mile in length The following are the principal casts*:-

Squire.

Boathole, or Gillies' Rock.

Geese.

Thompson's Rocks.

Pack About.

Nose End.

Sir Francis Blake proprietor of the above.

Hornwell. Good cast.

Scotch New Water. Good cast.

Mr. M'Briar proprietor of the above two casts.

* These are all good casts, but the fishing is best when full tides have not been flowing - the lower the tides the greater the sport with the rod. 
Start. Good cast.

Trustees of Lord Crewe, and Mrs. Shuttleworth, proprietors of above cast.

Finchey, includes two good casts-the Willow Tree and the Cloven Stone.

David Milne Home proprietor of above cast.

South Bells. Excellent cast at the "Throat."

Low Bells. Excellent for grilse in surnmer.

Berwick Shipping Company and others proprietors of the above two casts.

END OF SALMON CASTS. 
DESCRIPTIVE LIST

OF THE

\section{TRIBUTARIES OF THE TWEED,}

FOR TROUT ANGLERS.

BY THE EDITOR.

The Tweed is a fine trouting river from head to foot, and it is nearly 100 miles in length. Though a longer walk has often to be made from stream to stream than may be required on smaller rivers, the angler has generally the consolation of seeing in the long wide-spreading streams of the Tweed a few hours' respite from pedestrianism. Trout too are plentiful and large; and on none of the tributaries are the appellatives descriptive of large trout so frequently brought into play as on the Tweed. What would Mr. Briggs or his Cockney friends make of terms like these:-wauper, skelper, bummer, whauker, pinner, yerker, whupper, and the juvenile exclamation-aigh! sic a ane! And relative to large trout, these are terms in common use on the "canny" side of the Tweed. 
Tweed is free to trout anglers from its head down to the Pavilion property near Galashiels. From Pavilion to Kelso "notice to trespassers" is the rule, and the exceptions, we are sorry to say, are few and painfully far between. On the Pavilion water, we believe, anglers are now seldom, if at all, stopped, more especially about Melrose; but from Leader-foot to Kelso, about eleven miles, there are not more than two places open, and these small. From Kelso to Carham, six miles, trouting is unrestricted. Carham (about a mile) is preserved, but from Wark to Tweedmouth the river is free.

Beginning at the upper part of the Tweed, the first noteworthy stream-though there are many very good burns-is

The TALA - a small water. Fishing good. Angling free.

BIGGAR - a small water. Fishing middling; trout good. The Tweed itself between Biggar Water foot and the Lyne yields very good sport. Angling free.

Lyne, enters the Tweed three miles or so above Peebles. The angling is good, and trout pretty numerous. A mile or two from its mouth the Lyne is joined by the Tarth, which also yields good sport; and all ordinary lures may be used in both streams. Angling free. 
Manor, enters Tweed from the south two miles above Peebles, and is a first-rate trout stream. Angling free.

Edduestone, at Peebles. Fishing not good unless after a flood; the upper part of the water the best. Angling free.

QuAIR, at Innerleithen. Yields good sport to the troutsman, but the trout are small. Some very good burns enter it, the best being Glengaber and Kirkburn. Preserved in neighbourhood of GLEN.

Leimhen, at Innerleithen, affords very good sport, trout being plentiful; and some good burns enter it, Glentress burn being nearly as good as the Leithen itself. The Leithen is preserved from about four miles above Innerleithen to its source.

CADDon-a burn. Fair fishing after a flood. Angling free.

Еттитск-a large stream. Angling very good; many good burns about upper sources. The Ettrick is preserved for two or three miles from Yarrow foot upwards.

YARRow, also a large stream, falls into Ettrick two-and-a-half miles above Selkirk; it is preserved for a few miles at the foot. Fishing very good; trouts plentiful, some of them large; many first-rate burns at head. 
GALA, although very much fished by anglers from Edinburgh, is first-rate for fly, worm, or minnowfishing; trouts generally plentiful and good; and some good tributaries join it. Many excellent burns about its source. Angling free.

Ellwand, or Allan - a burn-falls into T'weed two miles below Galashiels. Angling poor, but a fair basket is sometimes made in it after a flood. Angling free.

LEADER, at Earlston; perhaps the best angling stream falling into the Tweed. All the ordinary flies and baits may be fished with successfully ; trout a good size and plentiful; many first-rate burns at head of the Leader-three-and-a-half miles at foot preserved, also about a mile at Lauder. The Editor has killed $24 \mathrm{lbs}$. of trout in the Leader in a day. This was in midsummer when the water was small and clear. Boon water falls into Leader three miles below Lauder. Fishing good, and free.

Tevrot. Enters the Tweed at Kelso, and is a splendid fishing stream, 35 miles long. Above Hawick the fishing is good, but for a few miles below that town it is rendered useless by the waste dye stuffs from the mills. Where the refuse no longer affects the water it again becomes a good angling stream. Opposite Jedburgh or Lanton the fishing 
is best after a flood, and that with fly or minnow; but when small and clear it is not good for wormfishing in this district. From below Nisbet until it joins the Tweed, however, it is all that could be desired by an angler-streams plentiful and goodtrouts ditto. About Ormiston it is preserved, and also opposite Mounteviot, near Jedburgh, and for about a mile at Chesters, opposite Lanton.

\section{TRIBUTARIES OF THE TEVIOT.}

ALL OF WHICH ARE FREE.

AluaN-a large burn which comes in four miles above Hawick. Fishing middling.

Borтншіск, two miles above Hawick. Fishing fair.

SuITrig-enters at Hawick. Lots of trout, and good fishing, but often spoiled by netters.

RULE-enters four miles above Jedburgh. Trout very plentiful but small on lower portion; not so plentiful, but of heavier dimensions in upper portion. Fishing easy. It divides into fine trouting burns near its head. The Editor has killed upwards of twelve dozen in the Rule in a day. This was on the lower portion of the river.

ALE-Younger's "native valley"-a small but 
pretty long stream, something like the Eden. The angling, as a whole, is very good, and the trout of a good size. It falls into the Teviot below Ancrum. JED, at Jedburgh. Best trouting after a flood; trout not very plentiful, but good. Easiest angling six or eight miles up, and burns good.

OxnaM-enters three miles below Jedburgh. Fishing pretty good after a flood.

$\mathrm{K}_{\mathrm{ALE}}$-enters five miles above Kelso, and is the last tributary of the Teviot-a first-rate stream; many good burns at head. Fished a good deal by Jedburgh and Kelso anglers. Trout al ways plentiful.

The tributaries of the Teviot average 15 miles in length.

EDEN-enters Tweed about three miles below Kelso. It is a very good fishing water, but is mostly preserved.

LeEt, at Coldstream. Fair as an angling stream in the spring and early summer-trouts large; most of the water preserved : a very sluggish river.

TiuL-below Coldstream. Trouts large, but wary and difficult to take; water deep and sluggish, and preserved here and there. An "early" river. The GLEN falls into it. Fishing in the Glen excellent, but part of it preserved. 
Bowmont, a few miles from the Till, is joined by Colledge, and the united rivers from thence to Till are named Guen. Bowmont is an excellent trouting stream from head to foot, and it is a pretty long river. The burns falling into it a few miles above Yetholm are most of them abounding in trout. The nnly day the Editor ever angled above Yetholm in Bowmont water and some of the burns, he killed upwards of 13 dozen smallish trout, in clear water. Whitling are often taken with the rod in the Bowmont. Angling free.

WHITADDER - a long excellent trouting-stream, one of the best; enters Tweed a few miles above Berwick. Some of the burns at its head rise within a few miles of the burns that feed the upper part of the Iseader; and we question if two as good trouting rivers, taking them from source to source, enter the Tweed. The Whitadder is fed by a number of fishable burns. Angling free.

Buackadder falls into Whitadder. It is in nature something like Till, sluggish, and trouts large. In the vicinity of Greenlaw fishing" good. Preserved for some miles at its mouth. 



P.

derso 160

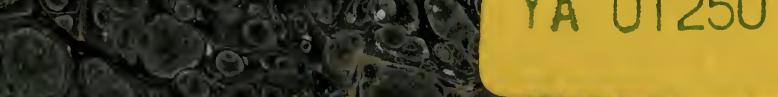

$\therefore$. H.

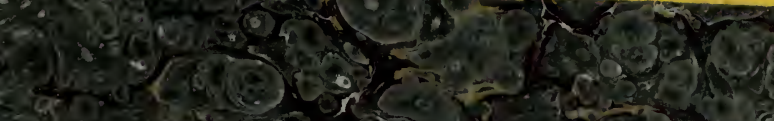

$390 \mathrm{cos}$ or

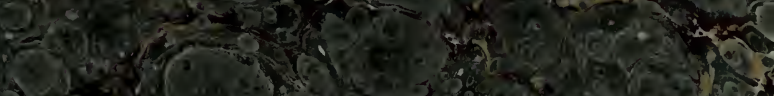

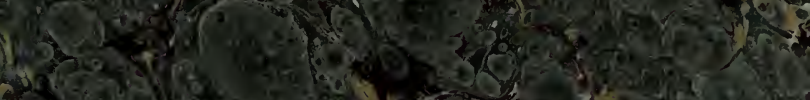

$20 \times 1 \times 1)$

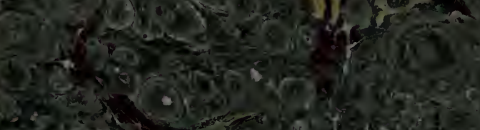

bestis

(1.5.

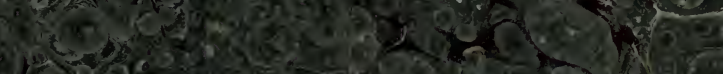

12030,13

weros

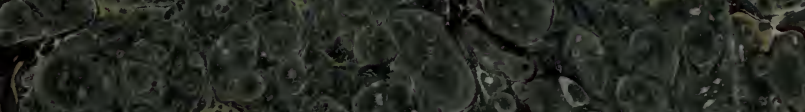

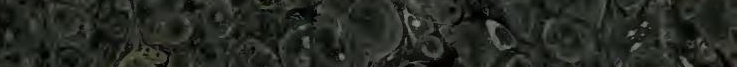

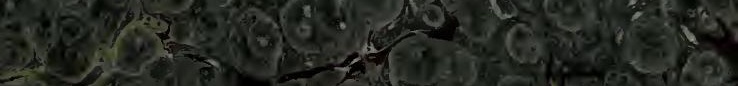
139.

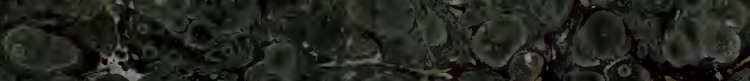

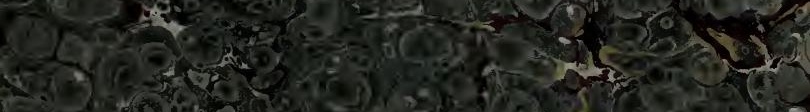

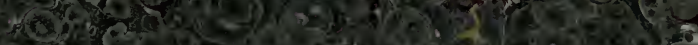

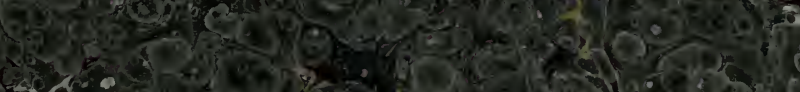

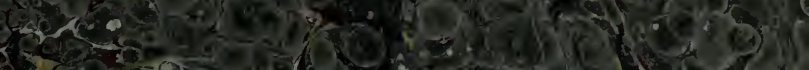
a. 96 (2).

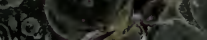


